Working Paper 97-16 / Document de travail 97-16

\title{
Canadian Policy Analysis Model: CPAM
}

by

Richard Black and David Rose

Bank of Canada Banque du Canada 
ISSN 1192-5434

ISBN 0-662-26005-8

Printed in Canada on recycled paper 
Bank of Canada Working Paper 97-16

June 1997

\title{
Canadian Policy Analysis Model: CPAM
}

\author{
by \\ Richard Black \\ Research Department, \\ Bank of Canada, Ottawa, K1A 0G9 \\ Tel: (613) 782-8399; Fax: 613) 782-8334 \\ E-mail: rblack@bank-banque-canada.ca
}

and

David Rose

QED SOLUTIONS,

248 Queen Elizabeth Drive, Ottawa, K1S 3M5

Tel: (613) 231-7846; Fax: (613) 231-6771

E-mail: drose@cyberus.ca

The views expressed in this paper are those of the authors and QED SOLUTIONS.

No responsibility for them should be attributed to the Bank of Canada. 


\section{Acknowledgments}

This work builds on other modelling work done at QED SOLUTIONS for the Reserve Bank of New Zealand. We thank Enzo Cassino, Aaron Drew, Eric Hansen, Ben Hunt, David Mayes, and Alasdair Scott for their questions and comments. We also thank participants in a seminar at the Bank of Canada for their input, particularly David Longworth, Tiff Macklem, and Simon van Norden. Any errors are our responsibility. 


\begin{abstract}
This paper documents the structure and properties of the Canadian Policy Analysis Model (CPAM). CPAM is designed to provide a reasonably complete representation of the Canadian macro economy. It is a one-domestic-good, small-open-economy model, which features an endogenous supply side, behavioural equations for the principal components of demand, forwardlooking expectations, and reaction functions for both the monetary and fiscal authorities. The model has an explicit steady state and is dynamically stable over a wide range of disturbances. CPAM is similar in many ways to the Bank of Canada's Quarterly Projection Model (QPM), and it has been calibrated to reflect QPM's dynamic properties in deterministic simulations. CPAM is smaller, however, and has been configured to simulate much faster than QPM so that stochastic simulations on a large scale are feasible.
\end{abstract}

\title{
Résumé
}

Les auteurs exposent la structure et les propriétés du Modèle d'analyse des politiques (MAP), qui a été conçu pour représenter assez fidèlement l'ensemble de l'économie canadienne. Le modèle décrit une petite économie ouverte qui ne produit qu'un seul bien et où l'offre est endogène et les attentes prospectives. Il comporte des équations formalisant le comportement des principales composantes de la demande ainsi que des fonctions de réaction propres aux autorités monétaires et budgétaires. Il englobe un régime permanent explicite, et sa structure dynamique est stable pour un large éventail de chocs. Le MAP ressemble à de nombreux égards au Modèle trimestriel de prévision (MTP) de la Banque du Canada, et son étalonnage reflète les propriétés dynamiques affichées par le MTP dans le cadre de simulations déterministes. Le MAP est toutefois plus petit et, comme il se résoud bien plus rapidement que le MTP, il permet des simulations stochastiques à grande échelle. 



\section{Contents}

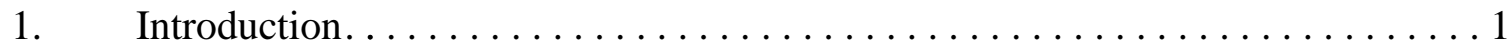

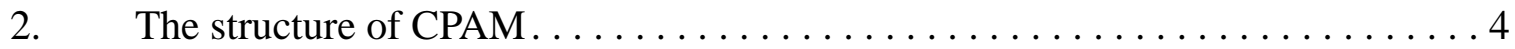

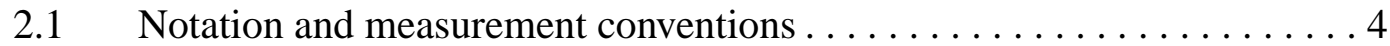

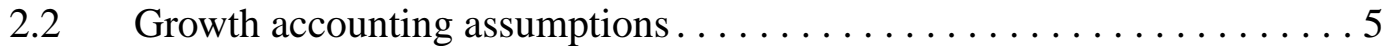

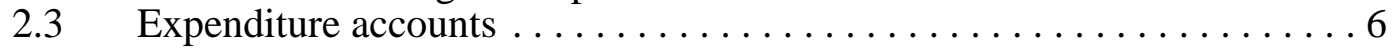

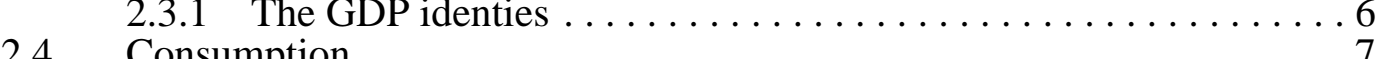

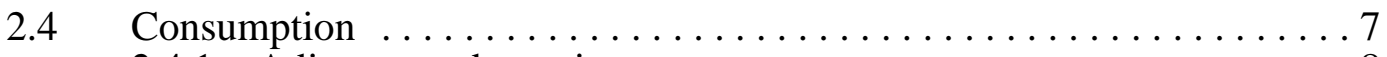

2.4.1 Adjustment dynamics . . . . . . . . . . . . . . 8

2.4.2 Equilibrium consumption and wealth .............

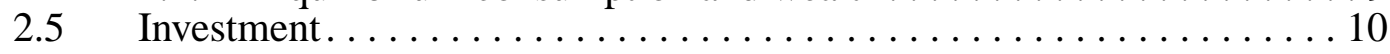

2.6 Government expenditure and transfers $\ldots \ldots \ldots \ldots \ldots \ldots \ldots \ldots \ldots$

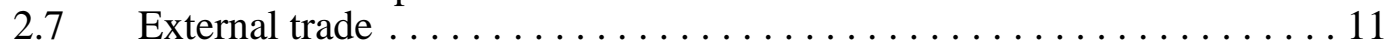

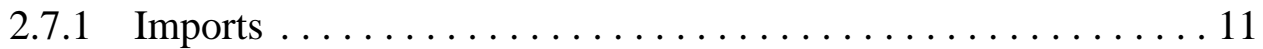

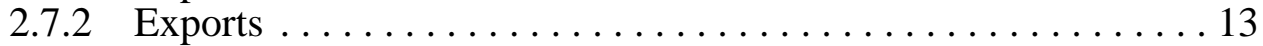

2.7.3 Trade balance identities .................. 14

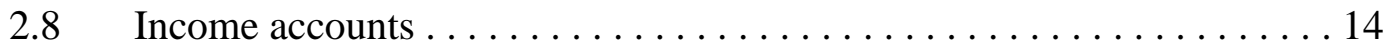

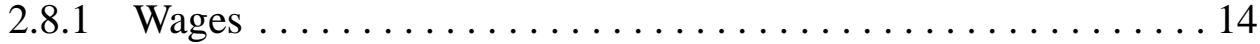

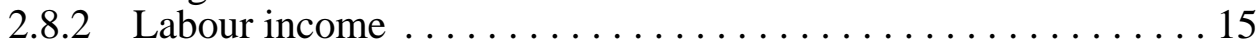

2.8 .3 Risk income ...................... 16

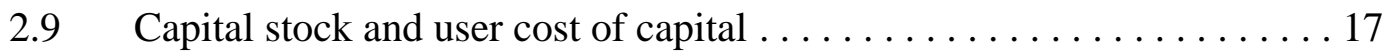

2.10 The government budget constraint: bonds and taxes $\ldots \ldots \ldots \ldots \ldots 17$

2.11 Net foreign assets and the remaining asset identities . . . . . . . . . . 18

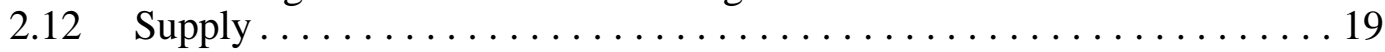

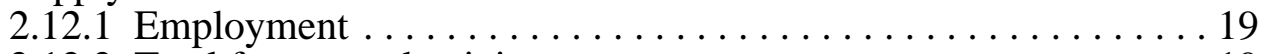

2.12 .2 Total factor productivity . . . . . . . . . . . . . . . . . 19

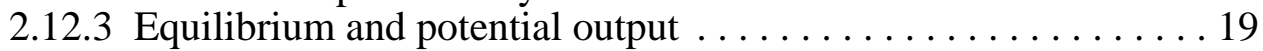

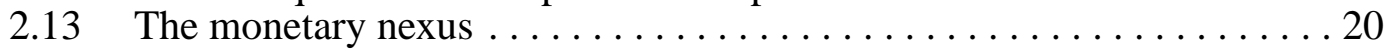

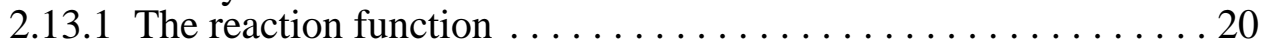

2.13.2 The term structure of interest rates ............. 21

2.13.3 Links to world rates and "risk" premia.............. 22

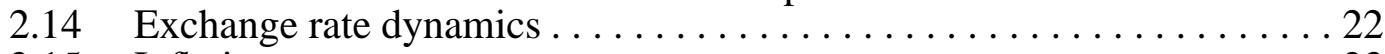

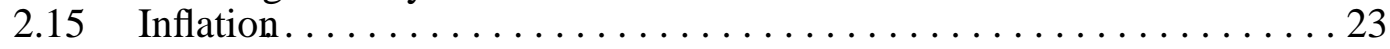

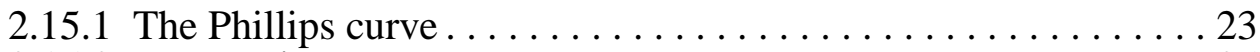

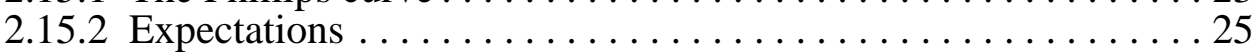

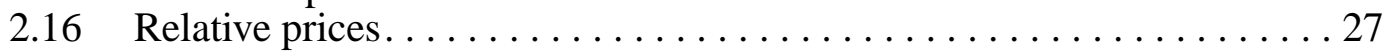

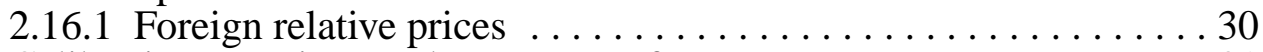

2.17 Calibration equations and output transforms $\ldots \ldots \ldots \ldots \ldots \ldots \ldots \ldots$

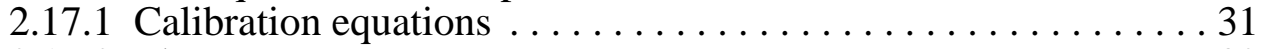

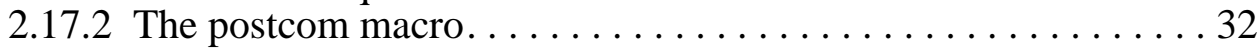

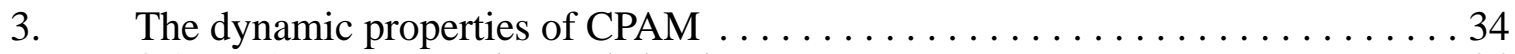

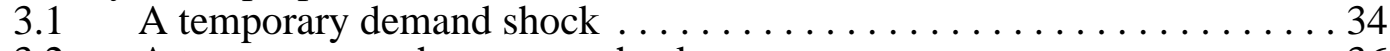

3.2 A temporary exchange rate shock .................. 36

3.3 A temporary tightening in monetary conditions . . . . . . . . . . 38

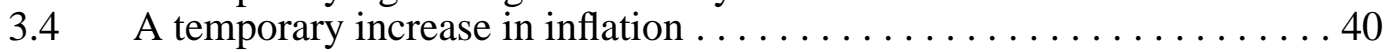

3.5 An increase in world commodity prices . . . . . . . . . . . . 42

3.6 An increase in total factor productivity. . . . . . . . . . . . . 44

3.7 A change in the target rate of inflation . . . . . . . . . . . . . 46

3.8 A permanent change in government debt ............... 48 


\section{Contents (continued)}

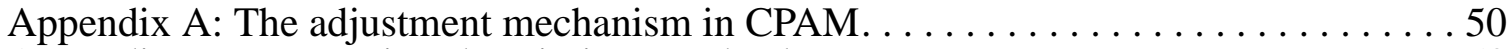

Appendix B: Mnemonics, descriptions, and values $\ldots \ldots \ldots \ldots \ldots \ldots \ldots \ldots \ldots \ldots$

References..................................66 


\section{Introduction}

This paper documents the structure and properties of a model designed for stochastic simulation analysis of the Canadian economy and, in particular, issues facing the monetary authority in implementing a nominal anchor for the economy. This model, dubbed CPAM, for Canadian Policy Analysis Model, is based on a family of models developed by QED SOLUTIONS. ${ }^{1}$

CPAM, which has quarterly frequency, is designed to provide a reasonably complete representation of the Canadian macro economy. It is a one-domestic-good, small-open-economy model, which features an endogenous supply side, behavioural equations for the principal components of demand, forward-looking expectations, and reaction functions for both the monetary and fiscal authorities. The model has an explicit steady state and is dynamically stable over a wide range of disturbances. CPAM has about 140 equations, of which perhaps 30 describe the essential agent behaviour. It has many features similar to the Bank of Canada's Quarterly Projection Model (QPM), including the same core theory of household behaviour, and it has been calibrated to reflect current Bank of Canada staff judgments regarding exogenous variables, the numerical steady-state solution, and many features of dynamic properties in deterministic simulations. ${ }^{2}$ CPAM is smaller, however, and has been configured to simulate much faster than QPM so that stochastic simulations on a large scale are feasible. ${ }^{3}$ Indeed, it was this desire to make stochastic simulations a practical tool for policy analysis that provided the central motivation for building CAPM. See Black, Macklem, and Rose (1997) for a first application of stochastic simulations with CPAM to consider alternative monetary-policy reaction functions for price stability.

There are three domestic sectors: households, firms, and a consolidated government. There is no formal financial sector. Households own capital directly; they also hold the bonds issued by the government and (reflecting the Canadian case) they have liabilities to foreigners. The steady

1. CPAM was prepared for the Bank of Canada under a research contract with David Rose of QED SOLUTIONS. CPAM exploits some of the structure and methodology developed in the construction of a model of the New Zealand economy for the Reserve Bank of New Zealand. A Reserve Bank publication on the new Forecasting and Policy System (FPS) is forthcoming.

2. For details on the structure and properties of QPM see Black, Laxton, Rose, and Tetlow (1994) and Coletti, Hunt, Rose, and Tetlow (1996). An overview is available in Poloz, Rose, and Tetlow (1994).

3. The difference in simulation times is at least a factor of 5 . 
state describes an equilibrium of a small open economy with stable ratios of each of these stocks to output.

Fiscal policy is characterized as choices about the debt-to-output and expenditure-to-output ratios; the rate of personal direct taxation is used as the instrument for fiscal closure (respecting the intertemporal budget constraint). Monetary policy is characterized as the choice of a target rate of inflation. This is implemented through a forward-looking reaction function, in which the monetary authority acts on the short-term interest rate according to where inflation is predicted to be, relative to the target rate, 7 to 8 quarters ahead.

There are some differences between CPAM and QPM. An important difference concerns the accounting and modelling structure for prices. QPM abandons the logic of the one-domesticgood paradigm to permit an independent Phillips curve for the CPI excluding food and energy. CPAM sticks more closely to the internal logic of the one-good paradigm. A core domestic price, the domestic aborption deflator at factor cost, PDFC, is treated as both the numeraire for the accounts and the fundamentally stochastic domestic price. ${ }^{4} \mathrm{We}$ choose PDFC as the core price, since it represents the average revenue received by firms on final sales into the domestic market, which is as close as we can get to a quintessentially domestic price. It is also the price that is most closely linked, in principle, to domestic costs.

All other price indexes are built from this core price and trade prices. Thus, for example, the consumption good price in the model comes from a weighted combination of the import price and the domestic core price for consumption goods, all appropriately adjusted for taxes, using the model's accounting identity structure. In particular, the endogenous share of imported consumption goods provides the weight for the import price in the index.

The Phillips curve in CPAM relates core inflation to domestic demand conditions and some other dynamic factors. But the monetary authority is concerned with the outcome for consumer price inflation. This means that the effect of monetary intervention on import prices through the exchange rate plays an important role in the transmission mechanism and in inflation dynamics generally.

4. The domestic absorption deflator is defined as follows: Domestic absorption is simply what is produced and not exported: $Y D=Y$ - $X$. The absorption deflator is then given implicitly from $P Y^{*} Y=P D^{*} Y D+P X^{*} X$. This is at market. To get the measure at factor cost, we must remove the direct effect of indirect taxes:

$P D * Y D=P D F C * Y D+$ indirect taxes. 
Another important difference between CPAM and QPM is in the modelling of dynamics. QPM expresses many adjustment processes using error-correction mechanisms based on the gap between the current value and the steady-state value of a variable. In many cases, however, especially in those shocks where the initial adjustment must be contrary to the steady-state effect, as in most cases where there is a change in the net foreign asset (NFA) position, QPM is forced to rely on other special terms to generate the appropriate short-term response. In CPAM, we exploit the underlying theory to a greater degree, building into what we call the "equilibrium" values of the endogenous variables this important distinction between the equilibrium transition path and the full steady-state effects. Thus, CPAM dynamics have an extra layer not developed in QPM. Much of what QPM represents as pure disequilibrium effects, appears in CPAM as "equilibrium dynamics." This enables us to make a much clearer distinction as to why "perverse" short-term movements often arise in scenarios with asset adjustment as a central feature.

Some differences between CPAM and QPM are more style than substance. For example, CPAM is written using Euler equations rather than QPM's explicit solutions in terms of expected future values. An advantage of the CPAM representation is that the equations are much more compact and easier to report. Indeed, all of the equations of CPAM are presented and described in this document. The model itself is also more compact, because explicit equations for all the future leads within the expectations structures are not required. ${ }^{5}$

The rest of the paper is organized as follows. In Section 2, we document the complete structure of CPAM. The model equations are reported using TROLL syntax, exactly as they appear in the simulation code. Appendix B provides extra details, including a complete list of all model mnemonics and definitions, the parameter values, the exogenous variable assumptions, and the other inputs into the steady-state solution, as well as that steady-state solution itself. Section 3 describes CPAM's dynamic properties through the results of deterministic simulations of the model's response to a number of standard shocks.

5. This means that CPAM does not need the macro for generating expectations that is relied on heavily in QPM. The same thing is achieved within TROLL in the stacking procedure used in the simulation algorithm. Armstrong, Black, Laxton, and Rose (1995) discuss this method. 


\section{The structure of CPAM}

We now turn to a detailed review of the equations of CPAM. We first review a few points of notation, TROLL syntax, and our measurement conventions, which are necessary background to understanding what follows. We then describe the model equations. The discussion is broken into sections in a relatively standard way, but with a few minor exceptions, the whole system is simultaneous.

\subsection{Notation and measurement conventions}

Variables with a suffix .eq are dynamic equilibrium values. The equilibrium values will converge on steady-state (SS) values. However, the .eq values differ, in principle, from the SS values when the model is shocked. Only in special cases will these equilibrium values be identical to the steady-state values in the immediate aftermath of a shock. CPAM exploits this information in modelling the dynamics.

All real variables in CPAM are measured relative to a trend that grows at the SS growth rate of output. In the control solution, the level of output has also been normalized to 1 (annual rates) in some notional base period. Thus, for example, all the annual rate GDP components are fractionsshares of output-in the control solution. Nominal variables are also divided by the domestic absorption deflator, measured at factor cost. In other words, every price in the core model is a relative price. Also, for the steady state, no trends are permitted in shares or relative prices, so all variables have particular numerical solutions. The SS numbers are computed from a solution of the model with leads and lags eliminated. The ease of this procedure is one advantage of writing the model in detrended form. Trend real and nominal growth are reintroduced in a separate component (a TROLL macro we call "postcom") that converts the core model variables to more familiar units.

The core model is written with all variables in their natural quarterly units. Thus, for example, all expenditure flows are at quarterly rates. Similarly, all growth rates, inflation rates, and interest rates are measured quarterly at quarterly rates. Under these conventions, model equations are almost void of code that merely converts units. For studying model output, however, annual rates are often more convenient. The postcom macro provides all the necessary transforms. A variable with prefix $a$, with underscore, as in $a \_x$, is the annualized version of the variable $x$. In the case of flows, this is just multiplying by 4 . In the case of rates etc., the calculation includes the effect of compounding. Thus, for example, the quarterly-at-annual-rate measure of inflation, a_pdot, is 
derived from $\left(1+a \_p d o t\right)=(1+p d o t) * * 4$. Another feature is level transforms. When growth and inflation are added to the model solution, variables with prefix $l_{-}$are created, where appropriate. Thus, one can see the solution for the level of the GDP deflator in the variable $l \_p y$.

As indicated above, the equations are reported in TROLL format. In TROLL syntax, $x(J)$ is the $J$ th lead of $x$, and for an endogenous variable in a deterministic simulation this will be the model solution $J$ periods ahead. Similarly, $x(-J)$ is the $J$ th lag of $x$. CPAM uses very few functions or other special operators. Where necessary, these are described with the equation.

The only other feature of TROLL syntax that is necessary for what follows is the labelling convention for equations. Each equation begins with a label, followed by a colon. Then comes the actual equation. It should go without saying, but just to be safe we will say it, labels are arbitrary in a simultaneous system. The entire $N$ equations of a non-singular system determine $N$ unknowns. Yet some economists persist in wanting to label everything as if this were not true and the model could be considered as a set of reduced-form equations. We use the phrase "proximately determine" when describing some equations to identify the variable that has conventionally been used as the notional "dependent" variable in such discussions, based on recursive solution methods, like Gauss-Seidel. In TROLL, it is the endogenous variable list that matters. Derivatives are taken for all equations with respect to all endogenous variables. Equations do not have to be written in a form already normalized on a particular variable. In fact, the label can be a variable that does not appear in the equation; there are several examples in CPAM. The labels are not actually used for anything real. Hence, they do not even have to be variable names. Of course, it is still necessary to have $N$ equations to solve for $N$ unknowns, and there is nothing wrong with using the names of the endogenous variables as labels - there are just the right number, after all. Essentially, that is what we have done.

\subsection{Growth accounting assumptions}

Trend population growth, ndot, and trend productivity growth, qdot, which is measured in labour units, are exogenous. In this version of the model, there are no variations in these trend values through time. Actual productivity growth, measured as the percentage change in the level of total factor productivity, say, will vary with the cycle. Overall trend real growth, ydot, is defined from the components, as required by the underlying neoclassical growth model:

$$
\text { ydot: } \quad y d o t=(1+n d o t) *(1+q d o t)-1 \text {. }
$$


Again, this is a trend growth concept and is essentially exogenous. It is not the growth rate in actual output period-by-period. That, of course, is endogenous to the model. The numerical assumptions for steady-state growth are taken from QPM (labour-embodied technical progress at 1.3 per cent per annum and population growth at just under 0.95 per cent per annum, for a trend growth in potential output of about 2.25 per cent per annum).

\subsection{Expenditure accounts}

The standard expenditure add-up identities are included, but with two twists, as alluded to previously. The first is our detrending procedure. Thus model variable $y$ is not constant-dollar output. If $Y$ is the constant-dollar measure at annual rates, it is rescaled according to $y(t)=Y(t) /$ $(4 * Y O *(1+y d o t) * * t)$, where $Y O$ is the annual-rate value in a base period (i.e., we also normalize the control annual-rate value of $y$ to be 1 and the quarterly rate value to be 0.25 ). The same rescaling is carried out for $c$, $i$, etc. Thus, the control levels of components of spending are their proportional shares of output.

The second twist is that the prices are not the national accounts deflators. Rather, all prices are measured relative to the numeraire price, which we take to be the domestic absorption deflator at factor cost (PDFC). Indirect taxes are levied on consumption, investment, and government goods, at effective rates taken from QPM.

As in QPM, the sectoral accounting framework is simplified. In particular, residential investment and changes in the stock of inventories are notionally included in model "consumption."

\subsubsection{The GDP identities}

In current terms, we have: ${ }^{6}$

$$
\begin{aligned}
y: & =c+i+g+x-m, \\
p y: & \quad p y^{*} y=p c^{*} c+p k^{*} i+p g * g+p x * x-p m * m .
\end{aligned}
$$

In .eq terms we have:

$$
\text { py.eq: } \quad y . e q=c . e q+i . e q+\text { g.eq }+x . e q-\text { m.eq } .
$$

Note that this is an example of an equation with a label given by a variable that does not appear in the equation itself. We think of y.eq as being proximately determined by the supply side of the

6. We use the seemingly inconsistent mnemonic $p k$ for the flow investment price simply because one of the software packages we use for applications reserves the mnemonic $p i$ for the mathematical constant. 
model. This equilibrium condition, which imposes the requirement that supply must equal demand, then proximately determines the equilibrium price.

Next comes the identity for the average price at factor cost:

$$
\begin{aligned}
p f c: \quad p y^{*} y= & p f c^{*} y+t i c * p c * c /(1+t i c) \\
& +t i i^{*} p k^{*} /(1+t i i)+t i g * p g * g /(1+t i g),
\end{aligned}
$$

where tic, tii, and tig are the rates of indirect tax on consumption, investment, and government purchases, all measured net of any subsidies. The terms involving these variables together reflect net indirect tax revenues. We have the same structure in .eq terms:

$$
\begin{aligned}
\text { pfc.eq: } \quad \text { py.eq*y.eq }= & \text { pfc.eq*y.eq }+ \text { tic*pc.eq*c.eq } /(1+t i c) \\
& +t i i^{*} p k . e q^{*} \cdot . e q /(1+t i i)+t i g * p g . e q^{*} g . e q /(1+t i g)
\end{aligned}
$$

The final equation in this block is a check that the equilibrium model satisfies the GDP identity. Note that, for reasons we explain later, the variable checkl, which must be identically zero if the identity holds, appears later in the model-in the risk income equation. But it can be thought of as the balancing entry for this identity.

$$
\begin{aligned}
\text { checkl: } \quad \text { py.eq*y.eq }= & \text { pc.eq*c.eq }+ \text { pk.eq*i.eq }+ \text { pg.eq*g.eq } \\
& + \text { px.eq*x.eq }- \text { pm.eq*m.eq. }
\end{aligned}
$$

\subsection{Consumption}

There are two kinds of consumers in CPAM. There are forward-looking agents, who make decisions with a view to picking the best path for current and future consumption. Their choices are shown in variables with "fl" in the mnemonic. Thus $c f l$ is consumption by forward-looking agents. CPAM also has agents who consume by the simple "rule of thumb" (rt) that they consume what they receive in income every period. Thus, all assets are held by the forward-looking agents. Total consumption, $c$, is the sum of the demands from the two types of agent.

$$
c: \quad c=c r t+c f l .
$$

Section 2.8.2 describes how disposable income is divided between the two types of agents. 


\subsubsection{Adjustment dynamics}

RT consumers just use up their real disposable income, $y d r t$. Note that the left side is not a current dollar expression; $p c$ is a relative price (the consumption price divided by PDFC). Thus $p c$ here simply converts the real units to be consistent.

$$
c r t: \quad \quad p c^{*} c r t=y d r t .
$$

The next equation contains the consumption dynamics for the forward-looking agents. The structure of the equation is typical of those in the rest of the model. It says that consumption (of forward-looking agents), $c f l$, will converge on its equilibrium value, $c f l . e q$, subject to an adjustment structure, provided through the variable $c f l a d j$, as well as to the influence of a number of special disequilibrium effects.

$$
\begin{aligned}
c f l: \quad \quad c f l= & c f l . e q+c v 1 *(y d f l(-2) / p c(-2)-y d f l . e q(-2) / p c . e q(-2)) \\
& -c v 2 *(r s l(-2)-r s l . e q(-2)) * c f l . e q(-2) \\
& +c v 3 *(n f a / p c-n f a . e q / p c . e q) \\
& -c f l a d j+c s h k .
\end{aligned}
$$

The eq variable comes from the core theory, described below. The adjustment code, which replaces cfladj, is added by a TROLL procedure that automatically overlays the equation with a polynomial adjustment cost (PAC) structure of order specified in the procedure call. This uses a version of the approach described in Pesaran (1991) and, particularly, in Tinsley (1993). In general, we use a 4th-order adjustment system in CPAM. The adjustment model is documented in Appendix A. However, what it does is add leads and lags of the specified order, all of which act to delay adjustment to the.$e q$ values. The TROLL code for the adjustment procedure(s) is available on request. ${ }^{7}$

For FL consumption dynamics, three special disequilibrium terms are included. First, there is an income effect for FL consumers, making them a little bit like RT consumers in responding more to income cycles than the pure c.eq theory and PAC dynamics would suggest. Second, as in QPM, there is a direct mechanism for the transmission of monetary policy to consumption demand. The model's policy framework is similar to QPM's; $r s l$ is the slope of the term structure. ${ }^{8}$ Third,

\footnotetext{
7. There are, in fact, two different adjustment procedures used in CPAM, one for the capital stock dynamics, the other for the rest of the equations. See Appendix A for details.

8. See Section 2.13 for discussion of this point.
} 
we have one of the mechanisms needed to make the pure theory usable in practice, a direct effect making consumption respond to the NFA gap, as in QPM, to speed the adjustment in cases where asset equilibrium is disturbed.

The variable $c s h k$ is used to incorporate disturbances (shocks) to consumer spending.

\subsubsection{Equilibrium consumption and wealth}

Total equilibrium consumption is given by the sum of the .eq values of the two components, with the RT variable defined precisely as above, but using the .eq price and the .eq disposable income.

$$
\begin{aligned}
& \text { c.eq: } \quad \text { c.eq }=\text { cfl.eq }+ \text { crt.eq, } \\
& \text { crt.eq: } \quad \text { pc.eq*crt.eq }=y d r t . e q .
\end{aligned}
$$

The equilibrium analysis for forward-looking consumers is based on Blanchard (1985) and Weil (1989), but in a discrete-time format, as in Frenkel and Razin (1992) and Black, Laxton, Rose, and Tetlow (1994). The variables have obvious names: $t w$ is total wealth, $h w$ is human wealth, $f a$ is financial assets, $m p c w$ is the marginal propensity to consume out of wealth. Note that extra discounting is added in two ways. First, we modify the definition of $c f l . e q$ so that it only has the standard form (consumption proportional to wealth) when assets are in steady-state equilibrium. If fa.eq, the temporary equilibrium level of financial assets, is above its steady-state level, we make the eq notion of consumption higher than it would otherwise be. This speeds convergence to the steady state. Second, in the definition of human wealth, we use a consumers' discount rate, rcon.eq, 
which is above the risk-free base rate. Gamma here is the probability of death, and sigma is the coefficient of intertemporal substitution.

$$
\text { cfl.eq: } \quad \text { pc.eq*cfl.eq }=\text { mpcw.eq } * \text { twfl.eq }+ \text { zeta } *(f a . e q-f a . s s) \text {, }
$$

mpcw.eq: $1 / m p c w . e q=(1-$ gamma $) *$ delta**igma* $*$ pc.eq $/$

$$
\text { pc.eq }(+1) *(1+\text { rcon.eq })) * *(\text { sigma }-1) / m p c w . e q(1)+1 \text {, }
$$

$$
\text { twfl.eq: } \quad \text { twfl.eq }=h w f l . e q+(1+\text { rcon.eq }(-1))^{*} f a . e q(-1) /(1+y d o t)
$$

hwfl.eq: $\quad$ hwfl.eq $=y d f l . e q+$ risk.eq $+(1-$ gamma $) *(1+q d o t) * h w f l . e q(1) /$

$$
(1+\text { rcon.eq }(1))
$$

$$
\text { fa.eq: } \quad \begin{aligned}
\text { fa.eq }= & y d f l . e q+\text { risk.eq }+(1+\text { rcon.eq }(-1))^{*} f a . e q(-1) /(1+y d o t)- \\
& \text { pc.eq*cfl.eq, }
\end{aligned}
$$

The fa.ss equation is just a trick to get the current SS solution for the fa.eq gap. ${ }^{9}$

One small point that might need elaboration is the role of the $(1+y d o t)$ deflator for a lagged stock (in the fa.eq equation, for example). These things appear in all cumulation equations in CPAM and sometimes in other equations with lags or leads. The adjustment is necessitated by the detrending transform. The core solution for fa.ss is a constant. In a converged solution, fa.eq will also be at this same value. In accumulation equations, therefore, the lagged stock must be deflated by the gross growth rate to keep the units consistent.

Note that, since all assets are held by forward-looking consumers, we allocate all "risk" income to them in the wealth accounting.

\subsection{Investment}

We choose to have investment represented by the perpetual inventory (PI) identities. The behaviour of firms is written into the equations that determine stock levels. This is not substantive; these equations could be considered as $k$ equations and vice-versa. (The behavioural $k$ equations could even be substituted into the PI equations and solved for $i$.) We prefer writing it this way to

9. Note that this equation effectively states that fa.ss is tied to a terminal condition that, in turn, comes from the steady-state model. 
highlight the fact that in a model where stock equilibrium considerations are central, flows adjust to establish and to maintain the desired stock levels. It is not the other way round.

$$
\begin{aligned}
i: & k & =(1-\text { depr }) * k(-1) /(1+y d o t)+i, \\
\text { i.eq }: & k . e q & =(1-\text { depr }) * k . e q(-1) /(1+y d o t)+\text { i.eq. }
\end{aligned}
$$

\subsection{Government expenditure and transfers}

In CPAM, the consolidated government sector provides a demand for goods and services and also transfers resources to households. The ratio of government spending, $g$, to output, $y$, written as $g_{-} y . e q$, is treated as an exogenous policy choice, as is the level of transfers, relative to output, gtr_y.eq. ${ }^{10}$

$$
\begin{aligned}
g: & g & =g 1^{*} g(-1)+(1-g 1) * g . e q, \\
\text { g.eq: } & g . e q & =g 2^{*} g . e q(-1)+(1-g 2)^{*} g \_y . e q * y . e q, \\
g t r: & g t r & =g t r 1 * g t r(-1)+(1-g t r 1) * g t r . e q, \\
\text { gtr.eq: } & \text { gtr.eq } & =g t r 2 * g t r . e q(-1)+(1-g t r 2) * g t r \_y . e q * y . e q .
\end{aligned}
$$

This version of CPAM has simple first-order adjustment towards the.$e q$ values in these equations. For most temporary shocks, where the .eq values are not affected, the government variables will not move at all, if the starting point is an equilibrium. Where, however, the .eq value of output does change endogenously in the shock, these equations will add extra dynamics coming from fiscal adjustment. If a user prefers fully exogenous fiscal variables, these equations must be overridden.

\subsection{External trade}

\subsubsection{Imports}

Like QPM, CPAM is configured under the assumption that imports are driven by end-use component demands. Thus, we break imports down into four parts, one for each component of

10. CPAM differs from QPM in accounting explicitly for transfers to households. As a result, CPAM's residual personal income tax rate is more realistic than QPM's. 
domestic demand ( $\mathrm{cm}$, im, and $\mathrm{gm}$ ) and one for those imports that go directly into exports, $\mathrm{xm}$. There are current value and $e q$ add-ups.

$$
\begin{aligned}
& m: \quad m=c m+i m+g m+x m, \\
& \text { m.eq: } \quad \text { m.eq }=\text { cm.eq }+ \text { im.eq }+ \text { gm.eq }+ \text { xm.eq. }
\end{aligned}
$$

Each component of imports is, in turn, written as a penetration ratio times the level of the total component demand. Thus, for example, imports for consumption are given by the product of the consumption import penetration ratio, written as $\mathrm{cm} \_c$, and the level of consumption demand. There are current-value and eq-value versions of each of these identities. The main import penetration ratios are endogenous (the exception is the re-export component, which we simply hold at a fixed share of exports). The equilibrium values are made functions of the appropriate relative price of the home-source to the foreign-source good. Thus, for example, cm_c.eq responds (negatively) to the ratio $p c m . e q / p c d . e q$, which is the domestic price of imported consumption goods relative to the domestic price for consumption goods.

We will show below that the law of one price is made to hold on the margin, so that pcm.eq can be considered to be the foreign price times the .eq real exchange rate. Hence, a permanent real depreciation or a permanent shock to the foreign consumption good price will lower the proportion of $c$ that comes from abroad. The actual current ratios, for example $c m_{-} c$, are determined by standard CPAM adjustment equations. Thus, the pass-through of a permanent foreign price shock or an exchange rate shock into domestic-currency import prices is not instantaneous. Note that we also allow for separate dynamic effects of the exchange rate within the adjustment equations, using the same relative price. This term will capture the effects of temporary shocks to the exchange rate or foreign prices, where the.$e q$ values are unchanged.

$$
\begin{aligned}
& \mathrm{cm}: \quad \mathrm{cm}=\mathrm{cm} \_\mathrm{c}^{*} c \text {, } \\
& \text { cm.eq: } \quad \text { cm.eq }=c m_{-} c . e q^{*} c . e q \text {, } \\
& \text { cm_c.eq: } \quad c m \_c . e q=c m \_c 0-c m s 2 * p c m . e q / p c d . e q \text {, } \\
& c m_{-} c: \quad c m_{-} c=c m \_c . e q-c m v l^{*}(p c m(-1) / p c d(-1) \\
& \text {-pcm.eq(-1)/pcd.eq(-1)) - cm_cadj, }
\end{aligned}
$$




$$
\begin{aligned}
& \text { im: } \quad \text { im }=i m \_i * i \text {, } \\
& \text { im.eq: } \quad \text { m.eq }=i m \_i . e q * i . e q \text {, } \\
& i m \_i: \quad \quad i m \_i=i m \_i . e q-i m v l^{*}(p k m(-1) / p k d(-1) \\
& \text { - pkm.eq(-1)/pkd.eq(-1)) - im_iadj, } \\
& \text { im_i.eq: } \quad \text { im_i.eq }=i m \_i 0-i m s 2 * p k m . e q / p k d . e q \text {, } \\
& g m: \quad g m=g m \_g * g \text {, } \\
& \text { gm.eq: } \quad \text { gm.eq }=g m \_g . e q^{*} g . e q \text {, } \\
& g m \_g: \quad \quad g m \_g=g m \_g . e q-g m v 1 *(p g m(-1) / p g d(-1) \\
& \text {-pgm.eq(-1)/pgd.eq(-1)) - gm_gadj, } \\
& \text { gm_g.eq: } \quad g m \_g . e q=g m \_g 0-g m s 2^{*} p g m . e q / p g d . e q \text {, } \\
& x m: \quad x m=x m \_x * x, \\
& \text { xm.eq: } \quad x m . e q=x m_{-} x . e q * x . e q \text {, } \\
& x m \_x: \quad x m \_x=x m \_x . e q .
\end{aligned}
$$

\subsubsection{Exports}

For exports, the equilibrium level, relative to output, is made a function of the domesticcurrency price of exports. This price, like all prices in the core of CPAM, is written relative to the numeraire price, PDFC. It thus already expresses the relevant margin for producers-what they can get abroad relative to what they can get at home by selling into the domestic market.

In this version of CPAM, the .eq export price is given by the world price multiplied by the .$e q$ price of foreign exchange. A permanent real depreciation will raise the ratio of exports to output, all else equal, as will a permanent increase in the world price for the domestic export good (which must be interpreted as a form of shock to the terms of trade, not as a general foreign price shock). Adjustment is then specified in the usual way, again with a term to allow for effects from temporary shocks. 
In the calibration of equations like the one for $x . e q$, the base level of the ratio, $x_{-} y 0$, is set to reflect the data. This can include any historical or predicted future trends that are judged to be exogenous to the macro cycle.

$$
\text { x.eq: } \quad \begin{aligned}
x . e q / y . e q & =x \_y 0+x 2 * p x . e q, \\
x: \quad x & =x . e q+x v 1^{*}(p x(-2)-p x . e q(-2)) * x . e q(-2)-x a d j .
\end{aligned}
$$

\subsubsection{Trade balance identities}

Finally, we have the identities for the trade balance.

$$
\begin{aligned}
& \text { netx: } \quad \text { netx }=p x * x-p m * m \text {, } \\
& \text { netx.eq: } \quad \text { netx.eq }=\text { px.eq*x.eq-pm.eq*m.eq. }
\end{aligned}
$$

\subsection{Income accounts}

\subsubsection{Wages}

The equilibrium real wage, w.eq, is given by the standard marginal product condition. The only thing at all unusual here is that w.eq is measured in the units of domestic absorption (i.e., the money wage is implicitly deflated by PDFC, like all nominal levels). This explains the presence of $p f c$ in the equation; it converts the units to factor cost as required by the marginal product condition. The parameter alpha is the exponent on capital in the CRS, Cobb-Douglas production function. The equilibrium unemployment rate, u.eq, is exogenous (more on this below).

$$
\text { w.eq: } \quad \text { w.eq }=(1-a l p h a) * p f c . e q * y . e q /(1-u . e q)
$$

The market real wage is determined by a standard CPAM adjustment equation. A term in the unemployment rate gap is added to the dynamics to allow for any direct cyclical properties of the real wage.

$$
\begin{aligned}
w: \quad w= & w . e q-w v 1 *(u-u . e q)+w \mathrm{v} 2 *(p f c(-1)-p f c . e q(-1)) \\
& +w v 3 *(t f p(-1)-t f p . e q(-1))-w a d j+w s h k .
\end{aligned}
$$

We also include the explicit transforms to give the real wage to the producer, $w p$, and to the consumer, $w c$. Since both $w$ and $p f c$ are divided by the absorption deflator at factor cost, $w p$ is equal to the nominal wage divided by the output deflator at factor cost, which is the real cost of labour to the firm. Similarly, $w c$ is equal to the nominal wage divided by the consumption deflator, as the 
rescaling of both numerator and denominator by PDFC cancels. Neither $w c$ nor $w p$ is used explicitly in this version of the model; these variables are included for information only.

$$
\begin{aligned}
\text { wp.eq: } & w p . e q & =w . e q / p f c . e q, \\
w p: & w p & =w / p f c, \\
w c . e q: & w c . e q & =w . e q / p c . e q, \\
w c: & w c & =w / p c .
\end{aligned}
$$

\subsubsection{Labour income}

Total labour income is simply the payments to labour implicit in the above:

$$
\begin{aligned}
\text { ylab: } & y l a b & =w^{*}(1-u), \\
\text { ylab.eq: } & \text { ylab.eq } & =\text { w.eq*(1-u.eq }) .
\end{aligned}
$$

Labour income is split between rule-of-thumb and forward-looking consumers and transfers are added. (The proportion of RT consumers in the model is represented by the parameter lamda.) The portion of transfers that is taxable is given by parameters, $y d l$ (for RT consumers) and $y d 2$ (FL consumers). Labour income plus taxable transfers are taxed at the same rate, $t d$, for both types of consumer, giving us the following equations for disposable income:

$$
\begin{array}{rlrl}
y d r t: & y d r t & = & ((1-t d) *(y l a b+y d 1 * g t r)+(1-y d 1) * g t r) * l a m d a, \\
y d r t . e q: & y d r t . e q & = & ((1-t d . e q) *(y l a b . e q+y d 1 * g t r . e q)+(1-y d 1) * g t r . e q) * l a m d a \\
y d f l: & y d f l & = & ((1-t d) *(y l a b+y d 2 * g t r)+(1-y d 2) * g t r) *(1-l a m d a), \\
y d f l . e q: & y d f l . e q & = & ((1-t d . e q) *(y l a b . e q+y d 2 * g t r . e q)+(1-y d 2) * g t r . e q) \\
& *(1-l a m d a) .
\end{array}
$$




\subsubsection{Risk income}

This term measures asset income over and above the level provided by rcon.eq, as well as some other miscellaneous items that need to be recorded as income somewhere. See also the discussion of relative rates of return on assets, below.

$$
\text { risk.eq: } \quad \begin{aligned}
\text { risk.eq }= & (r k . e q(-1)-r c o n . e q(-1))^{*} p k . e q(-1)^{*} k . e q(-1) /(1+y d o t) \\
& +k . e q(-1)^{*}\left((1+r k . e q(-1))^{*}(p i . e q(-1)-p k . e q(-1))\right. \\
& -(1-d e p r) *(p i . e q-p k . e q)) /(1+y d o t) \\
& +(\text { rgb.eq }(-1)-r c o n . e q(-1))^{*} g b . e q(-1) /(1+y d o t) \\
& +(\text { rnfa.eq }(-1)-r c o n . e q(-1))^{*} n f a . e q(-1) /(1+y d o t)+\text { checkl. }
\end{aligned}
$$

Note that the national accounts identity check variable, checkl, appears here. "Risk" is total household "income," over and above what is notionally paid either through wages or through returns on assets at the rate rcon.eq (which is used within the formal model of household choice). Any residual shows in checkl. We put this term here because there is a small problem of consistency in the first period of a shock that changes equilibrium values-associated with the imprecision of discrete representations of instantaneous effects. The effects of this problem are minimized when we put the check in the risk.eq equation, because the small discrepancy that appears tends to cancel an inappropriate blip in risk.eq that would otherwise appear.

There are two reasons why risk.eq is required to balance the accounts in CPAM. The first is that the core model assumes perfect capital mobility, that is, a single real interest rate, where as the accounting framework allows for different interest rates for capital, government debt, and net foreign assets. Terms in risk.eq serve to square this discrepancy by transferring the income from interest payments above that which the core model would imply back to the consumer in a lumpsum manner. See Black, Laxton, Rose, and Tetlow (1994) for more discussion of this technique. The second reason, described more below, is that the adjustment of the capital stock is costly in CPAM. The term risk.eq accounts for the costs of adjusting capital in a way that still allows the model's accounting structure to resemble that of the National Accounts. ${ }^{11}$

11. Macklem (1993) discusses this problem and incorporates a different solution that does imply a deviation from the conventions of the National Accounts. 


\subsection{Capital stock and user cost of capital}

The equation for the stock of capital, $k$, is a standard adjustment equation around the equilibrium level, k.eq. This is really an investment equation, written in the stock dimension. The $k . e q$ level comes from the firm's optimization problem.

In CPAM, firms chose k.eq by maximizing the present value of profits under quadratic adjustment costs. This means that, whenever a firm faces a change, it must balance off altering its capital stock and moving quickly to a more efficient point, with the costs of adjusting capital.

The way this is modelled is with the introduction of the price pi.eq. ${ }^{12}$ This price, which serves a similar purpose to Tobin's $q$, serves to indicate to the firm when and how quickly it should increase its stock of capital. From (62) it is seen that when investment increases above its steadystate level, pi.eq also increases. This, in turn, increases the cost of capital and counteracts the high investment demand.

$$
\begin{aligned}
& k: \quad k=k \cdot e q+k v 1 *(y(-4)-y \cdot e q(-4)) \\
& -k v 2 *(r s l(-4)-r s l . e q(-4)) * k . e q(-4)-k a d j+k s h k \text {, } \\
& \text { k.eq: } \quad c c . e q=\text { alpha*pfc.eq(1)*y.eq(1)*(1+ydot)/k.eq, } \\
& \text { cc.eq: } \quad c c . e q=((1+r k . e q) * \text { pi.eq }-(1-d e p r) * \text { pi.eq }(1) \\
& \text { - tk.eq*depr*pk.eq(1))/(1-tk.eq), } \\
& \text { pi.eq: } \quad \text { pi.eq }=p k 1 * p k . e q+(1-p k 1) * p k . s s+k e 1 *(i . e q-i . s s) \text {, } \\
& \text { i.ss: } \quad \text { i.ss }=i . s s(1) \text {, } \\
& \text { pk.ss: } \quad \text { pk.ss }=p k . s s(1) \text {. }
\end{aligned}
$$

\subsection{The government budget constraint: bonds and taxes}

The fundamental fiscal choice in CPAM is the debt/output ratio, gbtar_y. Given y.eq, this determines a target level of debt, gbtar. A structure is specified to handle transition paths; the variable $g b . e q$ can be considered as defining a transition target path when gbtar changes. The intertemporal government budget constraint, written with .eq values, then provides the personal income tax rate, td.eq, that would support those fiscal choices, conditional on all other .eq values.

12. The reader will recall that $p k$ is the relative price of investment goods. 
The regular government budget constraint determines actual government debt, $g b$, conditional on all other variables, and, in particular, on $t d$, the actual current personal income tax rate. The system is reconciled with the fiscal reaction function that sets the actual tax rate. This must achieve two goals. The personal tax rate, $t d$, must go to the right level in the end to support the steady state. But it must also generate the necessary dynamic profile to bring debt to the equilibrium or target level. The net indirect tax rates and the profits tax rate are exogenous.

$$
\begin{aligned}
& \text { gbtar: } \quad \text { gbtar }=\text { gbtar_y.eq*y.eq, } \\
& \text { gb.eq: } \quad \text { gb.eq }=\text { gb.eq }(-1)-t d 1 *(\text { gb.eq-gbtar }) \text {, } \\
& g b: \quad \quad g b+t d *(y l a b+(y d 1 * l a m d a+y d 2 *(1-l a m d a)) * g t r)+t i c * p c * c /(1+t i c)+ \\
& t i{ }^{*} p k^{*} i /(1+t i i)+t i g * p g * g /(1+t i g)+t k^{*}\left(p f c^{*} y-y l a b-\right. \\
& \left.d e p r * p k^{*} k(-1) /(1+y d o t)\right) \\
& =(1+r g b(-1))^{*} g b(-1) /(1+y d o t)+p g * g+g t r, \\
& \text { td.eq: } \quad \text { gb.eq }+ \text { td.eq*(ylab.eq }+(y d 1 * l a m d a+y d 2 *(1-l a m d a)) * g t r . e q) \\
& +i c^{*} p c . e q^{*} c . e q /(1+t i c)+t i i^{*} p k . e q^{*} i . e q /(1+t i i) \\
& +t i g * \text { pg.eq*g.eq } /(1+t i g)+t k . e q^{*}\left(p f c . e{ }^{*} y . e q-y l a b . e q-\right. \\
& \text { depr*pk.eq*k.eq(-1)/(1+ydot)) } \\
& =(1+r g b . e q(-1))^{*} g b . e q(-1) /(1+y d o t)+\text { pg.eq*g.eq }+ \text { gtr.eq, } \\
& t d: \quad t d=t d 0^{*} t d(-1)+(1-t d 0)^{*}\left(t d . e q+t d 3^{*}(g b-g b . e q)\right) .
\end{aligned}
$$

\subsection{Net foreign assets and the remaining asset identities}

Next, we have the NFA accumulation identities and the definitions of the asset sums. Note that we label the fa.eq equation as determining the level of the real exchange rate. This reflects the fact that the household model pins down a value for fa.eq. Given a choice of a debt level by government, and a choice by firms of the equilibrium level of $k$, the $n f a . e q$ position is the residual that can be set to satisfy the fa.eq decision. Through the nfa.eq accumulation equation, we have a level for equilibrium net exports consistent with this choice for $n f a . e q$. In effect, the real exchange 
rate gets determined to support this equilibrium. That may not be immediately clear from the labelling of these equations, but it is a good way to think about it.

$$
\begin{aligned}
n f a: & n f a & =(1+r n f a(-1)) * n f a(-1) /(1+y d o t)+n e t x, \\
n f a . e q: & n f a . e q & =(1+r n f a . e q(-1))^{*} n f a . e q(-1) /(1+y d o t)+n e t x . e q, \\
f a: & f a & =p k * k+g b+n f a, \\
\text { z.eq: } & \text { fa.eq } & =p k . e q * k . e q+\text { gb.eq }+ \text { nfa.eq. }
\end{aligned}
$$

\subsection{Supply}

\subsubsection{Employment}

The unemployment rate is proximately determined in a standard adjustment equation. It may be clearer to think of this as an employment equation. Two special cycle variables are used: the output gap to pick up direct links between employment and demand conditions, and a wage gap to pick up relative price effects (movements along the short-run demand function).

$$
u: \quad u=u . e q-u v 1 *(y-y . e q)+u v 2 *(w-w . e q)-u a d j+u s h k .
$$

\subsubsection{Total factor productivity}

The production function is imposed to solve for total factor productivity, tfp, on a periodby-period basis. This is how demand is satisfied in each period. Note, as well, that $t f p$ is normalized in the calibration to set the $y$ units to 1 , at annual rates, or 0.25 at quarterly rates, and is deflated by $(1+q d o t) * * t$.

$$
\text { tfp: } \quad y=0.25 * t f p *(k(-1) /(1+y d o t)) * * a l p h a *(1-u) * *(1-a l p h a) .
$$

\subsubsection{Equilibrium and potential output}

The model uses two different measures of "equilibrium" output. One, y.eq, uses .eq measures everywhere in evaluating the production function. This measure is used in all the forward-looking real equations. The other, $y p$, is potential output for the purpose of modelling inflation dynamics. It is simply the production function evaluated with actual capital and .eq values for everything else. This treats capital as a quasi-fixed factor and employment as a completely variable factor in the short run. It could be interesting to introduce a distinction between the NAIRU 
(short-term attainable labour use) and the natural rate (longer-term labour attainable use), but in this version of CPAM no such distinction is made and $u . e q$ is the natural rate, which is taken from QPM.

$$
\begin{aligned}
& \text { y.eq: } \left.\quad \text { y.eq }=0.25^{*} t \text { fp.eq*(k.eq }(-1) /(1+y d o t)\right) * * a l p h a \\
& *(1-u . e q)^{* *}(1-a l p h a), \\
& \text { yp: } \quad y p=0.25 * t f p . e q *(k(-1) /(1+y d o t)) * * \text { alpha } \\
& *(1-\text { u.eq }) * *(1-\text { alpha }) \text {. }
\end{aligned}
$$

\subsection{The monetary nexus}

\subsubsection{The reaction function}

The monetary authority in CPAM has a long-run target for the inflation rate, given by pdottar. To hit that target, the monetary authority influences an instrument variable, $r n$, which can be thought of as the short-term interest rate. The intermediate target is the slope of the term structure, $r s l$. The reaction function is forward-looking, using leads of 7 to 8 quarters. There is no interest rate "smoothing" term in CPAM.

The central bank is presumed to use consumer price inflation in evaluating the need for action. The variable pcdot4 is a 4-quarter rate of change. In the core model, it is measured at quarterly rates to be consistent with other units. In the output, its more natural annual-rate cousin appears as $a \_p c d o t 4$.

$$
\begin{aligned}
r n: \quad r s l= & r s l . e q+r s l 7^{*}(p \operatorname{dot} 4(7)-p \operatorname{dottar}(7)) \\
& +r s l 8^{*}(p c \operatorname{dot} 4(8)-p \operatorname{dottar}(8))+r s l s h k
\end{aligned}
$$

CPAM follows QPM in specifying the reaction function in terms of the slope of the term structure. There are a number of reasons for this approach. The main point concerns how we identify the transmission mechanism. Historical movements in real interest rates contain more than monetary innovations. Since monetary innovations will tend to have more influence on short rates than long rates, the slope of the term structure provides a better measure of the actions of monetary policy than does any measure of the level of interest rates. The empirical evidence supports this view. ${ }^{13}$

13. See Côté and Macklem (1996) and Macklem, Paquet, and Phaneuf (1996) for a review of this evidence and other arguments for writing a model this way. 


\subsubsection{The term structure of interest rates}

Nominal and real interest rates are linked through Fisher equations, such as:

$$
r: \quad 1+r n=(1+r)^{*}(1+p \operatorname{dot}(1)),
$$

$$
\text { rn.eq: } \quad 1+\text { rn.eq }=(1+\text { r.eq })^{*}(1+\text { pdottar })
$$

Here we use model-consistent expectations, and we assume that interest rates are influenced by the core inflation rate, pdot, and not by relative price changes, such as would be reflected in differences between consumer price inflation and pdot.

CPAM has a simplified version of the term structure of interest rates, relative to the model in QPM. The maximum explicit horizon is limited to five years, half the QPM value, to keep the size of the simulation problem smaller. The basic theory is similar to that in QPM, with the core structure coming from the expectations model of the term structure. The equations are written in a more compact form, however, using an Euler representation. In the mnemonics, we use a tag " 5 " for a five-year rate. We use a tag "l" for the model's long rate. The term premium, rt5.eq, is set to 50 basis points, as in QPM, and assumed to be constant in the database. The equations, however, allow for the possibility of a time-varying premium.

$$
\begin{aligned}
& \text { rn5.eq: } \quad 1+r n 5 . e q=(1+r n 5 . e q(1)) *((1+r t 5 . e q) /(1+r t 5 . e q(1))) *((1+r n . e q) / \\
& (1+r n . e q(20))) * *(1 / 20), \\
& \text { rn5: } \quad 1+r n 5=(1+r n 5(1)) *((1+r t 5 . e q) /(1+r t 5 . e q(1))) \\
& *((1+r n) /(1+r n(20))) * *(1 / 20), \\
& \text { rnl.eq: } \quad \text { rnl.eq }=\text { rn5.eq, } \\
& r n l: \quad 1+r n l=r l 1 *(1+r n) *(1+r t 5 . e q)+r l 2 *(1+r n 5)+(1-r l 1-r l 2) *(1+r n l . e q), \\
& \text { r5.eq: } \quad 1+r 5 . e q=(1+r 5 . e q(1)) *((1+r t 5 . e q) /(1+r t 5 . e q(1))) *((1+r . e q) / \\
& (1+r . e q(20))) * *(1 / 20) \text {, } \\
& \text { r5: } \quad 1+r 5=(1+r 5(1)) *((1+r t 5 . e q) /(1+r t 5 . e q(1))) \\
& *((1+r) /(1+r(20))) * *(1 / 20), \\
& \text { rl.eq: } \quad \text { rl.eq }=r 5 . e q \text {, }
\end{aligned}
$$




$$
\begin{array}{rlrl}
r l: & 1+r l & = & r l 1^{*}(1+r) *(1+r t 5 . e q)+r l 2 *(1+r 5) \\
& +(1-r l 1-r l 2) *(1+r l . e q), \\
r s l: & 1+r s l & = & (1+r n) /(1+r n l), \\
\text { rsl.eq: } & 1+r s l . e q & = & (1+r n . e q) /(1+r n l . e q) .
\end{array}
$$

\subsubsection{Links to world rates and "risk" premia}

Real domestic rates of return are linked to world rates. The base (risk-free) real rate, r.eq, is linked directly to the world rate, rrow.eq. This return is not available on any domestic asset, however. The net return (after depreciation) to capital, rk.eq, the return on domestic government bonds, rgb.eq, and the return on net foreign assets, rnfa.eq, are written as the long rate plus a differential. This we call the "risk" premium. Here, our notation becomes just a trifle ambiguous. For example, $r k \_r l . e q$ is a difference, not a ratio as elsewhere.

$$
\begin{aligned}
& \text { r.eq: } \quad \text { r.eq }=\text { rrow.eq, } \\
& \text { rk.eq: } \quad r k . e q=r l . e q+r k \_r l . e q \text {, } \\
& r g b: \quad \quad r g b=r l+r g b \_r l . e q, \\
& \text { rgb.eq: } \quad \text { rgb.eq }=\text { rl.eq }+ \text { rgb_rl.eq, } \\
& \text { rnfa: } \quad r n f a=r l+r n f a \_r l . e q \text {, } \\
& \text { rnfa.eq: } \quad \text { rnfa.eq }=\text { rl.eq }+ \text { rnfa_rl.eq, } \\
& \text { rcon.eq: } \quad \text { rcon.eq }=\text { rl.eq }+ \text { rcon_rl.eq. }
\end{aligned}
$$

Usually, the world real interest rate is simply set at its equilibrium value, but this equation can be used to bring this part of any cyclical effects of foreign shocks into CPAM, if desired.

$$
\text { rrow: } \quad \text { rrow }=\text { rrow.eq. }
$$

\subsection{Exchange rate dynamics}

Next we have the equation for the dynamics of the real exchange rate. It is important to understand that, as in QPM, the equilibrium level of the real exchange rate comes from elsewhere in the model-from the nexus that determines wealth and the equilibrium structure of trade. This discussion is about the dynamics. The key equation is a version of the nominal interest parity condition. However, the exchange rate does not act as a pure jumper variable because we include 
some inertia through a lag, and an independent role for the eeq value. We also assume that the expected $z, z e$, includes some inertia from a lag and from a weight on the z.eq value. In this version of the model, there is no weight on the.$e q$ value in the expectations equation.

$$
\begin{aligned}
& z e: \quad z e=z f l * z(1)+z l l * z(-1)+(1-z f l-z l l) * z . e q(1), \\
& z: \quad z=z 1 *_{z}(-1)+z 2 *_{z} e^{*}(1+\text { rrow }) /(1+r)+(1-z 1-z 2) * z . e q \\
& +z s h k \text {. }
\end{aligned}
$$

\subsection{Inflation}

\subsubsection{The Phillips curve}

The CPAM Phillips curve proximately determines inflation for the numeraire price, the domestic absorption deflator at factor cost (PDFC). The logic of CPAM's price sector will be spelled out below, in a description of the entire relative price system. For now, let us just say that each domestic price in CPAM is constructed as a weighted combination of the core domestic price and a foreign price, all appropriately adjusted for any indirect taxes. For example, the GDP deflator, the average output price, is given by a weighted combination of the average domestic price and the export price, with the weight on the latter given by the share of output that is exported. Similarly, all domestic spending is some mix of imports and domestic absorption, and all component prices reflect that combination of import prices and the core domestic price. Since the central bank is presumed to formulate its actions based on the anticipated course of consumer prices, all elements that have an effect on relative consumption prices have a special role in the nominal dynamics. But core inflation remains a concept applied to PDFC.

The model equation for the rate of change of PDFC, which we call pdot, is as follows:

$$
\begin{aligned}
& \text { pdot: } \quad \text { pdot }=p d f 1 *\left(p d a 4^{*} p d o t e a+(1-p d a 4) * p c d o t e a\right)+p d f 2^{*} p d o t(1) \\
& +(1-p d f 1-p d f 2) *\left(p d a 1^{*} p d o t(-1)+(1-p d a 1)^{*} p \operatorname{dot}(-2)\right) \\
& +p d 0^{*}(y(0)-y p(0))+p d 1^{*}(y(-1)-y p(-1)) \\
& +p d 2 * \operatorname{MAX}(y(0)-y p(0), 0)+p d 3 * \operatorname{MAX}(y(-1)-y p(-1), 0) \\
& +p d a 5^{*}(\mathrm{pm} / \mathrm{pm}(-1)-1)+p d a 6^{*}(\mathrm{px} / \mathrm{px}(-1)-1) \\
& \text { - } p d 4 *(p d 5 *(w . e q-w . e q(-1))+p d 6 *(w . e q(-1)-w . e q(-2)) \\
& +p d 7 *(w . e q(-2)-w . e q(-3)))+ \text { pdotshk. }
\end{aligned}
$$


The CPAM Phillips curve has many standard features. It imposes the long-run natural-rate hypothesis (i.e., there is no permanent trade-off between output or employment and the rate of inflation). In the short run, however, there is a dynamic link between excess demand, $y-y p$, and inflation, pdot. ${ }^{14}$ Recent empirical evidence suggests that this linkage is asymmetric, as in the original Phillips (1958) curve. This asymmetry is such that the positive effect of excess demand on inflation is stronger than the negative effect of an equivalent degree of excess supply. For Canada, results documented in Laxton, Rose, and Tetlow (1993) led to this feature being included in QPM. Turner (1995) and Debelle and Laxton (1996) have also found significant asymmetry of this sort for the Canadian data. ${ }^{15}$ The form of this function in CPAM is the same as in QPM-a piecewise linear version with a steeper slope when excess demand is positive, as provided by the MAX terms in equation (101).

The first part of equation (101) captures intrinsic and expectational dynamics. The structure is based on a contracting paradigm, with periodic bargaining, as in Fuhrer and Moore's (1995a; 1995b) "real wage" version of Taylor's (1980) model. The terms pdotea and pcdotea are averages of expectations formed in recent quarters when contracts still extant were signed. We assume that there is annual bargaining. Thus, for example,

$$
\text { pdotea:pdotea }=(\text { pdote }+ \text { pdote }(-1)+\text { pdote }(-2)+\text { pdote }(-3)) / 4 \text {, }
$$

where pdote( $-i)$ is the expectation that was formed $i$ quarters in the past. We describe how expectations are formed in the next subsection. The equation for $p c d o t e a$ has the same form:

(103) pcdotea: $\quad$ pcdotea $=(p c d o t e+p c d o t e(-1)+p c d o t e(-2)+p c d o t e(-3)) / 4$.

The presence of both expectations reflects the notional wage bargaining paradigm that lies behind this equation. Firms care about their selling price and the real wage in those terms, while workers

14. In simulation, the level of potential output, $y p$, in the model comes from evaluating the production function at full employment and trend factor productivity, but with the existing stock of capital. This treats capital as a quasi-fixed factor and employment as completely variable in the short run, as is traditional in such models.

15. This evidence is not limited to the Canadian case. Turner also reports significant asymmetry for the United States and for Japan. Laxton, Meredith, and Rose (1995) find significant asymmetry for a pooled sample of G7 countries. Clark, Laxton, and Rose (1996), Debelle and Laxton (1997), and Clark and Laxton (1997) find significant asymmetry for the United States. Fisher, Mahadeva, and Whitley (1996) find significant asymmetry for the U.K. data, as do Debelle and Laxton. Isard and Laxton (1996) find significant asymmetry for a pooled sample with France, Italy, and the United Kingdom. Bean (1996) reports evidence for modest asymmetry for a panel of OECD countries. 
care about consumer prices and the real wage in consumer goods. When relative prices are changing, both parties have some influence on nominal wage dynamics. ${ }^{16}$

Equation (101) also embodies a second level of dynamics in price setting. The bargaining/ expectations structure described above is thought of as reflecting cost pressures, but that is not the only source of inertia. The term $p d o t(1)$ represents a one-quarter-ahead, model-consistent forecast, and there are also lags of the actual inflation rate-reflecting quarterly price adjustment by firms conditional on the underlying cost trend.

We allow a small direct effect of trade prices on core inflation. We remind the reader that both $p m$ and $p x$ are measured relative to the numeraire price, so these terms are not inflation rates. Rather they are measures of the extent to which changes in these particular prices differ from those in the core price. Adding these effects can be motivated in two ways. First, no price is determined in isolation in a general system. If import prices fall, competition on the margin to retain domestic market share will have an effect on domestic prices. Similarly, if export prices rise, firms have an incentive to switch to export sales from domestic sales, and this will create competitive pressures for domestic prices to follow. The second motivation comes from the cost side. There is no direct measure of cost effects in the equation, but one can think of these terms as capturing any passthrough into costs (wages), and hence prices, from foreign shocks.

The term in the wage gap at the end is designed to capture the role of prices in engineering changes in the real wage when the equilibrium for the latter changes. The relative strength of this effect will determine how much of such adjustment comes through prices and how much through changes in the nominal wage. We use this term to calibrate CPAM to have similar properties to QPM for a productivity shock. ${ }^{17}$

\subsubsection{Expectations}

Inflation expectations are specified using a variant of the Buiter and Miller (1985) mixed model with both forward- and backward-looking components. We also add a small weight on the perceived (or expected) target rate of inflation, which we call pdottare (more on this below). We

16. In the larger model from which CPAM is drawn, these ideas are reflected more formally in the equations. For CPAM, we have stripped out the details of the bargaining model as part of the effort to speed simulation times.

17. This is another ad hoc element that replaces aspects of the larger model from which CPAM is drawn. 
assume, here, that $p d o t$ and pcdot expectations are formed in the same way. There is no fundamental reason why this has to be so. The equations are as follows:

$$
\begin{aligned}
& \text { pdote: } \quad \text { pdote }=(1-p d e 0-p d e 1) *(p d l 1 * p d o t(-1)+(1-p d l 1) * p d o t(-2)) \\
& + \text { pde } 1 * \text { pdot } 4(4)+\text { pde } 0^{*} \text { pdottare, } \\
& \text { pcdote: } \quad \text { pcdote }=(1-p d e 2-p d e 3) *(p d l 1 * p c d o t(-1)+(1-p d l 1) * p c d o t(-2)) \\
& + \text { pde } 2 * \text { pcdot4(4) }+ \text { pde } 3 * \text { pdottare. }
\end{aligned}
$$

The backward-looking component is a weighted average of the previous two observations of inflation. The forward-looking component is a model-consistent forecast. The term pdot 4 stands for a 4-quarter rate of change; it enters with lead 4, which makes this term the forecast rate of inflation over the next 4 quarters, the assumed bargaining horizon.

The perceived target is formulated as follows:

(106) pdottare: $\quad$ pdottare $=p t l 1 *$ pdottare $(-1)+$ ptl $2 *$ pdottare $(-2)+(1-p t l 1-p t l 2)$

$$
*(p t l 3 *(p d o t 4(16)+p d o t 4(20)) / 2+(1-p t l 3) * \text { pdottar }) \text {. }
$$

The expected target rate of inflation evolves as a second-order transfer function, with the underlying process driven by a weighted average of the model-consistent forecast for the 4-quarter inflation rate 4 and 5 years ahead (we put 0 weight on the actual target, i.e., ptl3=1). This term is used only in the expectations equations, (104) and (105), where it is given a relatively small weight of 0.1 . It is designed to represent the effects of credibility. If the monetary authority is expected to keep inflation within a reasonable range of the target level in the medium term, then the expected target will remain very close to the announced target. This will provide something of an anchor to expectations, damping their response to short-term cyclical effects. By contrast, if the monetary authority's reaction function is not expected to keep inflation close to the target, this term will pull expected inflation away from the announced target, even if the recent history is good and the shortrun prospects are for inflation to remain close to that target level. This captures the idea that it can take more than a few good outcomes for the monetary authority to gain credibility, and that credibility is fragile and, once lost, is hard to regain.

In a policy shock, where the target is changed, the above equation acts as a learning rule. Agents gradually learn the new target rate. The dominant root in the AR part is about 0.84 . Thus, it takes about five years for expectations of the target to converge on the actual new target 
(assuming that the monetary authority is doing what is necessary to make the actual outcome conform to that new target).

\subsection{Relative prices}

The key to CPAM's representation of price dynamics is the identification of a core process for inflation, onto which is built an elaborate system of relative price dynamics that exploits all the available information from the identities that describe the composition of the components of spending. 18

The core domestic price in CPAM is the domestic absorption deflator at factor cost, PDFC. This is the average revenue received by firms from final sales with domestic end use. ${ }^{19}$ Each domestic price can be considered to be a weighted average of the price paid for domestic-source goods and the price paid for imported goods of that type. In each case, moreover, there is an identity that must be respected in this construct; it is not just any weighted average, the weights have to be consistent with the quantities.

Both import and export prices are tied to exogenous world values. ${ }^{20}$ However, pass-through is not instantaneous. The.$e q$ version has relatively quick pass-through, but we model the actual domestic currency import prices using standard CPAM adjustment equations.

For the three main components of domestic absorption, $c$, $i$, and $g$, we also allow for variation in the relative domestic absorption price. This is another example of the compromise necessary to give the one-good paradigm of domestic production a chance to match the complexity of the real world. For example, the pricing of domestically produced investment goods has been as profoundly affected by the revolution in computer and communications technology as has world pricing. We need, therefore, to break the strict logic of the supply side that says that there is one output good sold for all purposes. We do this by introducing three domestic price relatives: $p c d$,

18. In this, CPAM has a slightly cleaner system for relative price accounting than does QPM, as well as a clearer accounting distinction between domestic and foreign "components" of the inflation process. QPM deliberately violates the logic of the one-domestic-good paradigm to allow an independent equation for the dynamics of the CPI, excluding food and energy. In CPAM, we return to the methodology of SAM (Rose and Selody 1985) and build all prices up from their source components.

19. If the price received for exports is the same, then PDFC is the same as PFC, the overall deflator at factor cost. However, that is not the case, in fact, so there is a small wedge between the two measures. It is the overall $P F C$ that is relevant to firms in their decisions.

20. This version of CPAM does not have the almost-small-open-economy feature of QPM. 
$p k d$, and $p g d .^{21}$ As is the case for all CPAM prices, these are written relative to the numeraire, PDFC. Thus, there is an identity that requires that the appropriately weighted average of these domestic price relatives equal 1 . There are two versions of this identity, towards the end of the following list, in the equations labelled for $p c d . e q$ and $p c d$. Note also that in the equation immediately above the one for $p c d . e q$, we show the numeraire convention explicitly via the " 1 " in front of the domestic absorption terms in an identity that provides a second check on whether the .eq model has obeyed all the necessary restrictions to satisfy the add-up identity using factor cost measures.

$$
\begin{aligned}
& \text { pc: } \quad p c^{*} c=(1+t i c) *\left(p c d^{*}(c-c m)+p c m^{*} c m\right) \text {, } \\
& \text { pc.eq: } \quad \text { pc.eq*c.eq }=(1+t i c) *(p c d . e q *(c . e q-c m . e q)+\text { pcm.eq*cm.eq }) \text {, } \\
& \text { pcm: } \quad \text { pcm }=\text { pcm.eq }+ \text { pcmvl*(z-z.eq)*pcrow.eq } \\
& + \text { pcmv } 2 *(\text { pcrow-pcrow.eq }) * z . e q-\text { pcmadj, } \\
& \text { pcm.eq: } \quad \text { pcm.eq }=(1-p c m 1) * p c m . e q(-1)+\text { pcml }{ }^{*} \text { pcrow.eq*z.eq, } \\
& p k: \quad \quad p k * i=(1+t i i) *(p k d *(i-i m)+p k m * i m), \\
& \text { pkm.eq: } \quad \text { pkm.eq*i.eq }=(1+t i i) *(p k d . e q *(i . e q-i m . e q)+\text { pkm.eq*im.eq }) \text {, } \\
& \text { pkm: } \quad \text { pkm }=\text { pkm.eq }+ \text { pkmv1*pkrow.eq* }(z-z . e q) \\
& + \text { pkmv2*(pkrow-pkrow.eq }) * z . e q-\text { pkmadj, } \\
& \text { pkm.eq: } \quad \text { pkm.eq }=(1-p k m 1) * p k m . e q(-1)+p k m 1 * p k r o w . e q * z . e q \text {, } \\
& \text { pkd: } \quad \quad p k d=p k . e q+p k d v 1 *(i / i . e q-1)-p k d a d j, \\
& p g: \quad \quad p g * g=(1+t i g) *(p g d *(g-g m)+p g m * g m), \\
& \text { pg.eq: } \quad \text { pg.eq*g.eq }=(1+t i g) *(p g d . e q *(g . e q-g m . e q)+\text { pgm.eq*gm.eq }) \text {, } \\
& \text { pgm: } \quad \quad \text { pgm }=\text { pgm.eq }+ \text { pgmvl*pgrow.eq*(z-z.eq) } \\
& + \text { pgmv } 2 *(\text { pgrow-pgrow.eq }) * z . e q-\text { pgmadj, } \\
& \text { pgm.eq: } \quad \text { pgm.eq }=(1-p g m 1) * \text { pgm.eq }(-1)+\text { pgml }{ }^{*} \text { pgrow.eq*z.eq, } \\
& \text { pgd: } \quad \text { pgd }=p g d . e q+p g d v 1 *(y / y . e q-1)-p g d a d j,
\end{aligned}
$$

21. These price relatives are accounted for at factor cost. We chose to keep the mnemonics as simple as possible, given that the accounting convention is very clear in the way indirect taxes enter all the identities. 


$$
\text { pxm: } \quad \text { pxm }=p m,
$$

$$
\text { pxm.eq: } \quad \text { pxm.eq }=\text { pm.eq, }
$$

$$
\begin{aligned}
& \text { px.eq: } \quad \text { px.eq }=(1-p x l) * p x . e q(-1)+p x l * \text { pxrow.eq*z.eq, } \\
& \quad p m: \quad \quad p m * m=p c m * c m+p k m * i m+p g m * g m+p x m * x m,
\end{aligned}
$$

pm.eq: $\quad$ pm.eq*m.eq $=$ pcm.eq*cm.eq + pkm.eq*im.eq + pgm.eq*gm.eq

$$
+ \text { pxm.eq*xm.eq, }
$$

$$
\begin{aligned}
\text { check2: } \quad \text { pfc.eq*y.eq }= & 1 *(\text { pcd.eq } *(\text { c.eq-cm.eq })+\text { pkd.eq*(i.eq-im.eq }) \\
& + \text { pgd.eq*(g.eq-gm.eq }))+ \text { px.eq*x.eq- pxm.eq*xm.eq } \\
& + \text { check } 2
\end{aligned}
$$

$$
\begin{gathered}
\text { pcd.eq:pcd.eq*(c.eq-cm.eq })+ \text { pkd.eq*(i.eq-im.eq })+ \text { pgd.eq*(g.eq-gm.eq }) \\
=\text { c.eq-cm.eq }+ \text { i.eq-im.eq }+ \text { g.eq-gm.eq, }
\end{gathered}
$$

$$
\begin{aligned}
& \text { pcd:pcd* }(c-c m)+p k d^{*}(i-i m)+p g d^{*}(g-g m) \\
&=c-c m+i-i m+g-g m, \\
& \text { pgd.eq: } \quad \text { pgd.eq }=\text { pgd.eq }(-1)^{*}\left(1+0.2^{*}(z . s s / z . s s(-1)-1)\right), \\
& \text { pkd.eq: } \quad \text { pkd.eq }=\text { pkd.eq }(-1)^{*}(1+0.2 *(z . s s / z . s s(-1)-1)), \\
& \text { z.ss: } \quad z . s s=z . s s(1) .
\end{aligned}
$$

Consider, for example, the first block of four equations. Equation (110) provides for adjustment of the equilibrium price of consumption imports, pcm.eq, to the world level of the consumption good price. We make this relatively rapid. Equation (109) provides the dynamics of the actual consumption import price, $p \mathrm{~cm}$. Here, as in all similar equations, we add two types of dynamic disequilibrium effect. The first one is intended to capture the effects of changes in the exchange rate when the.$e q$ prices are not disturbed. Thus, in shocks where there is a temporary depreciation of the currency, this term will provide for some temporary effects on consumption import prices. The second term is there to permit us to add extra dynamics for world shocks, where 
world relative prices may be expected to deviate temporarily from their.$e q$ values. ${ }^{22}$ Equations (108) and (107) define the eq and actual levels of overall consumption prices as weighted averages of the domestic price and the import price. As in QPM, we assume that there are no tariffs; the market price reflects the indirect tax on consumption goods, at rate tic. Finally, the domestic relative consumption price is linked to PDFC through equations (127) and (128). The equations for investment and government absorption prices are similar in structure.

Export prices are also linked to a world price. We note, in passing, that we make a simplifying assumption for the pricing of the direct import component of exports. We assume that these goods are priced as the average import good. This does two things. It simplifies the import price accounting and eliminates any effect of this component on overall import prices. It also eliminates any potential problem with economic rents available from just changing the scale of reexporting. In this formulation, exporters make no surplus profits from importing for re-export. None of this is essential, but we find this the simplest way to handle this odd, but empirically important, component of Canadian trade.

The two somewhat unusual equations at the end are devices to allow for endogenous movement in the .eq values of two of the domestic price relatives in those cases where the steadystate real exchange rate changes in a shock. This particular formulation picks up that effect using the value from the first-period of the simulation (the new SS solution) relative to the lag (the old, control solution), passing some of that into pkd.eq and pgd.eq. The identity then completes the system and proximately determines what happens to pcd.eq. All of this is ad hoc, in the sense that we have no formal market structure to apply to solve for changes in the domestic price relatives. But without something like this, all the effect ends up in the variable chosen for the normalization of the identity (here, the pcd.eq equation). So, we spread the effect, as shown.

\subsubsection{Foreign relative prices}

The following four equations serve only to provide a framework for introducing different forms of foreign shock. In all cases, foreign prices are exogenous. But we want to be able to distinguish permanent shocks from temporary shocks. The .eq parts are intended to represent the

22. These terms were included in CPAM to enable us to consider world economy shocks in the stochastic simulation project for which this model was built. In the end, this feature of the model was not exploited in Black, Macklem, and Rose (1997); these terms are all set to zero. 
permanent part of foreign price structure. In the default mode, all the shock terms are zeros, but these terms can be used to construct an exogenous foreign cycle if needed.

$$
\begin{array}{ll}
\text { pcrow: } & \text { pcrow }=\text { pcrow.eq }+ \text { pcrowsh }, \\
\text { pkrow: } & \text { pkrow }=\text { pkrow.eq }+ \text { pkrowsh }, \\
\text { pgrow: } & \text { pgrow }=\text { pgrow.eq }+ \text { pcrowsh }, \\
\text { pxrow: } & \text { pxrow }=\text { pxrow.eq }+ \text { pxrowsh } .
\end{array}
$$

Note that these are all relative prices. Each is deflated by whatever base foreign price is used implicitly or explicitly in transforming between real and nominal exchange rates. Take, for example, the pcm.eq equation, written in SS form (with all the adjustment completed): pcm.ss= pcrow.ss*z.ss. If uppercase symbols are the original, undeflated values, we have PCM.ss= $P C R O W . s s^{*} S$, where $S$ is the nominal exchange rate. As usual, we deflate by PDFC. Here, however, we need an extra step to finish the foreign part. Let $P W$ be some numeraire foreign price. It could be, but does not have to be, the world equivalent to PDFC. We then have:

$$
\text { pcm.ss: } \quad \text { pcm.ss }=(P C R O W . s s / P W) *(P W / P D F C) * S=\text { pcrow.ss } * \text { z.ss. }
$$

The intermediate steps here are not visible in any CPAM equation. But from any simulation, the implicit transform above can be used to retrieve results for the nominal exchange rate. This type of thing is done in a macro we call "postcom," which is introduced in the next section.

\subsection{Calibration equations and output transforms}

There are a few equations in the core model used for calibration runs and a few more in the output module, over and above those that simply convert units.

\subsubsection{Calibration equations}

The calibration equations are included to facilitate the imposition of judgment on certain aspects of the numerical steady state. We show here a set of equations that facilitate tuning in desired values for steady-state relative prices. In the first of these, for example, a utility variable $p c \_p y . e q$ is introduced. In normal simulation, this equation just computes the ratio of $P C . E Q$ to $P Y . E Q$ from the model's endogenous determination of these prices. In calibration, however, we exogenize $p c \_p y . e q$ and set it at the desired steady-state ratio. Working back through the relative 
price system, we endogenize pcrow.eq to make this hold. (In fact, there is a bit more to it, but that is the essential point.)

(138) $p c \_p y . e q: \quad$ pc_py.eq $=p c . e q / p y . e q$,

(139) pi_py.eq: $\quad$ pi_py.eq $=$ pi.eq/py.eq,

(140) pg_py.eq: $\quad$ pg_py.eq $=$ pg.eq/py.eq,

(141) px_py.eq: $\quad$ px_py.eq $=p x . e q / p y . e q$,

(142) pm_py.eq: $\quad$ pm_py.eq $=$ pm.eq/py.eq.

\subsubsection{The postcom macro}

It is most convenient to simulate the core model in detrended form. However, it is, of course, essential to be able to reintroduce trend real growth and trend inflation to the output. Also, there are various measures one might want to see that are transforms of core output, such as cumulative gap measures or cumulative price drift measures. All of this is provided in a macro, called postcom, for ex post computations. This is also where we compute all the annual rate measures and level measures. 



\section{The dynamic properties of CPAM}

In this section, we describe aspects of CPAM's properties by presenting the results of eight shocks. We begin with some temporary shocks.

\subsection{A temporary demand shock}

The first shock is a temporary increase in demand that increases aggregate demand by 1 per cent, from exogenous increases in both consumption and investment. Consumption increases by 2 per cent and investment by 1 per cent.

A first-pass analysis of this shock is straightforward. The increase in demand leads to an increase in inflation, which the monetary authority counteracts by increasing interest rates. This, with the associated appreciation in the real exchange rate, reduces demand and eventually there is excess supply. Inflation turns, and eventually, by the fifth year, returns to control. Notice how the monetary authority is able to do this with little cycling.

It is possible to garner more from this shock than the simple analysis above. First, it provides an example of how the dynamic solution returns to the steady state when the model is perturbed. Notice how all three stocks, government debt, physical capital, and net foreign assets, return to the control after about 10 years. Government debt falls initially as tax revenues increase with demand. In response, the government reduces the tax rate and the level of government debt

begins to return to its target level. Capital increases slightly with the increase in investment. ${ }^{23}$ However, this latter increase is reversed quite quickly by the interest rate increases, and capital returns to its equilibrium level. Finally, the economy runs a trade deficit over the general course of the shock, owing to the increase in demand for imported consumption and investment goods and the reduction in exports brought about from the appreciation in the currency.

Although a better example is provided in the next subsection, a second more subtle illustration of one of CPAM's properties is how the shock leads to a greater increase in inflation of PDFC compared with that of $P C$. This reflects the exchange rate pass-through into $P C$, which in this case acts to dampen the inflationary pressure stemming from excess demand.

23. Note that due to the large increase in output, the ratio of capital to GDP actually falls. 
Figure 1: A demand shock

(\% is per cent shock minus control, \%p is percentage points shock minus control)
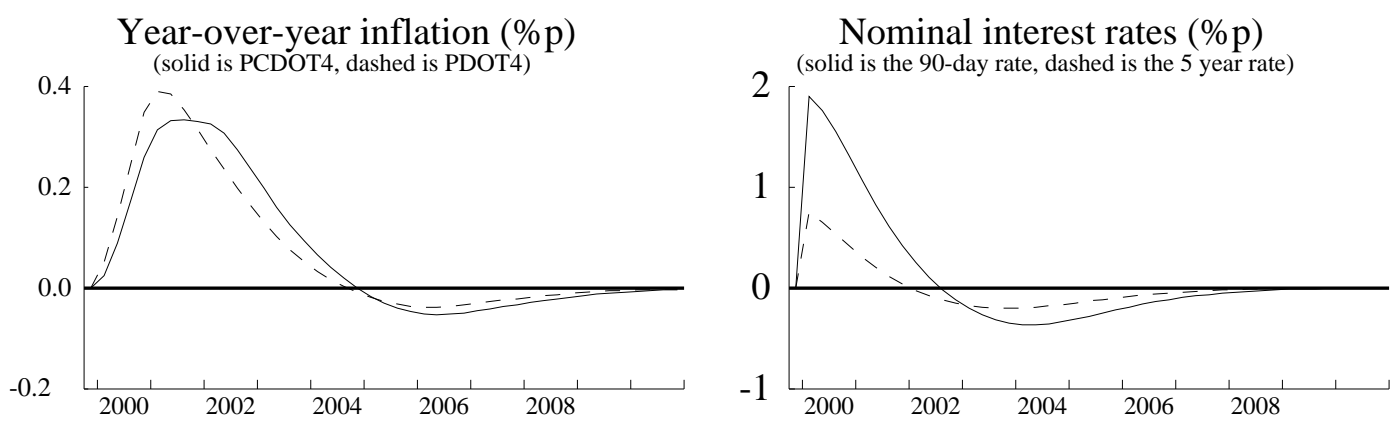

Output gap and yield curve slope (\%p)
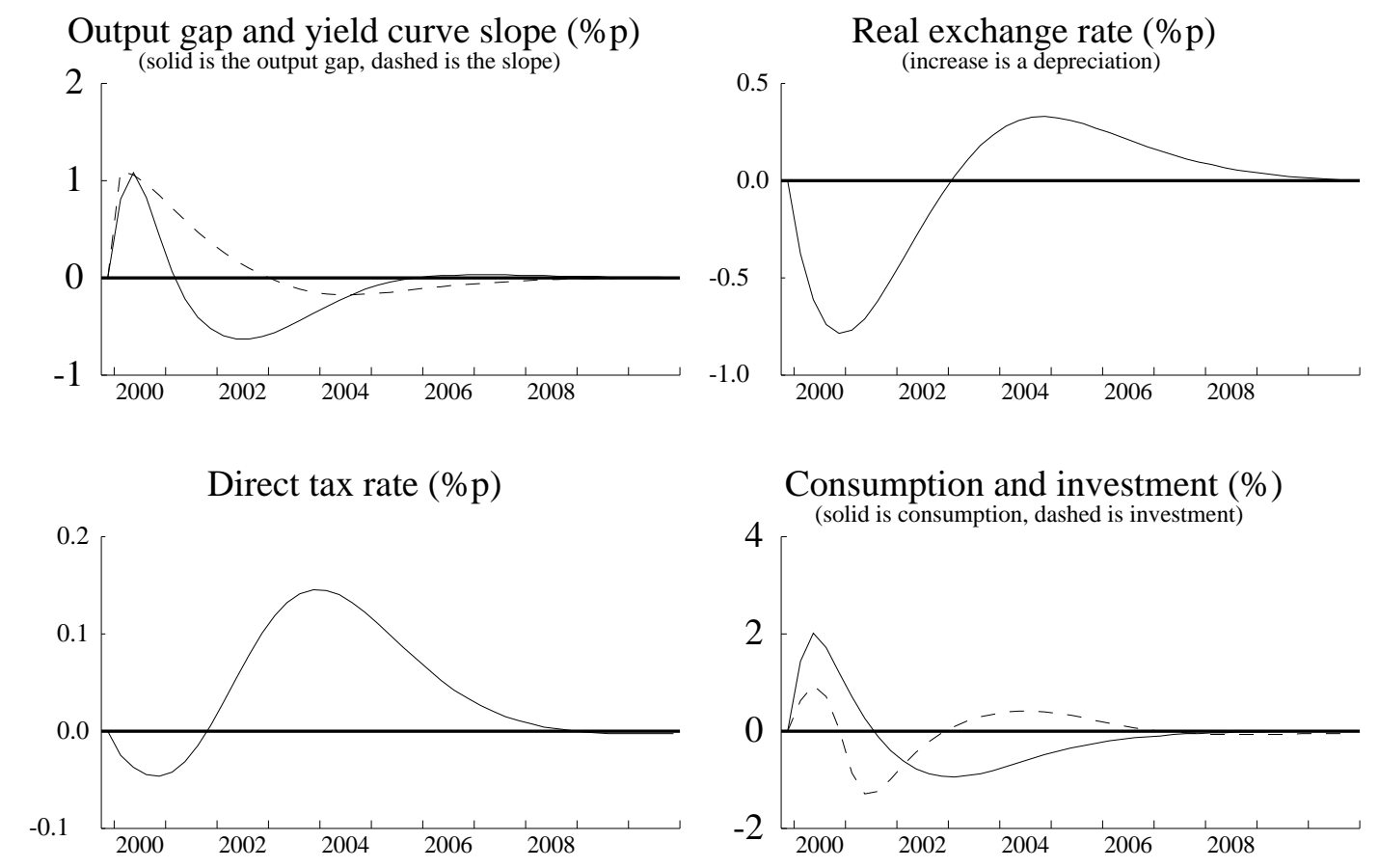

\section{Consumption and investment $(\%)$}

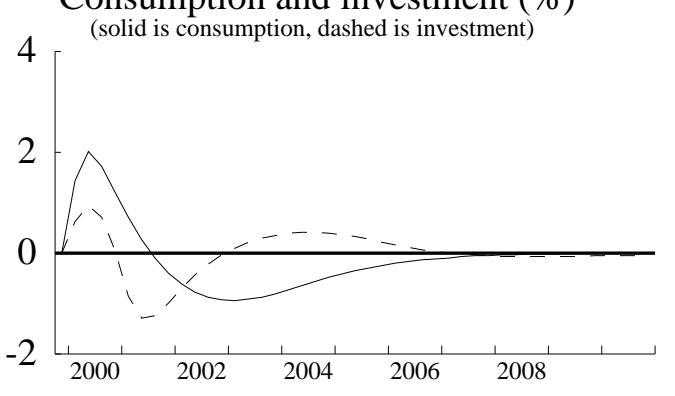

Trade $(\%)$
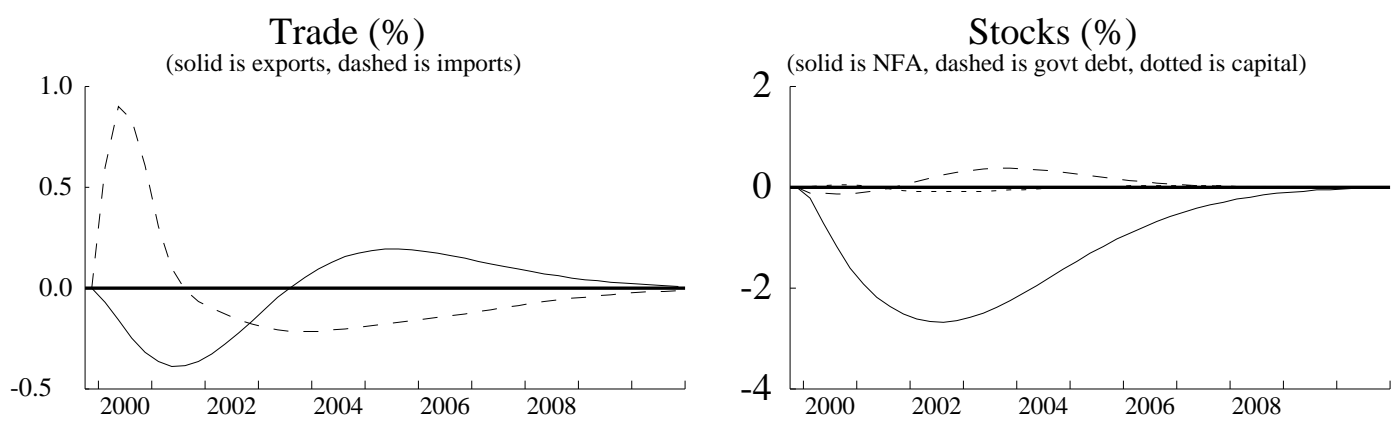


\subsection{A temporary exchange rate shock}

This shock, where the real exchange rate depreciates by a little over 1.2 percentage points, highlights how the real exchange rate affects prices and the real economy in CPAM.

The real exchange rate operates first through prices and from there the real economy. A depreciation in the real exchange rate means that the price of exports falls and the price of imports rises. These relative price movements affect the components of aggregate demand. Exports rise and imports fall, increasing domestic demand. However, as substantial proportions of consumption and investment goods are imported, the overall relative prices of these goods increase and quantities decrease following an exchange rate depreciation. Overall, the effect on aggregate demand is ambiguous. However, CPAM has been calibrated so that the trade effect dominates and aggregate demand increases.

As in the demand shock, the increase in aggregate demand, together with a direct price effect described below, induces some inflation and consequently a tightening by the monetary authority. In passing, it is worth emphasising that this tightening is purely a response of the monetary authority to return inflation to its target rate, rather than a desire to target or smooth the exchange rate in any direct sense. As before, the economy returns to control following a period of stock adjustment.

There is an interesting "blip" in the shock minus control results for the rate of inflation in consumer prices, PCDOT4, which corresponds with the initial spike in the exchange rate. Notice how PCDOT4 jumps over 0.25 percentage points, then quickly falls to 0.1 percentage points above control, before gradually returning to control. In contrast, the PDFC deflator jumps by only 0.2 percentage points initially and then immediately starts its gradual return to the target- there is no jump down or "blip." The reason for this difference is the exchange rate effect. Imported goods have a direct effect on consumer prices, but only an indirect dynamic effect on the PDFC deflator, so the depreciation of the exchange rate feeds more quickly into $P C$ inflation. Conversely, when the exchange rate starts to appreciate in response to the rise in interest rates, the rate of PC inflation falls more sharply, leading to the "blip." 


\section{Figure 2: An exchange rate shock}

(\% is per cent shock minus control, \%p is percentage points shock minus control)
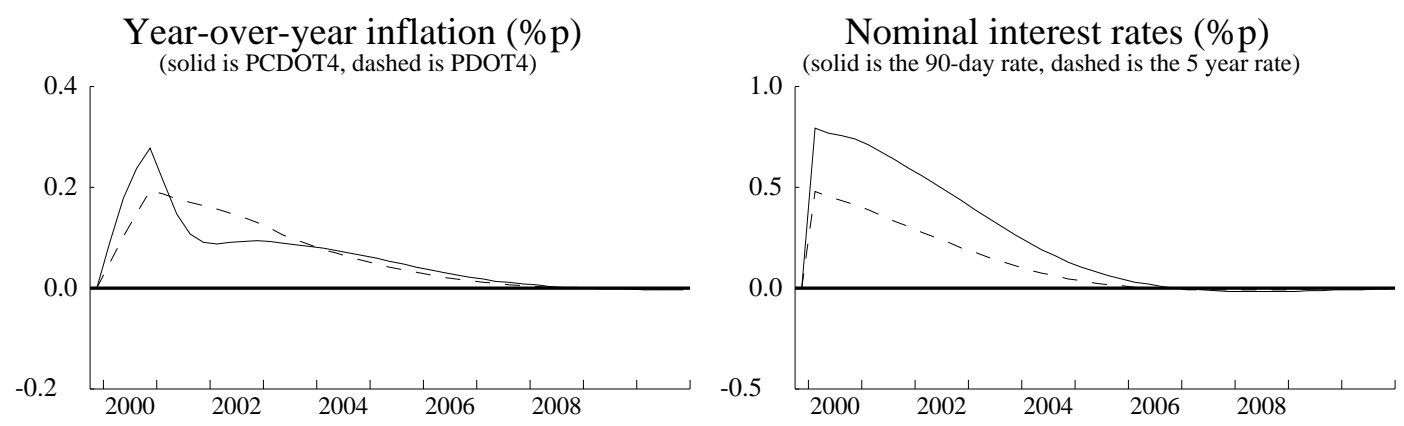

Output gap and yield curve slope (\%p)
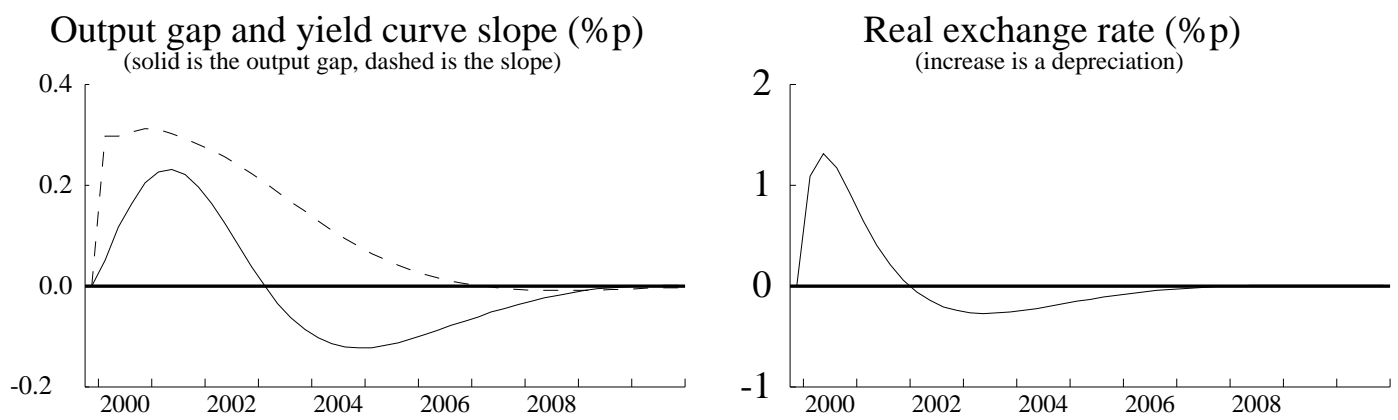

\section{Direct tax rate $(\% \mathrm{p})$}

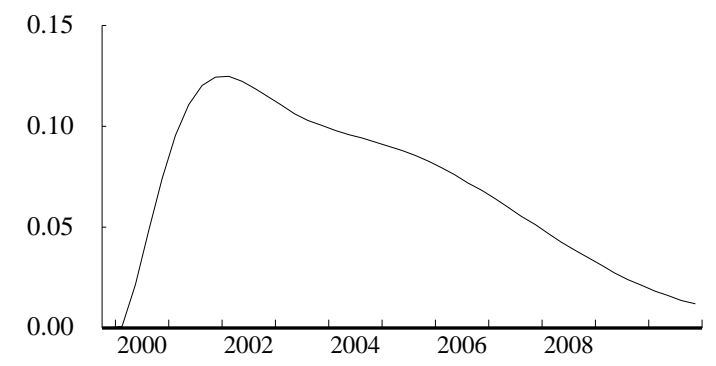

Consumption and investment (\%)

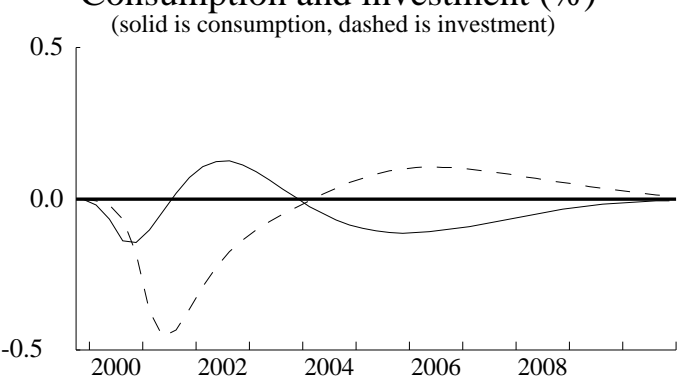

Trade $(\%)$

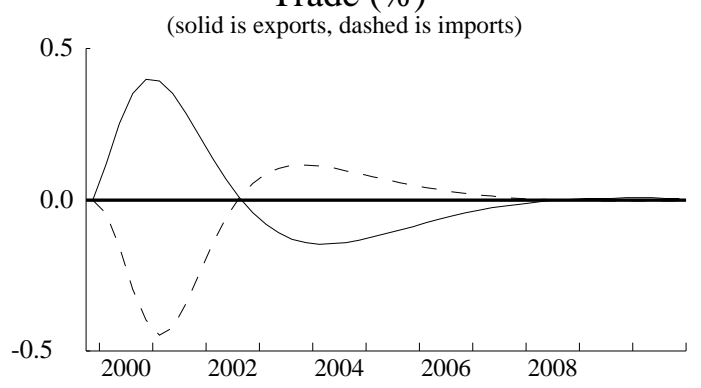

Stocks $(\%)$

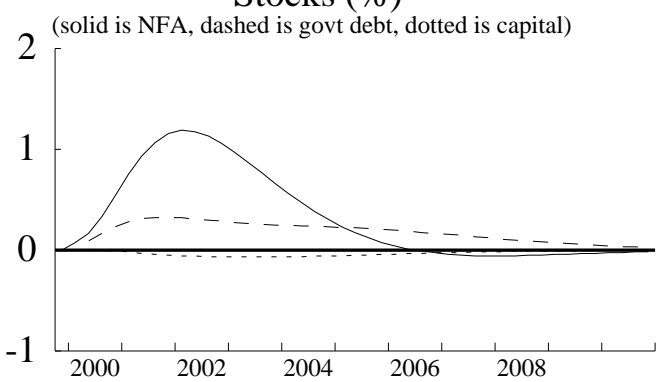




\subsection{A temporary tightening in monetary conditions}

This shock is intended to illustrate how monetary policy is transmitted through the model. We describe the results of a temporary (four-quarter) increase in the intermediate monetary target - the slope of the term structure of interest rates.

The net effective shock is shown in the second panel, left side, of Figure 3. For this shock, we have left the normal monetary reaction function to operate. Since the economy weakens and inflation falls in response to the shock, the endogenous response is to reverse part of the shock.

As has already been discussed, monetary policy acts first through the exchange rate, and then through aggregate demand. As shown in the figure, the exchange rate appreciates by a little over 0.5 percentage points, before starting to depreciate back towards the control solution. The weakening of aggregate demand lags this reaction by a couple of quarters. The exchange rate response itself contributes to the transmission of the shock to the real economy, as exports decline relatively quickly. As the interest rate effects on domestic demand begin to bite, however, the trade effects become dominated by the profile of imports, which reflect the cycle in investment spending.

The results of an exchange rate appreciating faster than demand is falling can also be inferred by comparing the fall of $P C$ inflation compared with PDFC inflation. The former falls faster, again about two quarters sooner, than the latter.

As is to be expected, the tightening of monetary conditions for no particular reason necessitates an offsetting loosening over the medium term to return inflation to the target level. Inflation returns to the target after about six years. 
Figure 3: A temporary tightening in monetary conditions
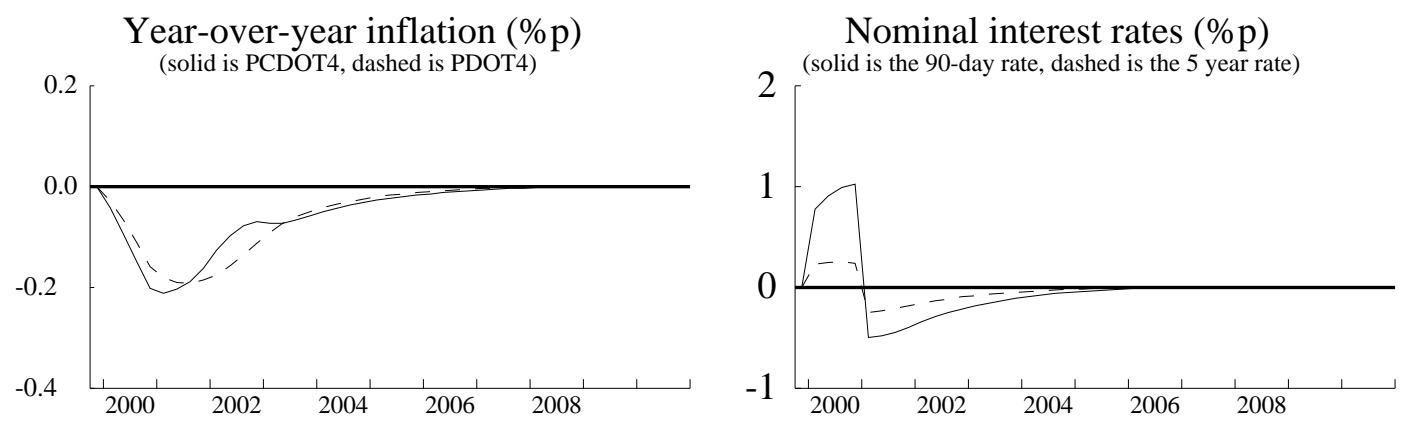

Output gap and yield curve slope (\%p)
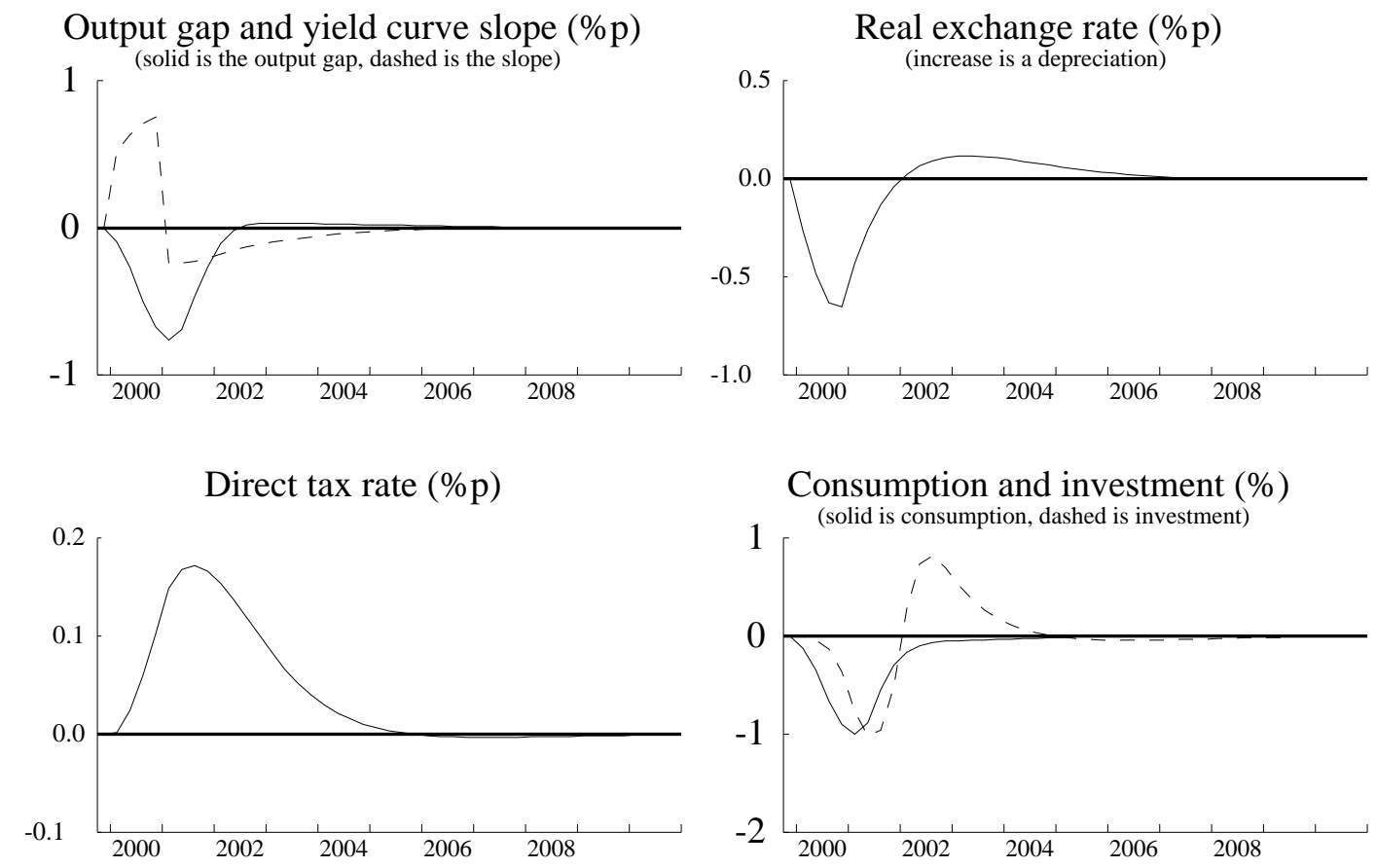

Consumption and investment (\%)

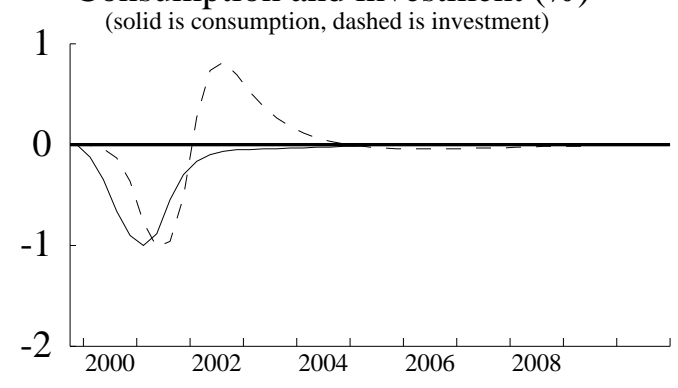

Trade $(\%)$
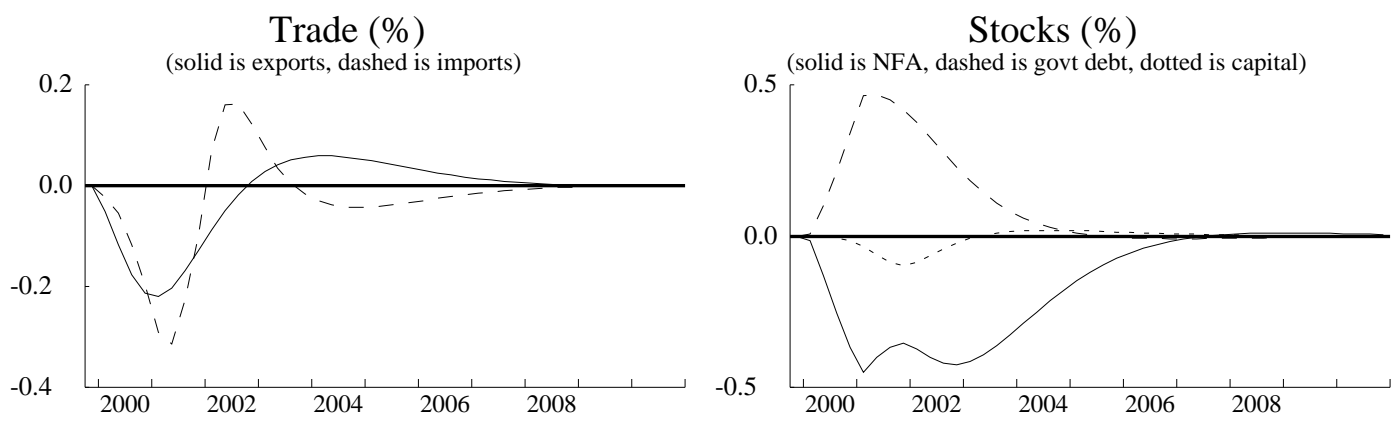


\subsection{A temporary increase in inflation}

This shock reports the results of a temporary increase in inflation. More specifically, the residual associated with the Phillips curve is shocked for one quarter. The shock, however, is substantial enough to raise the four-quarter inflation rate by close to a percentage point by the end of the first year.

The mechanics of the shock are straightforward. The monetary authority tightens in order to bring inflation back to the target rate. This tightening triggers an exchange rate appreciation, which helps reduce inflation via a direct effect on consumer prices of lower import prices as well as by reinforcing the effect of higher interest rates in reducing aggregate demand by discouraging exports. The substitution of cheaper imports for domestic goods in consumption also works to reduce domestic demand. Aggregate demand falls by about 1 per cent in the first year, and inflation is back at control within three years.

The profile of the monetary response is worth noting. As in the demand shock, the forwardlooking monetary authority raises rates sharply and then begins to reduce them long before inflation is back to the target rate. As a result, there is not a lot of overshooting and secondary cycling.

One small point of interest in this shock is that there is some degree of policy co-ordination in the response. The monetary tightening leads to lower tax revenues, and the government finances its activity with a temporary increase in the deficit causing debt to rise above the target level. The response is to raise the tax rate, which helps reduce spending, assisting the monetary authority in resisting the temporary surge in inflation. 


\section{Figure 4: A temporary increase in inflation}
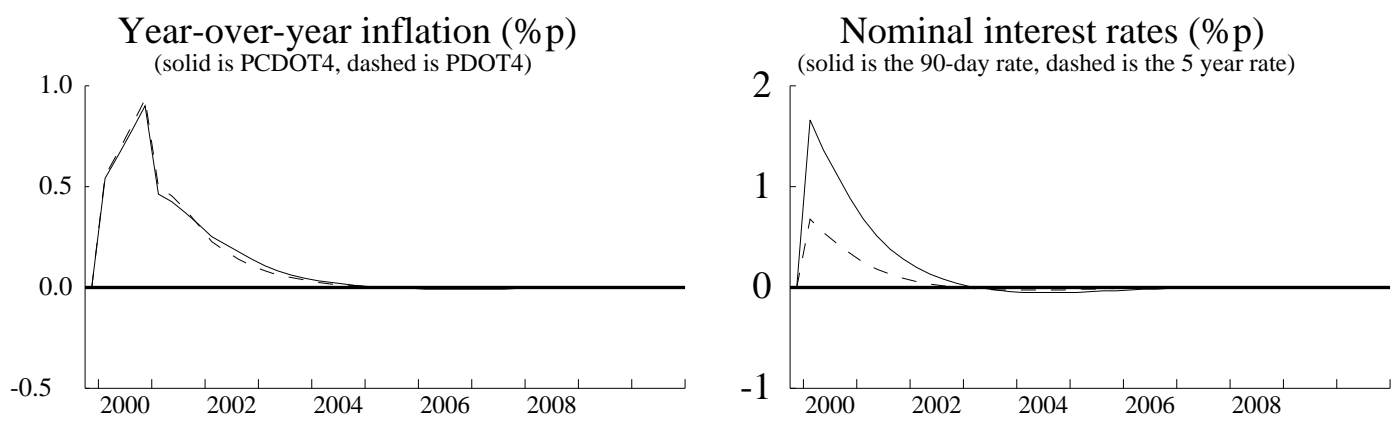

Output gap and yield curve slope (\%p)
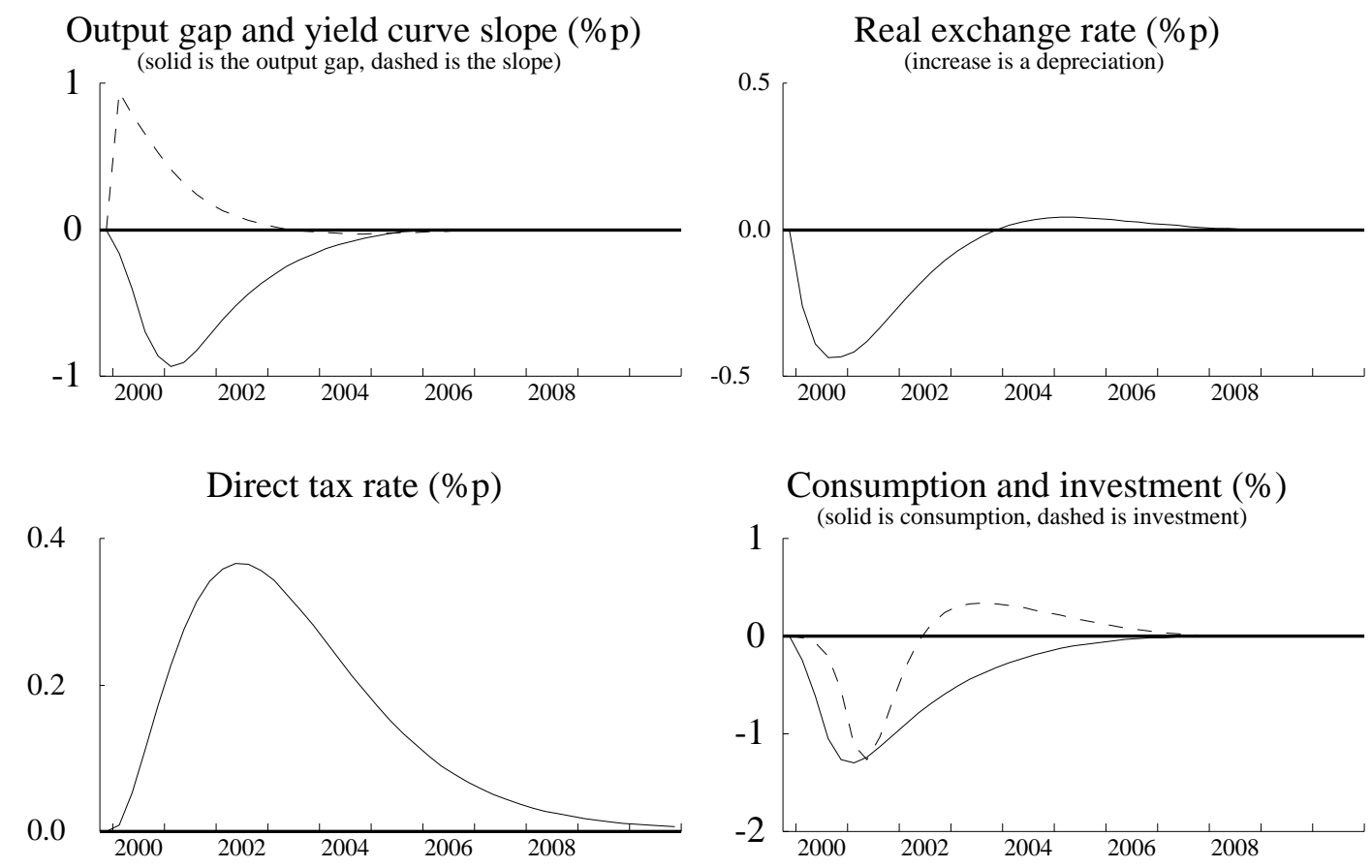

Consumption and investment (\%)

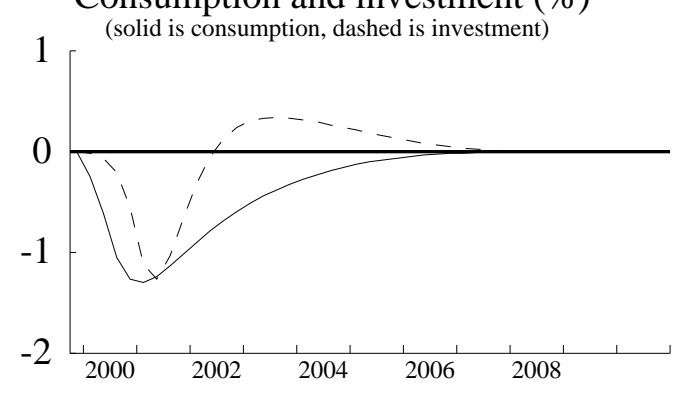

Trade (\%)
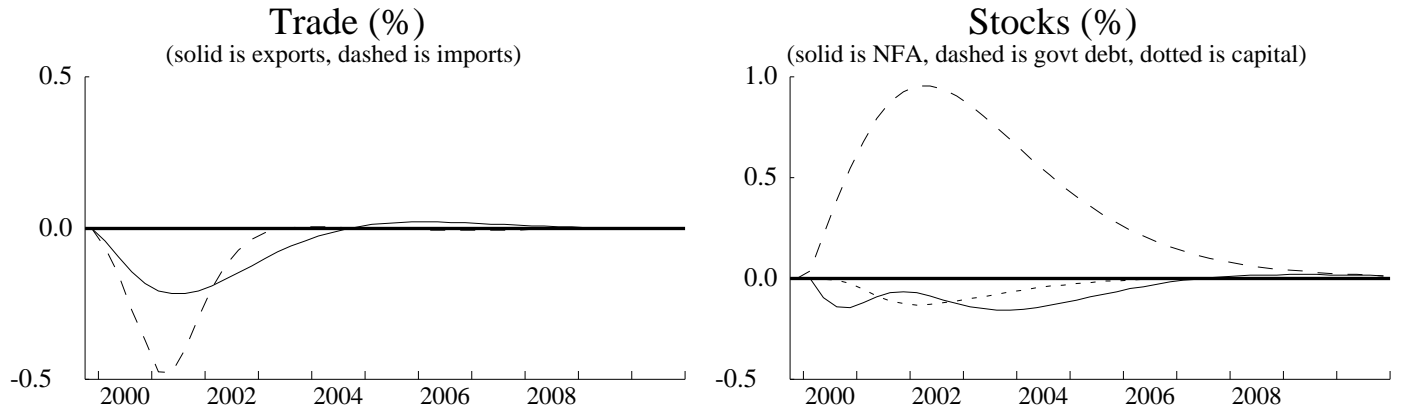


\subsection{An increase in world commodity prices}

In this shock, the price of world commodities rises. In CPAM, this shock is introduced as a 10 percentage point increase in the relative price of Canadian exports in world markets.

As CPAM is a model of a small open economy, exporters are price takers. This means that when prices increase, exporters increase their production, and aggregate exports increase. In addition, as the shock represents an increase in wealth for consumers, this increase is echoed in the consumption sector. Overall, aggregate demand increases, and this kicks off an inflation and monetary policy response that is familiar from the demand shock in Section 3.1. There is also an apparent difference between the $P C$ and PDFC inflation measures stemming from the exchange rate appreciation, just as in Section 3.2.

Note the initial decline in aggregate investment. It might be reasonable to expect an increase here to reflect exporters building up their capital stock. That investment actually falls is due to the relative price effect, from the appreciation in the dollar, and the impact of the rise in interest rates, which outweigh the (small) direct effect. This is consistent with the results reported by Macklem (1993) from a more complete (multi-sector) model. An important point here is that firms know that this particular shock is temporary. Although we do not show this here, we can report that if the shock were permanent, there would be a strong increase in investment due to the larger direct effect.

The changes in the real exchange rate here have both a real and a policy (interest rate) component. The effect of the interest rate is as described above, and operates through the uncovered interest parity condition (equation 100). The real component comes from the role of the real exchange rate in supporting the overall asset equilibrium (see Section 2.11). For a given level of net foreign debt, higher export prices mean that less real output is needed to service that debt. The pressure is thus for the exchange rate to appreciate to remove some of the shock. One can also think of this as part of the mechanism whereby the favourable terms-of-trade shock gets passed on to households. The real appreciation makes imports cheaper and facilitates the brief surge in consumption. 
Figure 5: An increase in commodity prices

(\% is per cent shock minus control, \%p is percentage points shock minus control)
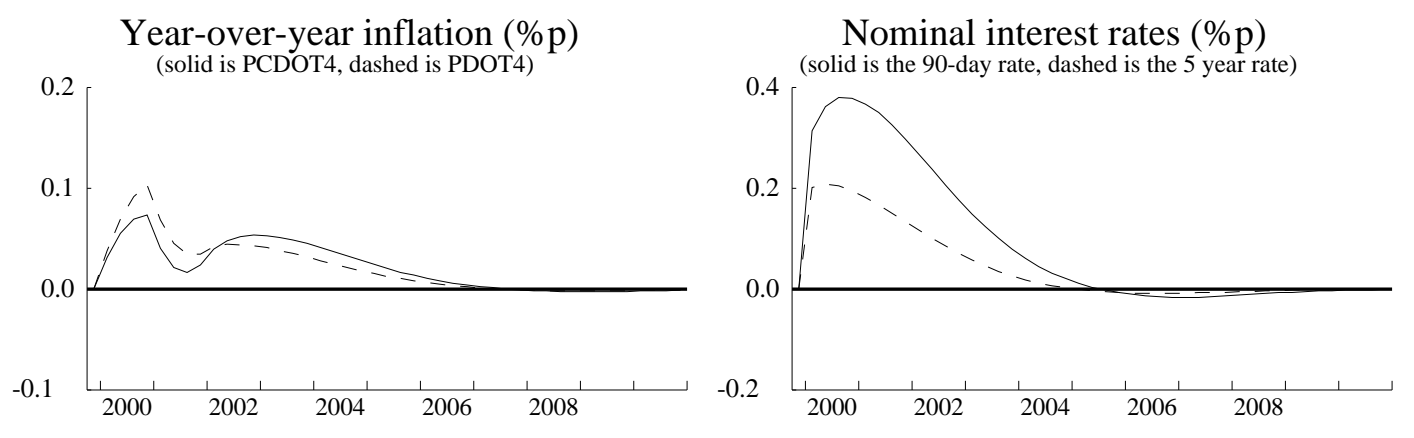

Output gap and yield curve slope (\%p)
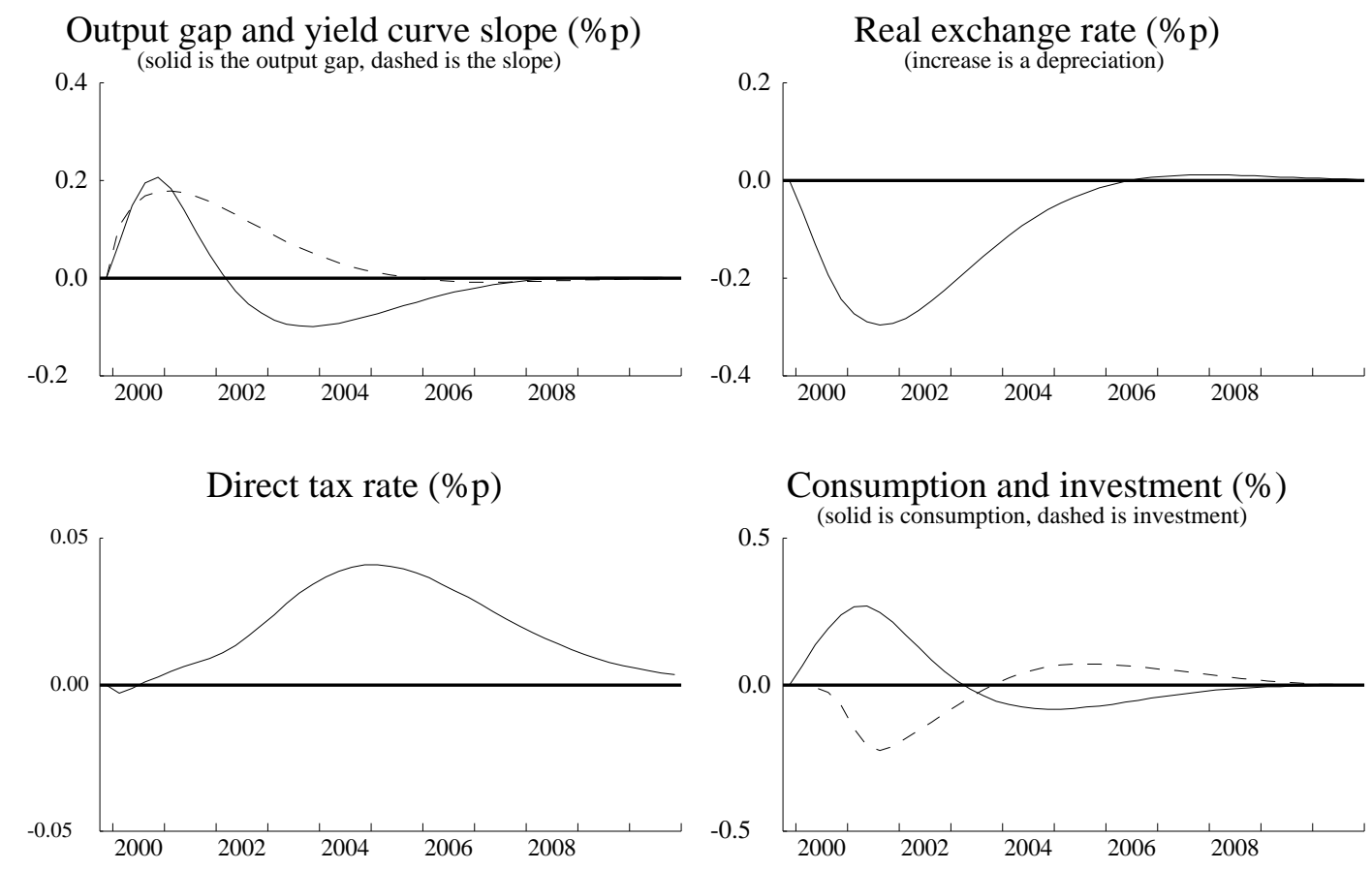

Consumption and investment (\%)

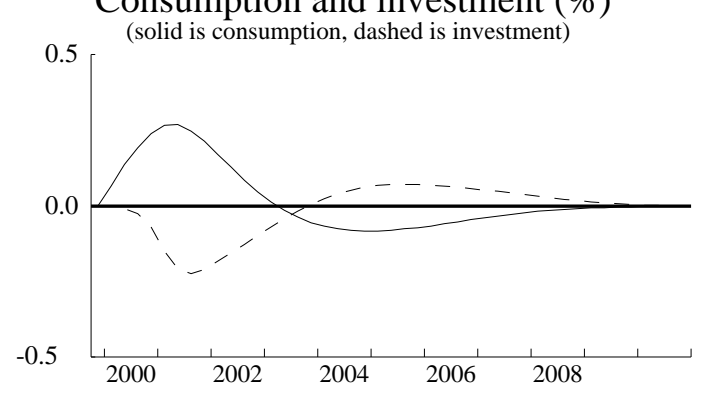

Trade $(\%)$

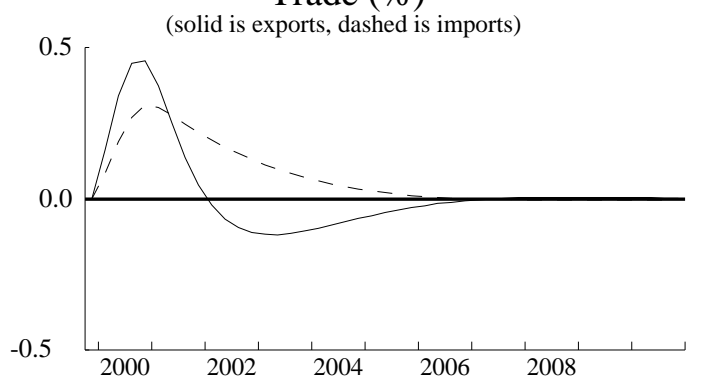

Stocks $(\%)$

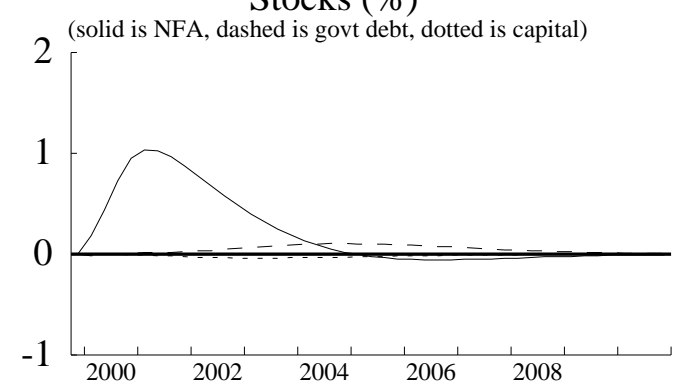




\subsection{An increase in total factor productivity}

So much for temporary shocks; we now turn to permanent shocks. In this shock, the level of total factor productivity increases permanently by 1 per cent.

Such a change has a permanent effect on the steady state of CPAM — all real levels increase by just over 1.5 per cent (the equivalent increase in labour productivity). However, no ratio of prices or real variable changes. ${ }^{24}$ The only exception is relative factor prices; the real wage, however measured, rises to reflect the higher productivity.

The adjustment to the new steady state commences with an investment boom, as firms put new capital in place to take advantage of the higher level of productivity. Households also increase their consumption, in response to their new-found wealth. Both these effects contribute to a large increase in imports. Exports, too, increase to their new equilibrium level. Overall, the increase in imports outstrips that of exports, as it must in order that NFA fall to its new equilibrium level. ${ }^{25}$

As, initially, supply outstrips demand, the shock is deflationary. In addition, as nominal wages are sticky, firms pay workers less than their marginal product in the short run. Competition among firms then leads to a reduction in the inflation rate as firms reduce their (increases in) prices in line with their lower marginal cost.

Overall, $P C$ inflation falls by a little under 1 percentage point, and the monetary authority loosens monetary conditions accordingly.

24. This is different from QPM where the economy is not, strictly speaking, a small open economy so the increase in domestic productivity leads to a modest depreciation in the exchange rate. This, in turn, affects the cost of capital and the rest of the model.

25. As Canada is a net debtor, $N F \mathrm{~A}$ is negative. In order that the NFA-to-GDP ratio be constant, this means that NFA must decrease (i.e., become more negative). 


\section{Figure 6: An increase in total factor productivity}

(\% is per cent shock minus control, \%p is percentage points shock minus control)
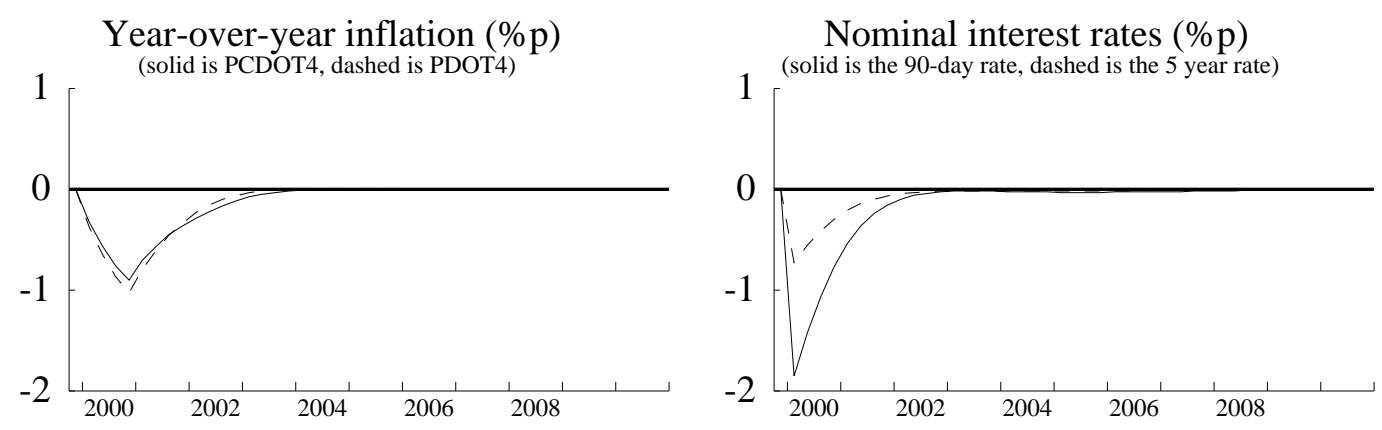

Output gap and yield curve slope (\%p)
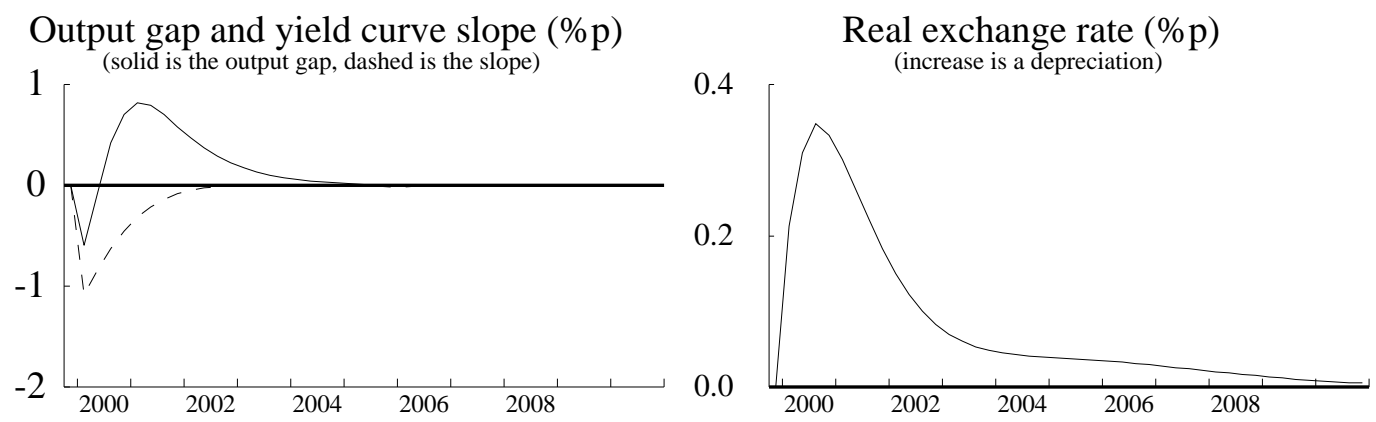

Direct tax rate $(\% \mathrm{p})$

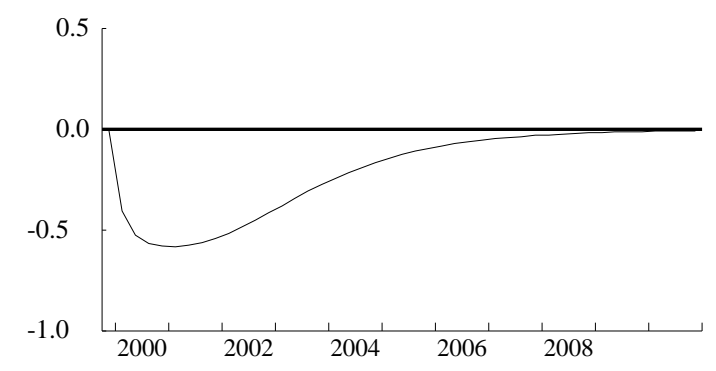

Consumption and investment (\%)

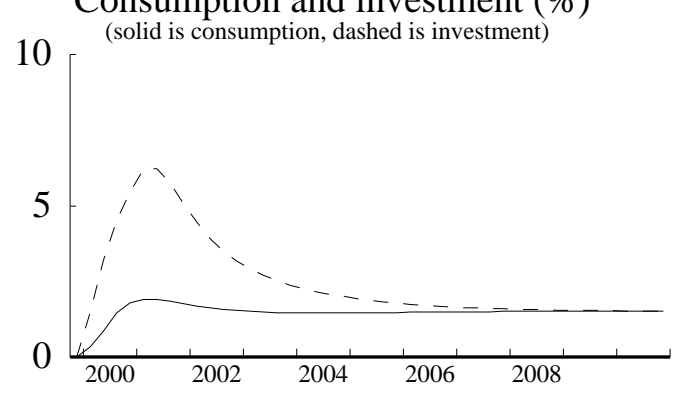

Trade $(\%)$

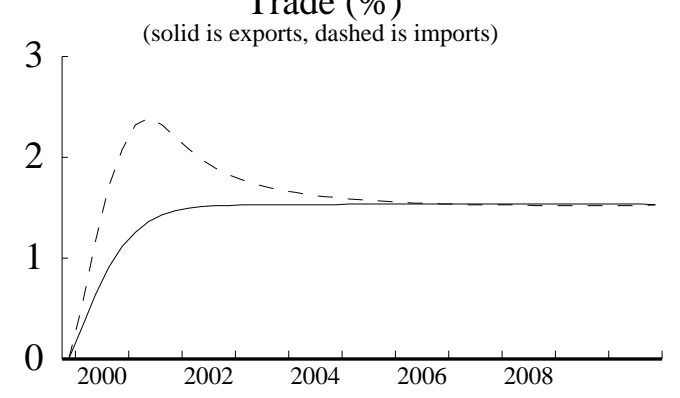

Stocks $(\%)$

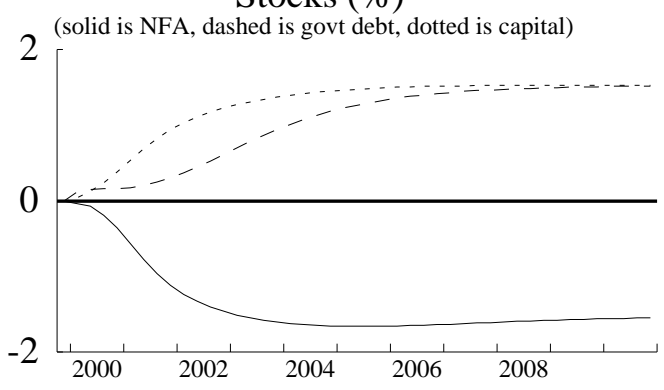




\subsection{A change in the target rate of inflation}

The last two shocks illustrate how CPAM is useful for analyzing changes in policy. In this subsection, the monetary authority reduces its target inflation rate by 1 percentage point.

In CPAM, there are no free lunches in the form of announcement effects, so the monetary authority must tighten monetary conditions in order to reduce the inflation rate to its new level. It does so, and the slope of the yield curve increases by 1 percentage point in the first year. This triggers an appreciation of the currency, which helps move consumption prices down, initially, and also adds to the reduction of aggregate demand through the trade balance. A negative output gap emerges, and the inflation rate declines until it reaches its new target level.

This shock also illustrates some aspects of interest rate determination in CPAM. In CPAM, the long-term rate is based on the expectations hypothesis, but with a little extra weight on current conditions, such that the long rate tends to move more with the short rate than would be predicted by the expectations hypothesis. Nevertheless, as the monetary authority has credibility, in the sense that agents know that it will carry out the planned reduction in the rate of inflation, the long-term interest rate falls immediately. ${ }^{26}$ This means that the short rate does not have to be raised as much as the slope to achieve the objective. In this respect, it is interesting to contrast this shock with the temporary shock to inflation in Section 3.4. There, in contrast, the long rate rises with the short rate, and so the short rate has to rise relatively more to reverse inflation than it does here to reduce it.

One common measure of the costs of disinflation, is the sacrifice ratio, measured as the cumulative loss in output necessary to reduce inflation permanently by 1 percentage point. CPAM has been calibrated to have a sacrifice ratio of just under 2.7, which is slightly less than in QPM.

26. In QPM, the long rate increases slightly for the first few quarters of the shock. 
Figure 7: An decrease in the target rate of inflation

(\% is per cent shock minus control, \%p is percentage points shock minus control)
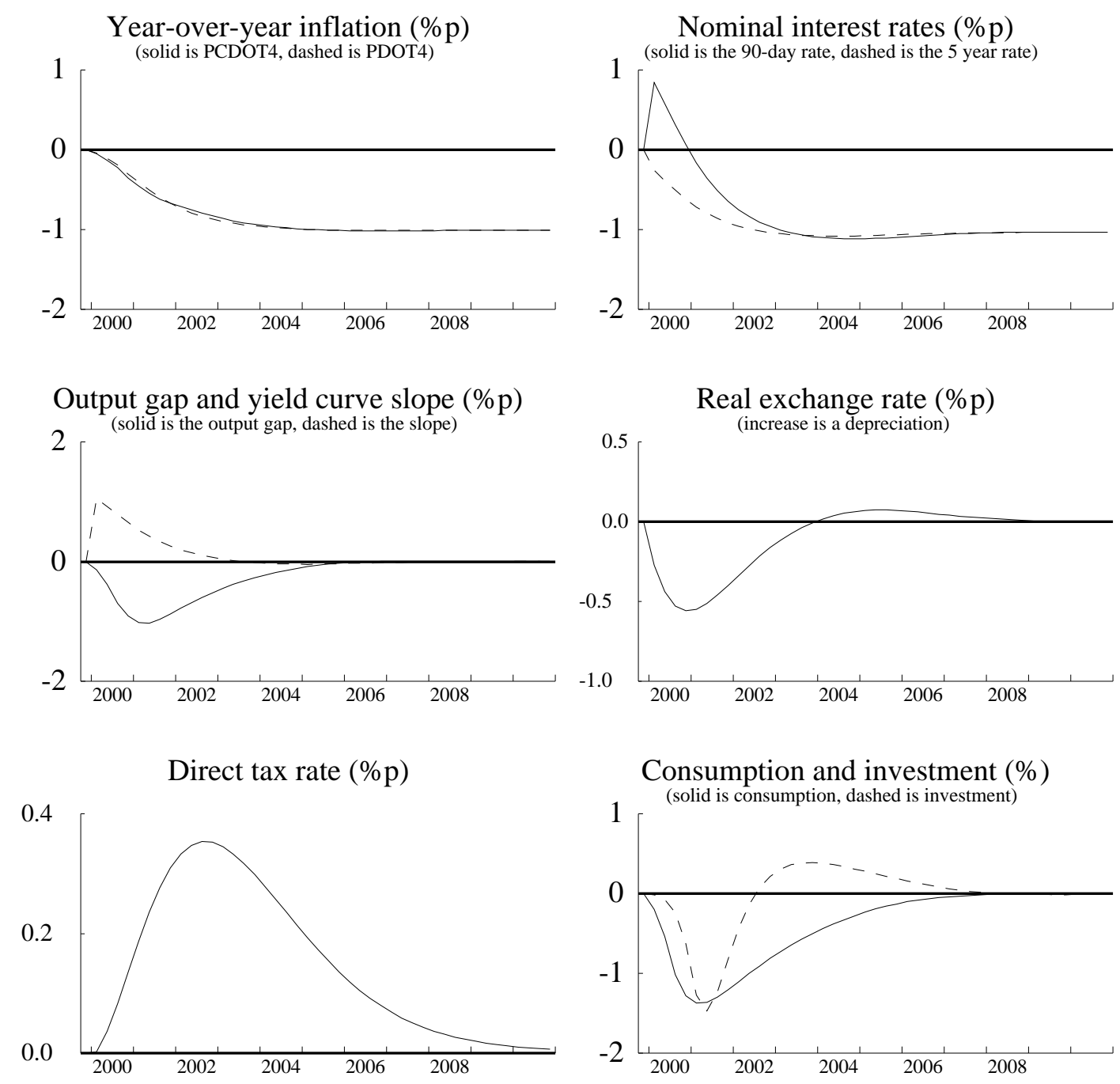

\section{Consumption and investment (\%)}

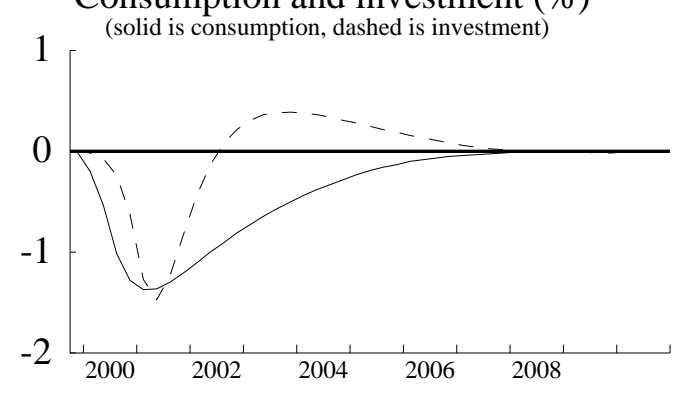

Trade $(\%)$
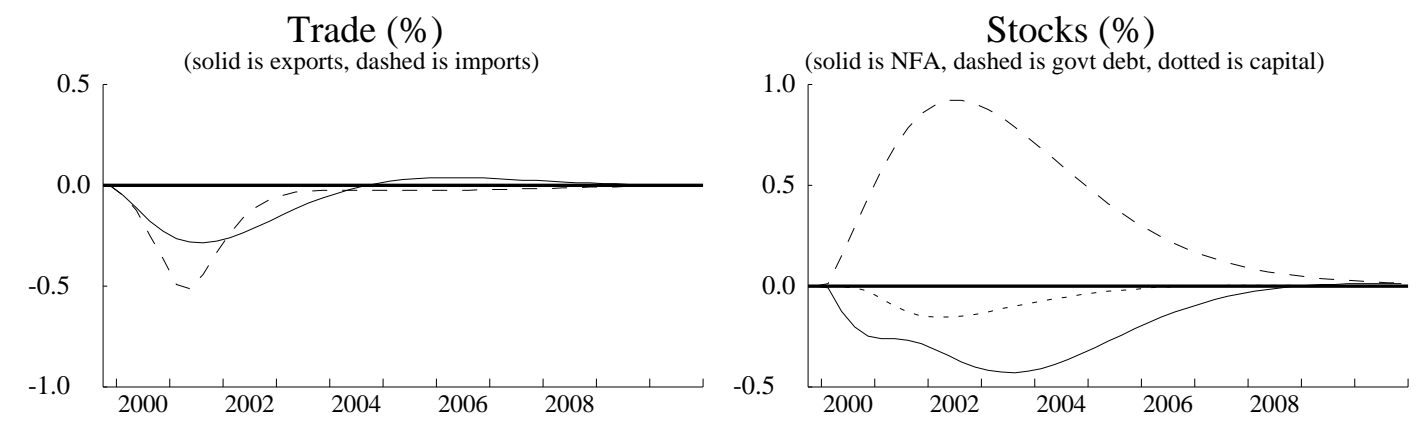


\subsection{A permanent change in government debt}

In this shock, the government lowers the target ratio of debt to GDP by 10 percentage points. To analyse this shock, it is convenient to start with the steady-state implications, and then move to the dynamic effects.

The basic result from the steady-state model is that, as the direct tax rate is lower in the end, consumers have more wealth, and this leads to an increase in consumption of 0.46 per cent. The lower tax rate reflects the lower debt-service burden in the new steady state. There is also a substantial reallocation of assets within the portfolio, as consumers switch from holding government assets to holding net foreign assets. The ratio of net foreign assets to GDP increases by just over 10 percentage points. Finally, a small relative price effect reduces the cost of capital and output increases by 0.03 per cent. $^{27}$

Moving now to the dynamics, we see that a key difference arises from the profile of the personal tax rate. Though it will eventually fall below control, it has to rise sharply at first to secure the revenues to pay off part of the debt. Hence, although consumption is higher in the steady state, the increased tax burden during the adjustment means that consumption over the medium term is depressed. Indeed, consumption falls by over 6 per cent, relative to control, in the first couple of years of the shock, and does not rise above control until year five. Such a large reduction in consumption leads to a significant decline in imports, and it is this, supported by a depreciation in the currency and the consequential increase in exports, that facilitates the substitution away from government debt towards net foreign assets.

The short-term implications of the shock for the monetary authority are interesting. Overall, the economy is in a position of excess supply, so PDFC inflation falls. However, the strong depreciation of the currency causes the inflation rate, as measured by consumer prices, to increase slightly in the first year before the effects of depressed demand pull it down too. As the monetary authority looks past the initial rise in consumer price inflation to the period where it will be below control, they loosen monetary conditions from the start. With a less forward-looking policy rule, there would be less willingness to ease early and to let the exchange rate depreciate as part of the adjustment.

27. The reader is referred to Black, Laxton, Rose, and Tetlow (1994) for a more detailed discussion of the steadystate implications of this shock. 
Figure 8: An decrease in the target debt-to-GDP ratio

(\% is per cent shock minus control, \%p is percentage points shock minus control)
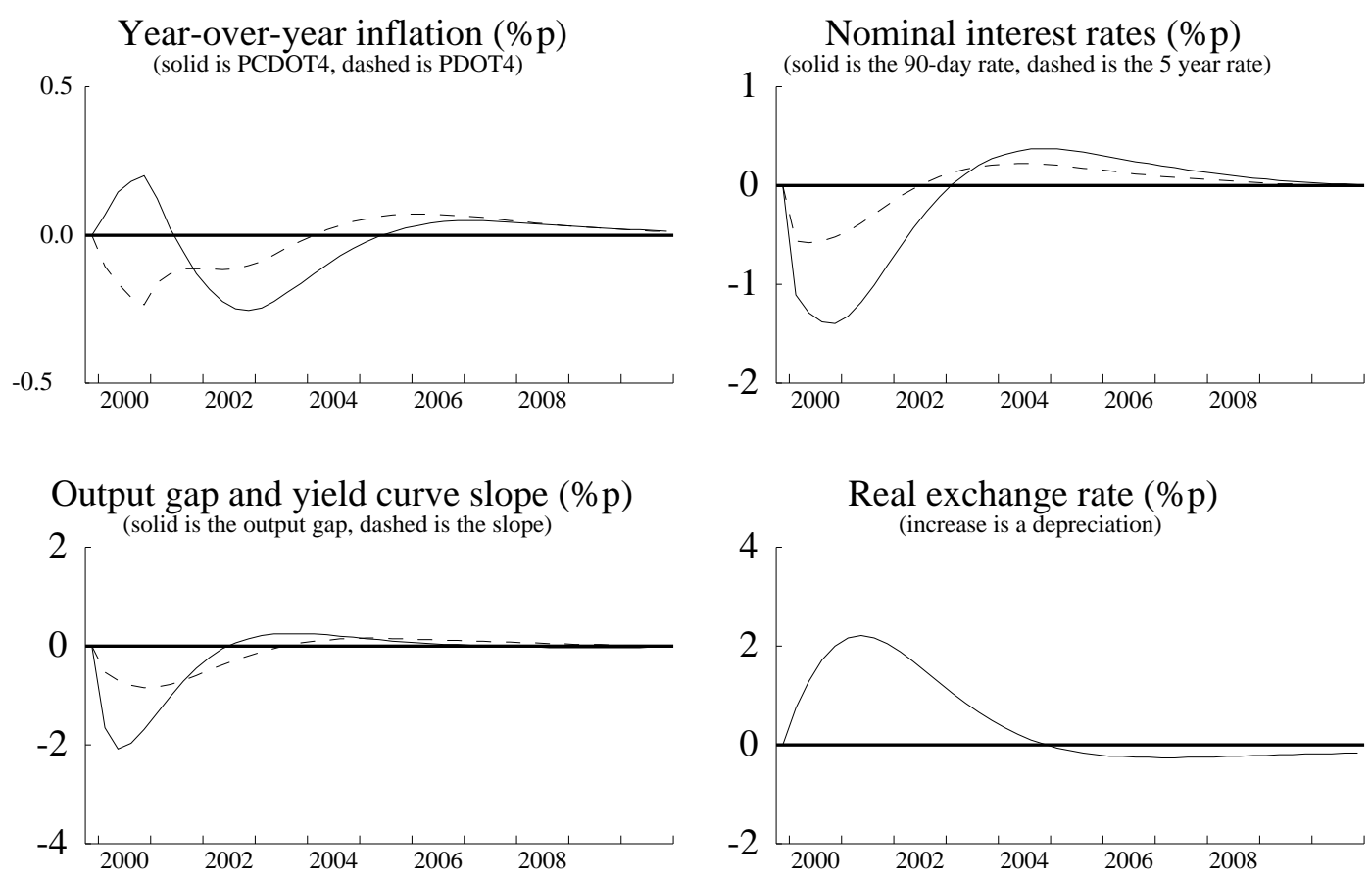

Direct tax rate (\%p)

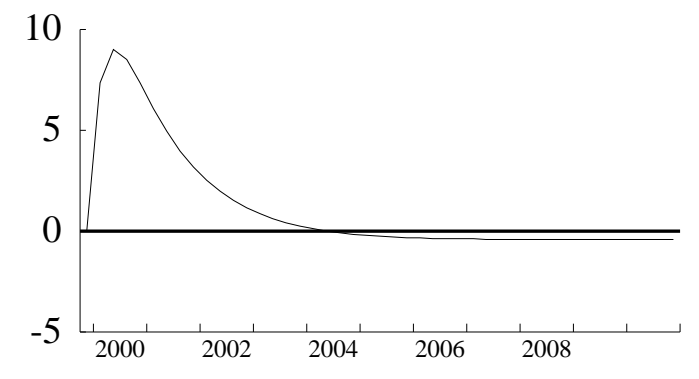

Consumption and investment (\%)

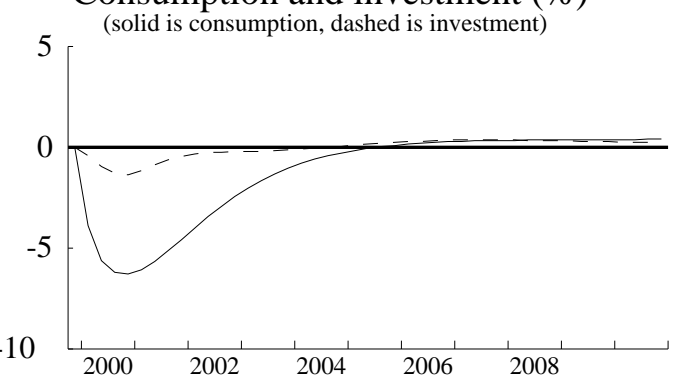

Trade $(\%)$
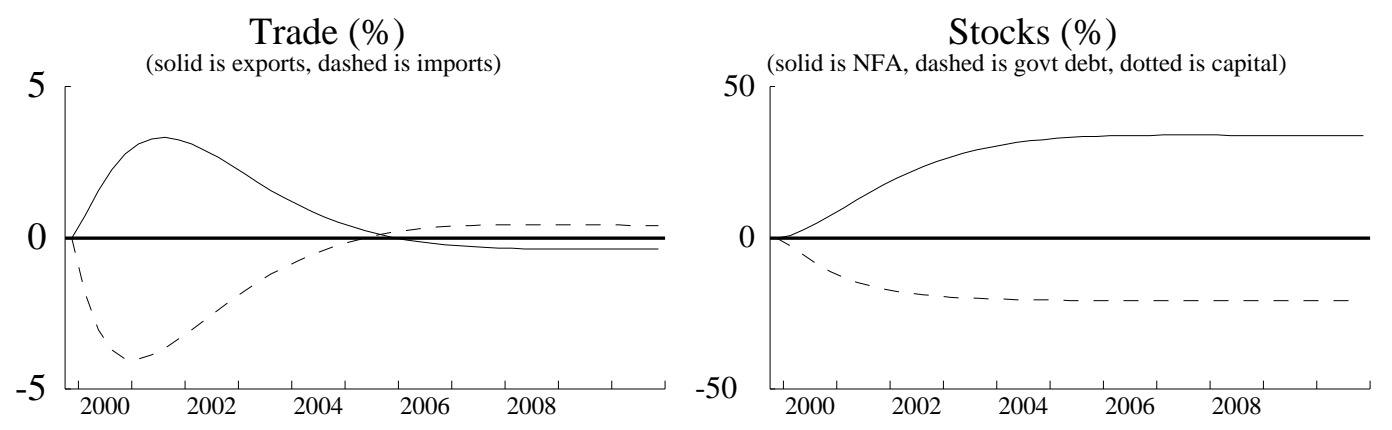


\section{APPENDIX A: The adjustment mechanism in CPAM}

This appendix describes the generic adjustment process used in CPAM. CPAM has dynamics arising from three main sources. The first is intrinsic dynamics, that is, dynamic structure that arises from the tendency for economic agents to adjust gradually to disturbances, even when those disturbances are understood perfectly. Such behaviour arises when adjustment is costly. The other two general sources of dynamic structure in CPAM are expectations formation and the endogenous response of monetary and fiscal policy to economic conditions. The focus of this appendix is on the first source; the other two have been addressed in the main text.

In CPAM, intrinsic dynamics are modelled as the solution to a quadratic optimization problem. In this problem, agents must weigh a cost of being away from a target with the cost of adjusting towards it. The result is that agents adjust "slowly" towards the new target, with "slowly" being defined as a matter of calibration. The following discussion is based on Pesaran (1991) and particularly on the formulation in Tinsley (1993).

\section{The generic dynamic adjustment model}

Let $y$ be the variable to be modelled, and $y^{*}$ its "desired" value in the absence of adjustment costs. At time $t$, the general intrinsic adjustment model is derived from choosing $y_{t+\tau}$, for $\tau \geq 0$, to minimize the following cost function:

(A1) $\mathrm{E}\left[\sum_{\tau=0}^{\infty}\left(y_{t+\tau}-y_{t+\tau}^{*}\right)^{2}+0.5 \sum_{i=0}^{n} \phi_{i}\left(A_{i}(L) y_{t+\tau}\right)^{2}\right]$,

where $A_{i}(L)$ is a polynomial in the lag operator and $n$ is the order of the adjustment process. The first term of this equation penalizes being away the desired level. The second term, which is made up of $n$ quadratic terms of past values of $y$, is chosen so as to penalize changes in $y$. Note that, given the definitions of $A_{i}$ below, having high $\phi$ weights will penalize changes in $y$ and lead to gradual adjustment. 
In CPAM, two different forms for $A_{i}$ are used, depending on whether the adjustment is for a stock or not. If the adjustment is for a flow or a relative price, then $A_{i}$ is chosen so that changes in the $i$ th (equally-weighted) moving average of $y$ are penalized. This change is given by

(A2) $\sum_{j=0}^{i}\left(y_{t+\tau-j}\right)-\sum_{j=0}^{i}\left(y_{t+\tau-1-j}\right)=y_{t+\tau}-y_{t+\tau-1}$,

so that $A_{i}$ is given by

(A3) $A_{i}(L)=1+L^{i+1}$.

For stocks, in particular capital, $A_{i}$ is chosen so that changes in the $i$ th difference of $y$ are penalized. This leads to the definition

(A4) $A_{i}(L)=(1-L)^{i}$.

Having these two different styles of adjustment costs facilitates the calibration of the model. For flows, the data suggest that past flows are good indicators of the current flow. This is captured in the model by placing high $\phi$ weights on changes in moving averages. As can be seen in equation (2), this penalizes a movement in $y$ compared to what it was in the past. For stocks, the problem is slightly different. In this case, it was found that, when the first form of adjustment is used, even though the dynamics of stock itself look fine, the flows resulting from the changes in the stock are very volatile. The second form, which penalizes differences, provides a similar path for the level of the stock, but one with smoother changes in flows.

The solution to minimization of (1) is a straightforward application of dynamic programming, and results in an Euler equation in $n$ lags and $n$ leads. ${ }^{28}$ In CPAM, the equations are left in this form, unlike in QPM where they are rewritten as an infinite sum and truncated. The leads are taken to be model-consistent expectations. The solution can be written in the form:

(A5) $y=y^{*}-y a d j$,

as in the main text, where yadj is a function that depends on $n-1$ leads and lags of $y$ as well as the parameters in $A$ and $\phi$.

28. In CPAM, these Euler equations are generated using a TROLL macro. 


\section{An example of a customized equation}

Take the case of the model's equation for the dynamics of consumer spending (by forwardlooking consumers). This is given by a fourth-order adjustment model that penalizes changes in moving averages. The target rate is given by

(A6) $c f l^{*}=c f l^{e q}-\lambda_{1}\left(r-r^{e q}\right)+\lambda_{2}\left(n f a-n f a_{e q}\right)+c f l s h k$.

In addition to the equilibrium value of consumption, there are several other terms in this equation. The first two, with coefficients $\lambda_{1}$ and $\lambda_{2}$, are there to capture special features of cyclical correlation among economic variables. These have been described in the main text. There is also a third extra term, $c f l s h k$, that can be used to shock consumption.

The solution to this, as noted in (5), can be written as

(A7) $c f l=c f l^{e q}-\lambda_{1}\left(r-r^{e q}\right)+\lambda_{2}\left(n f a-n f a_{e q}\right)+c f l s h k-c f l a d j$.

For completeness, the $c f l a d j$ term is included below. For this equation, we return to TROLL syntax; it is the equation exactly as generated by the TROLL macro described earlier.

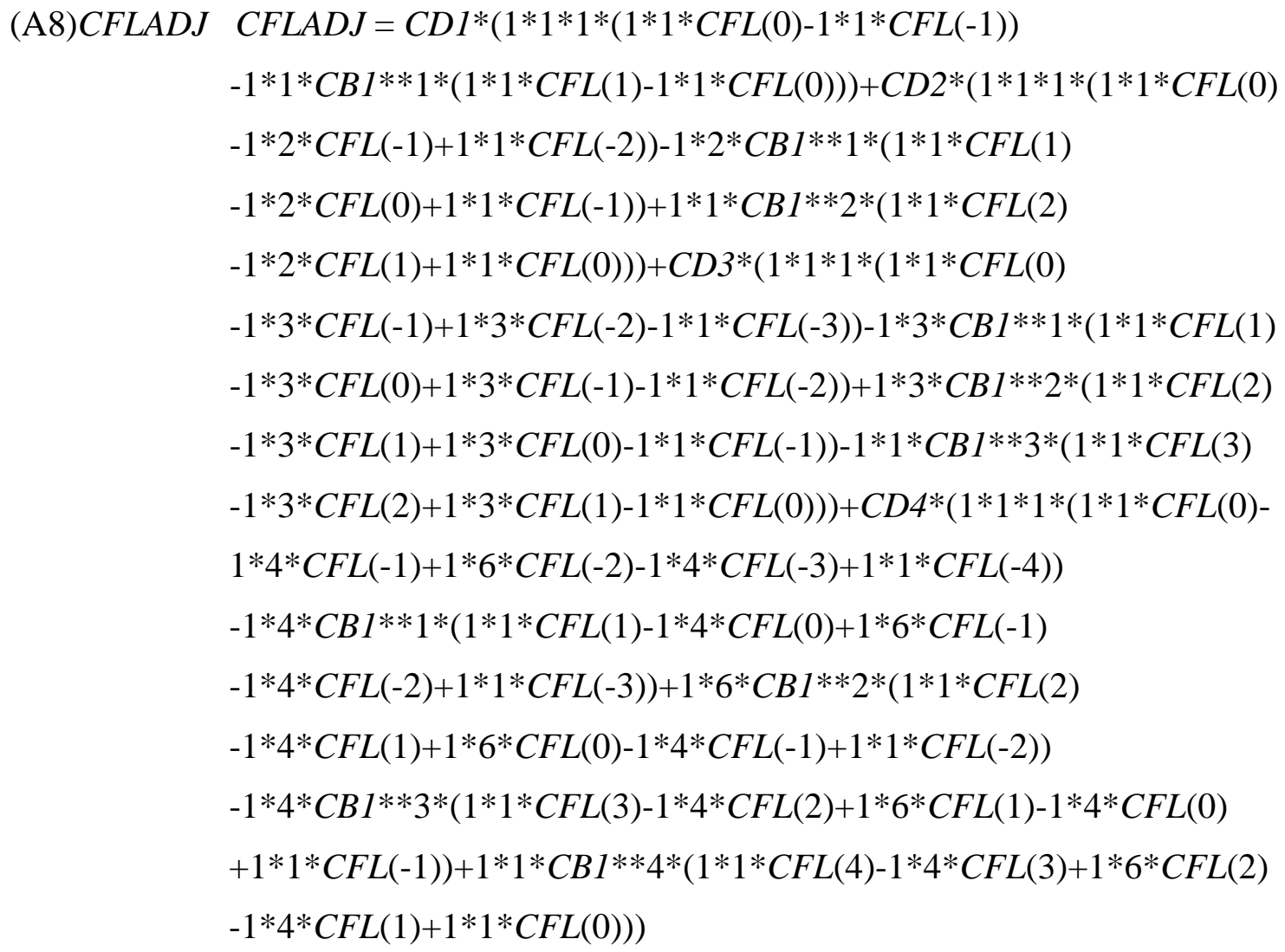




\section{APPENDIX B:Mnemonics, descriptions, and values}

This appendix contains the mnemonics and descriptions of the variables and parameters in the model CPAM. They are grouped by endogenous, exogenous, and parameter types. Variables that are exogenous for calibration only are labelled as such with an indication to the corresponding variable that is made endogenous. The values shown for exogenous and endogenous variables are their steady-state values. 
Table 1: Exogenous variables

\begin{tabular}{|c|c|c|}
\hline Mnemonic & Description & Value \\
\hline CM_CO & Level term in the $\mathrm{cm}$ share equation (calibrated from $\mathrm{cm}_{-}$c.eq) & 1.14638 \\
\hline CSHK & Shock term in the consumption model equation & 0.00000 \\
\hline$\overline{D E L T A}$ & Discount factor of consumers (calibrated from $n f a$ ) & 0.99062 \\
\hline DSHK & Shock term for demand shocks & 0.00000 \\
\hline GBTAR_Y.EQ & Equilibrium target ratio of government bonds to output & 1.93800 \\
\hline GM_GO & Level term in the $g m$ share equation (calibrated from $g m \_g . e q$ ) & 1.36238 \\
\hline GTR_Y.EQ & Equilibrium target ratio of government transfers to output & 0.14000 \\
\hline G_Y.EQ & Equilibrium target ratio of government expenditure to output & 0.18500 \\
\hline IM_IO & Level term in the im share equation (calibrated from $i m \_i . e q$ ) & 1.59147 \\
\hline KSHK & Shock term in the capital model equation & 0.00000 \\
\hline NDOT.EQ & Equilibrium population growth rate & 0.00235 \\
\hline PCROW.EQ & $\begin{array}{l}\text { Equilibrium world price of imported consumption goods (calibrated from } \\
\text { p__py.eq) }\end{array}$ & 0.99381 \\
\hline PCROWSHK & Shock term in the pcrow equation & 0.00000 \\
\hline PDOTSHK & Shock term in the inflation equation & 0.00000 \\
\hline PDOTTAR.EQ & Equilibrium target inflation rate & 0.00249 \\
\hline PGROW.EQ & Equilibrium world price of imported government goods & 1.09655 \\
\hline PKROW.EQ & Equilibrium world price of imported investment goods & 0.76053 \\
\hline PKROWSHK & Shock term in the pirow equation & 0.00000 \\
\hline PSHIFT & Shock term in the unemployment model equation & 0.00000 \\
\hline PXROW.EQ & Equilibrium world price of export goods & 1.02533 \\
\hline PXROWSHK & Shock term in the pxrow equation & 0.00000 \\
\hline QDOT.EQ & Equilibrium growth rate of labour augmenting technical progress & 0.00325 \\
\hline RCON_R.EQ & Equilibrium real risk premium for consumers & 0.00992 \\
\hline$R G B \_R . E Q$ & Equilibrium real risk premium on government bonds & 0.00367 \\
\hline$R K \_R . E Q$ & Equilibrium real risk premium on capital & 0.04524 \\
\hline$R N F A \_R . E Q$ & Equilibrium real risk premium on $N F A$ & 0.00469 \\
\hline RROW.EQ & Equilibrium real interest rate in the rest of the world & 0.00705 \\
\hline RSLSHK & Shock term in the $R S L$ equations & 0.00000 \\
\hline RT5.EQ & Equilibrium 5-year term premium & 0.00125 \\
\hline TFPSHK & Shock term in the $t f p$ equation & 0.00000 \\
\hline TIC.EQ & Equilibrium indirect tax rate on consumption goods & 0.16540 \\
\hline TICM.EQ & Equilibrium tariff rate on imported consumption goods & 0.00000 \\
\hline TIG.EQ & Equilibrium indirect tax rate on goverment goods & 0.03000 \\
\hline TIGM.EQ & Equilibrium tariff rate on imported government goods & 0.00000 \\
\hline TII.EQ & Equilibrium indirect tax rate on investment goods & 0.08000 \\
\hline TIIM.EQ & Equilibrium tariff rate on imported investment goods & 0.00000 \\
\hline TK.EQ & Equilibrium tax rate on profits & 0.07500 \\
\hline
\end{tabular}


Table 1: Exogenous variables

\begin{tabular}{|l|l|c|}
\hline \multicolumn{1}{|c|}{ Mnemonic } & \multicolumn{1}{c|}{ Description } & Value \\
\hline \hline$T U N E \_R S L$ & Utility variable for delaying monetary policy response & 1.00000 \\
\hline$T U N E \_Z$ & Utility variable for holding the exchange rate fixed, temporarily & 1.00000 \\
\hline$U . E Q$ & Equilibrium rate of unemployment & 0.08000 \\
\hline$U S H K$ & Shock term in the unemployment model equation & 0.00000 \\
\hline$W S H K$ & Shock term in the real wage equation & 0.00000 \\
\hline$X M_{-} X . E Q$ & Equilibrium ratio of imports for re-export (calibrated from $x . e q)$ & 0.34921 \\
\hline$X \_Y O$ & Level term in the equilibrium export equation (calibrated from $z$ ) & -0.59507 \\
\hline$Z S H K$ & Shock term in the real exchange rate equation & 0.00000 \\
\hline
\end{tabular}


Table 2: Endogenous variables

\begin{tabular}{|c|c|c|}
\hline Mnemonic & Description & Value \\
\hline $\bar{C}$ & Consumption & 0.17300 \\
\hline C.EQ & Equilibrium consumption & 0.17300 \\
\hline CC.EQ & Equilibrium user cost of capital & 0.06367 \\
\hline$C F L$ & Consumption by forward-looking consumers & 0.12209 \\
\hline CFL.EQ & Equilibrium consumption by forward-looking consumers & 0.12209 \\
\hline CFLADJ & $c f l$ adjustment cost & 0.00000 \\
\hline CHECK1.EQ & A check on the equilibrium SNA identity & 0.00000 \\
\hline CHECK2.EQ & A check on the equilibrium $P D$ identity & 0.00000 \\
\hline$C M$ & Imports of consumption goods & 0.03308 \\
\hline CM.EQ & Equilibrium imports of consumption goods & 0.03308 \\
\hline$C M \_C$ & Share of imported consumption goods & 0.19120 \\
\hline CM_C.EQ & Equilibrium share of imported consumption goods (calibrates $\mathrm{cm}_{-} \mathrm{cO}$ ) & 0.19120 \\
\hline CM_CADJ & $c m \_c$ adjustment cost & 0.00000 \\
\hline CRT & Consumption by rule-of-thumb consumers & 0.05091 \\
\hline CRT.EQ & Equilibrium consumption by rule-of-thumb consumers & 0.05091 \\
\hline 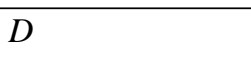 & Demand index $(c+i)$ & 0.20984 \\
\hline$F A$ & Real financial assets & 1.27983 \\
\hline FA.EQ & Equilibrium financial assets & 1.27983 \\
\hline FA.SS & Steady-state financial assets & 1.27983 \\
\hline$G$ & Real government expenditures & 0.04625 \\
\hline G.EQ & Equilibrium government expenditures & 0.04625 \\
\hline$G B$ & Real government assets & 0.48450 \\
\hline GB.EQ & Equilibrium government assets & 0.48450 \\
\hline GBTAR & Government target debt level & 0.48450 \\
\hline GM & Imports of government goods & 0.01641 \\
\hline GM.EQ & Equilibrium imports of government goods & 0.01641 \\
\hline$G M \_G$ & Share of imported government goods & 0.35490 \\
\hline GM_G.EQ & Equilibrium share of imported government goods (calibrates $g m \_g 0$ ) & 0.35490 \\
\hline GM_GADJ & $g m \_g$ adjustment cost & 0.00000 \\
\hline GTR & Real government transfers & 0.03500 \\
\hline GTR.EQ & Equilibrium government transfers & 0.03500 \\
\hline$H W F L . E Q$ & Equilibrium human wealth & 5.19519 \\
\hline$I$ & Real investment & 0.03684 \\
\hline I.EQ & Equilibrium investment & 0.03684 \\
\hline I.SS & Steady-state investment & 0.03684 \\
\hline$I M$ & Imports of investment goods & 0.02225 \\
\hline$I M . E Q$ & Equilibrium imports of investment goods & 0.02225 \\
\hline$I M \_I$ & Share of imported investment goods & 0.60390 \\
\hline
\end{tabular}


Table 2: Endogenous variables

\begin{tabular}{|c|c|c|}
\hline Mnemonic & Description & Value \\
\hline IM_I.EQ & Equilibrium share of imported investment goods (calibrates $i m \_i 0$ ) & 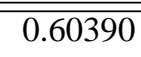 \\
\hline$I M \_I A D J$ & $i m_{-} i$ adjustment cost & -0.00000 \\
\hline K & Production capital & 1.37645 \\
\hline K.EQ & Equilibrium production capital & 1.37645 \\
\hline$K A D J$ & $k$ adjustment cost & 0.00000 \\
\hline$M$ & Imports & 0.10697 \\
\hline M.EQ & Equilibrium imports & 0.10697 \\
\hline$M P C W . E Q$ & Equilibrium marginal propensity to consume out of wealth & 0.02202 \\
\hline NDOT & Population growth rate & 0.00235 \\
\hline NETX & Real net exports & 0.00229 \\
\hline NETX.EQ & Equilibrium net exports & 0.00229 \\
\hline NFA & Net foreign asset ratio & -0.31122 \\
\hline NFA.EQ & Equilibrium net foreign asset ratio (calibrates delta) & -0.31122 \\
\hline$P C$ & Relative price of consumption goods & 1.17076 \\
\hline$P C . E Q$ & Equilibrium relative price of consumption goods & 1.17076 \\
\hline$P C D$ & Relative price of domestic consumption goods & 1.01328 \\
\hline PCD.EQ & Equilibrium relative price of domestic consumption goods & 1.01328 \\
\hline PCDADJ & $p c d$ adjustment cost & 0.00000 \\
\hline$P C D O T$ & Inflation rate for $P C$ & 0.00249 \\
\hline PCDOT4 & 4-quarter inflation rate for $P C$ & 0.00249 \\
\hline PCDOTE & Expected $P C$ inflation rate & 0.00249 \\
\hline PCDOTEA & Effective average expected $P C$ inflation rate & 0.00249 \\
\hline PCLEVEL & Level price of consumption goods & 1.69447 \\
\hline PCLEVELTAR & Optional term for price-level targeting & 1.69447 \\
\hline$P C M$ & Relative price of imported consumption goods & 0.96787 \\
\hline PCM.EQ & Equilibrium relative price of imported consumption goods & 0.96787 \\
\hline PCMADJ & pcm adjustment cost & 0.00000 \\
\hline PCROW & World price of imported consumption goods & 0.99381 \\
\hline$P C_{-} P Y . E Q$ & Equilibrium price of consumption relative to $p y$ & 1.02670 \\
\hline PDOT & Inflation rate for PDFC & 0.00249 \\
\hline PDOT.EQ & Equilibrium inflation rate & 0.00249 \\
\hline PDOT4 & 4-quarter inflation rate for $P$ & 0.00249 \\
\hline PDOTE & Expected inflation rate & 0.00249 \\
\hline PDOTEA & Effective average expected $P$ inflation rate & 0.00249 \\
\hline PDOTTAR & Target inflation rate & 0.00249 \\
\hline PDOTTARE & Expected target inflation rate & 0.00249 \\
\hline$P F C$ & Relative price of output at factor cost & 1.01065 \\
\hline PFC.EQ & Equilibrium relative price of output at factor cost & 1.01065 \\
\hline
\end{tabular}


Table 2: Endogenous variables

\begin{tabular}{|c|c|c|}
\hline Mnemonic & Description & Value \\
\hline$\overline{P G}$ & Relative price of government goods & 1.09470 \\
\hline PG.EQ & Equilibrium relative price of government goods & 1.09470 \\
\hline$P G D$ & Equilibrium relative price of domestic government goods & 1.06000 \\
\hline PGD.EQ & Equilibrium relative price of domestic government goods (cals. from $p g \_p y . e q$ ) & 1.06000 \\
\hline$P G D A D J$ & $p g d$ adjustment cost & 0.00000 \\
\hline$P G M$ & Relative price of imported government goods & 1.06793 \\
\hline PGM.EQ & Equilibrium relative price of imported government goods & 1.06793 \\
\hline PGMADJ & pgm adjustment cost & 0.00000 \\
\hline PGROW & World price of imported government goods & 1.09655 \\
\hline$P G \_P Y . E Q$ & Equilibrium price of government goods relative to $p y$ (calibrates $p g . e q$ ) & 0.96000 \\
\hline PI.EQ & Equilibrium relative price of capital goods & 0.80392 \\
\hline$P K$ & Relative price of investment goods & 0.80392 \\
\hline$P K . E Q$ & Equilibrium relative price of investment goods & 0.80392 \\
\hline PK.SS & Steady-state relative price of investment goods & 0.80392 \\
\hline$P K D$ & Relative price of domestic investment goods & 0.75000 \\
\hline PKD.EQ & Equilibrium relative price of domestic investment goods & 0.75000 \\
\hline$P K D A D J$ & $p k d$ adjustment cost & 0.00000 \\
\hline$P K M$ & Relative price of imported investment goods & 0.74068 \\
\hline PKM.EQ & Equilibrium relative price of imported investment goods & 0.74068 \\
\hline PKMADJ & $p k m$ adjustment cost & 0.00000 \\
\hline PKROW & World price of imported investment goods & 0.76053 \\
\hline$P K \_P Y . E Q$ & Equilibrium price of investment relative to $p y$ & 0.70500 \\
\hline$P M$ & Relative price of import goods & 0.92030 \\
\hline$P M . E Q$ & Equilibrium relative price of import goods & 0.92030 \\
\hline$P M_{-} P Y . E Q$ & Equilibrium price of import goods relative to $p y$ & 0.80707 \\
\hline$P X$ & Relative price of export goods & 0.99857 \\
\hline$P X . E Q$ & Equilibrium relative price of export goods & 0.99857 \\
\hline$P X A D J$ & $p x$ adjustment cost & 0.00000 \\
\hline$P X M$ & Relative price of imported export goods & 0.92030 \\
\hline PXM.EQ & Equilibrium relative price of imported export goods & 0.92030 \\
\hline PXROW & World price of export goods & 1.02533 \\
\hline$P X \_P Y . E Q$ & Equilibrium price of export goods relative to $p y$ (calibrates pxrow.eq) & 0.87570 \\
\hline$P Y$ & Relative price of output & 1.14031 \\
\hline$P Y . E Q$ & Equilibrium relative price of output at market prices & 1.14031 \\
\hline PYDOT & Inflation rate for $P Y$ & 0.00249 \\
\hline$Q D O T$ & Trend growth in labour augmenting technical progress & 0.00325 \\
\hline$R$ & Real interest rate & 0.00705 \\
\hline R.EQ & Equilibrium real interest rate & 0.00705 \\
\hline
\end{tabular}


Table 2: Endogenous variables

\begin{tabular}{|c|c|c|}
\hline Mnemonic & Description & Value \\
\hline R5 & 5-year moving average of real rates & 0.00831 \\
\hline$R 5 . E Q$ & Equilibrium 5-year moving average of real rates & 0.00831 \\
\hline RCON.EQ & Equilibrium real interest rate for consumers & 0.01823 \\
\hline$R G B$ & Real interest rate for government assets & 0.01198 \\
\hline$R G B . E Q$ & Equilibrium real return on government bonds & 0.01198 \\
\hline RISK & Transfer to individuals from asset holders & 0.03747 \\
\hline RISK.EQ & Equilibrium transfer to individuals from asset holders & 0.03747 \\
\hline RK.EQ & Equilibrium real interest rate for capital & 0.05354 \\
\hline$R L$ & Real long interest rate & 0.00831 \\
\hline$R L . E Q$ & Equilibrium real long interest rate & 0.00831 \\
\hline$R N$ & Nominal interest rate & 0.00956 \\
\hline$R N . E Q$ & Equilibrium nominal interest rate & 0.00956 \\
\hline RN5 & 5-year moving average of nominal rates & 0.01082 \\
\hline RN5.EQ & Equilibrium 5-year moving average of nominal rates & 0.01082 \\
\hline RNFA & Real interest rate for net foreign assets & 0.01300 \\
\hline RNFA.EQ & Equilibrium real return on net foreign assets & 0.01300 \\
\hline$R N L$ & Nominal long interest rate & 0.01082 \\
\hline RNL.EQ & Equilibrium nominal long interest rate & 0.01082 \\
\hline RROW & Real interest rate in the rest of the world & 0.00705 \\
\hline$R S L$ & Slope of the yield curve & -0.00125 \\
\hline RSL.EQ & Equilibrium slope of the yield curve & -0.00125 \\
\hline$T D$ & Net direct tax rate & 0.28144 \\
\hline$T D . E Q$ & Equilibrium net direct tax rate & 0.28144 \\
\hline TFP & Total factor productivity & 0.94777 \\
\hline TFP.EQ & Equilibrium level of total factor productivity (calibrated from $y$ ) & 0.94777 \\
\hline TIC & Indirect tax rate on consumption goods & 0.16540 \\
\hline TICM & Tariff rate on imported consumption goods & 0.00000 \\
\hline$T I G$ & Indirect tax rate on government goods & 0.03000 \\
\hline$T I G M$ & Tariff rate on imported government goods & 0.00000 \\
\hline TII & Indirect tax rate on investment goods & 0.08000 \\
\hline TIIM & Tariff rate on imported investment goods & 0.00000 \\
\hline$T K$ & Tax rate on profits & 0.07500 \\
\hline TWFL.EQ & Equilibrium total wealth & 6.49109 \\
\hline$U$ & Rate of unemployment & 0.08000 \\
\hline$U A D J$ & $u$ adjustment cost & 0.00000 \\
\hline$W$ & Relative wage & 0.17991 \\
\hline W.EQ & Equilibrium relative wage & 0.17991 \\
\hline WADJ & $w$ adjustment cost & -0.00000 \\
\hline
\end{tabular}


Table 2: Endogenous variables

\begin{tabular}{|l|l|l|}
\hline \multicolumn{1}{|c|}{ Mnemonic } & & Vescription \\
\hline \hline$W C$ & Consumer real wage & 0.15367 \\
\hline$W C . E Q$ & Equilibrium consumer real wage & 0.15367 \\
\hline$W P$ & Producer real wage & 0.17802 \\
\hline$W P . E Q$ & Equilibrium producer real wage & 0.17802 \\
\hline$X$ & Exports & 0.10088 \\
\hline$X . E Q$ & Equilibrium exports & 0.10088 \\
\hline$X A D J$ & adjustment cost & 0.00000 \\
\hline$X M$ & Imports for re-export & 0.03523 \\
\hline$X M . E Q$ & Equilibrium imports for re-export & 0.03523 \\
\hline$X M \_X$ & Share of imports for re-export & 0.34921 \\
\hline$Y$ & Output & 0.25000 \\
\hline$Y . E Q$ & Equilibrium output (calibrates tfp.eq) & 0.25000 \\
\hline$Y D F L$ & Real disposable income for forward-looking consumers & 0.08941 \\
\hline$Y D F L . E Q$ & Equilibrium disposable income for forward-looking consumers & 0.08941 \\
\hline$Y D O T$ & Trend output growth rate & 0.00561 \\
\hline$Y D O T . E Q$ & Equilibrium output growth rate & 0.00561 \\
\hline$Y D R T$ & Real disposable income for rule-of-thumb consumers & 0.05960 \\
\hline$Y D R T . E Q$ & Equilibrium disposable income for rule-of-thumb consumers & 0.05960 \\
\hline$Y L A B$ & Real labour income & 0.16552 \\
\hline$Y L A B . E Q$ & Equilibrium real labour income & 0.16552 \\
\hline$Y P$ & Potential output & 0.25000 \\
\hline$Z$ & Real price of foreign exchange & 0.97390 \\
\hline$Z . E Q$ & Equilibrium real price of foreign exchange (calibrates $\left.X \_Y O\right)$ & 0.97390 \\
\hline$Z . S S$ & Steady-state real price of foreign exchange & 0.97390 \\
\hline$Z E$ & Expected real price of foreign exchange & 0.97390 \\
\hline
\end{tabular}


Table 3: Parameters

\begin{tabular}{|c|c|c|}
\hline Mnemonic & Description & Value \\
\hline$\overline{A L P H A}$ & Capital exponent in Cobb-Douglas production function & 0.34490 \\
\hline$C B 1$ & Discount factor in the consumption adjustment model & 0.95000 \\
\hline$C D 1$ & Weight on difference 1 in the $c f$ adjustment model & 2.00000 \\
\hline$C D 2$ & Weight on difference 2 in the $c f$ adjustment model & 1.00000 \\
\hline CD3 & Weight on difference 3 in the $c f l$ adjustment model & 0.00000 \\
\hline$C D 4$ & Weight on difference 4 in the $c f l$ adjustment model & 0.00000 \\
\hline$C M B 1$ & Discount factor in the consumption import model & 0.85000 \\
\hline CMD1 & Weight on difference 1 in the $c m_{-} c$ adjustment model & 2.00000 \\
\hline$C M D 2$ & Weight on difference 2 in the $c m_{-} c$ adjustment model & 1.00000 \\
\hline CMD3 & Weight on difference 3 in the $c m_{-} c$ adjustment model & 0.50000 \\
\hline CMD4 & Weight on difference 4 in the $c m_{-} c$ adjustment model & 0.25000 \\
\hline$C M S 2$ & Parameter in equilibrium $\mathrm{cm}$ share equation & 1.00000 \\
\hline$C M V 1$ & Coefficient 1 in the VAR in the consumption import model & 0.70000 \\
\hline CV1 & Coefficient 1 in the VAR in the consumption model & 0.10000 \\
\hline CV2 & Coefficient 2 in the VAR in the consumption model M & 9.00000 \\
\hline CV3 & Coefficient 3 in the VAR in the consumption model & 0.35000 \\
\hline$D E P R$ & Capital depreciation rate & 0.02131 \\
\hline G1 & Parameter in the fiscal expenditure reaction function & 0.60000 \\
\hline$G 2$ & Parameter in the fiscal expenditure reaction function & 0.30000 \\
\hline GAMMA & Probability of death for consumers & 0.00985 \\
\hline GMBI & Discount factor in the government import model & 0.85000 \\
\hline GMDI & Weight on difference 1 in the $g m \_g$ adjustment model & 2.50000 \\
\hline GMD2 & Weight on difference 2 in the $g m \_g$ adjustment model & 1.25000 \\
\hline GMD3 & Weight on difference 3 in the $g m \_g$ adjustment model & 0.75000 \\
\hline GMD4 & Weight on difference 4 in the $g m \_g$ adjustment model & 0.50000 \\
\hline GMS2 & Parameter in equilibrium $g m$ share equation & 1.00000 \\
\hline GMVI & Coefficient 1 in the 2nd VAR in the government import model & 0.40000 \\
\hline GTR1 & Parameter in the fiscal transfer reaction function & 0.50000 \\
\hline GTR2 & Parameter in the fiscal transfer reaction function & 0.20000 \\
\hline IMBI & Discount factor in the investment import model & 0.85000 \\
\hline IMDI & Weight on difference 1 in the $i m \_i$ adjustment model & 2.50000 \\
\hline IMD2 & Weight on difference 2 in the $i m \_i$ adjustment model & 1.25000 \\
\hline IMD3 & Weight on difference 3 in the $i m \_i$ adjustment model & 0.75000 \\
\hline IMD4 & Weight on difference 4 in the $i m \_i$ adjustment model & 0.50000 \\
\hline IMS2 & Parameter in equilibrium im share equation & 1.00000 \\
\hline IMVI & Coefficient 1 in the VAR in the investment import model & 0.60000 \\
\hline K1 & Utility parameter for apportioning $c / i$ split of demand shocks & 2.50000 \\
\hline KB1 & Discount factor in the capital model & 0.40000 \\
\hline
\end{tabular}


Table 3: Parameters

\begin{tabular}{|c|c|c|}
\hline Mnemonic & Description & Value \\
\hline KDI & Weight on difference 1 in the $k$ adjustment model & 6.00000 \\
\hline KD2 & Weight on difference 2 in the $k$ adjustment model & 4.00000 \\
\hline KD3 & Weight on difference 3 in the $k$ adjustment model & 3.00000 \\
\hline KD4 & Weight on difference 4 in the $k$ adjustment model & 1.00000 \\
\hline KE1 & Weight on $k . e q$ adjustment term in the $c c . e q$ equation & 0.55000 \\
\hline KVI & Coefficient 1 in the VAR in the capital model & 0.18000 \\
\hline KV2 & Coefficient 2 in the VAR in the capital model & 1.10000 \\
\hline$L A M D A$ & Proportion of rule-of-thumb consumers in the population & 0.40000 \\
\hline PCDB1 & Discount factor for the $p c d$ adjustment model & 0.95000 \\
\hline PCDDI & Weight on difference 1 in the $p c d$ adjustment model & 0.00000 \\
\hline PCDD2 & Weight on difference 2 in the $p c d$ adjustment model & 0.00000 \\
\hline PCDD3 & Weight on difference 3 in the $p c d$ adjustment model & 0.00000 \\
\hline PCDD4 & Weight on difference 4 in the $p c d$ adjustment model & 0.00000 \\
\hline$P C M 1$ & Pass-through coefficient, relative imported consumption .eq trade prices & 0.80000 \\
\hline$P C M B 1$ & Discount factor in the price of consumption imports model & 0.95000 \\
\hline PCMDI & Weight on difference 1 in the $p c m$ adjustment model & 2.00000 \\
\hline PCMD2 & Weight on difference 2 in the $p c m$ adjustment model & 1.00000 \\
\hline PCMD3 & Weight on difference 3 in the $p c m$ adjustment model & 0.00000 \\
\hline PCMD4 & Weight on difference 4 in the $p c m$ adjustment model & 0.00000 \\
\hline PCMVI & Pass-through coefficient, relative imported consumption trade prices & 0.50000 \\
\hline PCMV2 & Coefficient 2 in the VAR in the $p c m$ model & 0.80000 \\
\hline$P D O$ & Coefficient on the gap in the inflation equation & 0.02000 \\
\hline PDI & Coefficient on lagged gap in the inflation equation & 0.04000 \\
\hline PD2 & Coefficient on the positive gap in the inflation equation & 0.09000 \\
\hline$P D 3$ & Coefficient on the lagged positive gap in the inflation equation & 0.03000 \\
\hline PD4 & Coefficient on wage effects in the inflation equation & 2.00000 \\
\hline PD5 & Coefficient on wages changes in the inflation equation & 0.60000 \\
\hline PD6 & Coefficient on wages changes in the inflation equation & 0.25000 \\
\hline$P D 7$ & Coefficient on wages changes in the inflation equation & 0.15000 \\
\hline$P D A 1$ & Weight on lagged inflation in the inflation equation & 0.35000 \\
\hline$P D A 2$ & Weight on second lag of inflation in the inflation equation & 0.25000 \\
\hline PDA3 & Weight on third lag of inflation in the inflation equation & 0.20000 \\
\hline PDA4 & Relative weight of producer price expectations & 0.60000 \\
\hline PDA5 & Coefficient on import price change in the inflation equation & 0.05000 \\
\hline PDA6 & Coefficient on export price change in the inflation equation & 0.05000 \\
\hline$P D E O$ & Weight on the expected target in $P$ inflation expectations & 0.10000 \\
\hline$P D E 1$ & Weight on the lead in $P$ inflation expectations & 0.55000 \\
\hline$P D E 2$ & Weight on the lead in $P C$ inflation expectations & 0.55000 \\
\hline
\end{tabular}


Table 3: Parameters

\begin{tabular}{|c|c|c|}
\hline Mnemonic & Description & Value \\
\hline PDE3 & Weight on the expected target in $P C$ inflation expectations & 0.10000 \\
\hline PDE4 & Weight on the level gap in inflation expectations & 0.00000 \\
\hline$P D F 1$ & Weight on trend expectations in the inflation equation & 0.25000 \\
\hline$P D F 2$ & Weight on expected inflation in the inflation equation & 0.43000 \\
\hline$P D L 1$ & Weight on lagged pdot in the inflation expectations equation & 0.70000 \\
\hline$P G D B 1$ & Discount factor in the $p g d$ model & 0.95000 \\
\hline$P G D D 1$ & Weight on difference 1 in the $p g d$ adjustment model & 1.00000 \\
\hline$P G D D 2$ & Weight on difference 2 in the $p g d$ adjustment model & 0.00000 \\
\hline PGDD3 & Weight on difference 3 in the $p g d$ adjustment model & 0.00000 \\
\hline PGDD4 & Weight on difference 4 in the $p g d$ adjustment model & 0.00000 \\
\hline$P G D V 1$ & Coefficient 1 in the VAR in the $p g d$ model & 0.05000 \\
\hline$P G M 1$ & Pass-through coefficient, relative imported government .eq trade prices & 0.80000 \\
\hline$P G M B 1$ & Discount factor in the price of government imports model & 0.95000 \\
\hline PGMD1 & Weight on difference 1 in the $p g m$ adjustment model & 2.00000 \\
\hline PGMD2 & Weight on difference 2 in the $p g m$ adjustment model & 1.00000 \\
\hline PGMD3 & Weight on difference 3 in the $p g m$ adjustment model & 0.00000 \\
\hline PGMD4 & Weight on difference 4 in the $p g m$ adjustment model & 0.00000 \\
\hline$P G M V 1$ & Pass-through coefficient, relative import government trade prices & 0.50000 \\
\hline$P G M V 2$ & Coefficient 2 in the VAR in the price of government imports model & 0.80000 \\
\hline$P K 1$ & Parameter in definition of price of capital goods & 0.45000 \\
\hline$P K D B 1$ & Discount factor in the $p k d$ model & 0.95000 \\
\hline$P K D D 1$ & Weight on difference 1 in the $p k d$ adjustment model & 1.00000 \\
\hline$P K D D 2$ & Weight on difference 2 in the $p k d$ adjustment model & 0.00000 \\
\hline$P K D D 3$ & Weight on difference 3 in the $p k d$ adjustment model & 0.00000 \\
\hline PKDD4 & Weight on difference 4 in the $p k d$ adjustment model & 0.00000 \\
\hline$P K D V 1$ & Coefficient 1 in the VAR in the $p k d$ model & 0.00000 \\
\hline PKM1 & Pass-through coefficient, relative imported investment .eq trade prices & 0.80000 \\
\hline$P K M B 1$ & Discount factor in the price of investment imports model & 0.95000 \\
\hline PKMD1 & Weight on difference 1 in the $p k m$ adjustment model & 2.00000 \\
\hline PKMD2 & Weight on difference 2 in the $p k m$ adjustment model & 1.00000 \\
\hline PKMD3 & Weight on difference 3 in the $p k m$ adjustment model & 0.00000 \\
\hline PKMD4 & Weight on difference 4 in the $p k m$ adjustment model & 0.00000 \\
\hline$P K M V I$ & Pass-through coefficient, relative imported investment trade prices & 0.50000 \\
\hline$P K M V 2$ & Coefficient 2 in the VAR in the $p k m$ model & 0.80000 \\
\hline PTL1 & Weight on lagged pdottar in the pdottar expectations equation & 1.35000 \\
\hline PTL2 & Weight on 2nd lagged pdottar in the pdottar expectations equation & -0.42500 \\
\hline PTL3 & Weight on forward pdot in the pdottar expectations equation & 1.00000 \\
\hline$P X 1$ & Pass-through coefficient, relative export .eq trade prices & 0.75000 \\
\hline
\end{tabular}


Table 3: Parameters

\begin{tabular}{|c|c|c|}
\hline Mnemonic & Description & Value \\
\hline$P X B 1$ & Discount factor in the price of exports model & 0.95000 \\
\hline PXD1 & Weight on difference 1 in the $p x$ adjustment model & 0.80000 \\
\hline PXD2 & Weight on difference 2 in the $p x$ adjustment model & 0.50000 \\
\hline PXD3 & Weight on difference 3 in the $p x$ adjustment model & 0.00000 \\
\hline PXD4 & Weight on difference 4 in the $p x$ adjustment model & 0.00000 \\
\hline$P X V 1$ & Pass-through coefficient, relative export trade prices & 0.50000 \\
\hline$P X V 2$ & Coefficient 2 in the VAR for the price of exports & 0.00000 \\
\hline$P X V 3$ & Coefficient 3 in the VAR for the price of exports & 0.10000 \\
\hline$R I I$ & Parameter in the risk equation & 0.95000 \\
\hline$R L 1$ & Weight on the short rate in the $r l$ equation & 0.30000 \\
\hline$R L 2$ & Weight on the $r 5$ rate in the $r l$ equation & 0.50000 \\
\hline RSLO & Coefficient on inflation gap, lead 0 , monetary reaction function & 0.00000 \\
\hline RSL1 & Coefficient on inflation gap, lead 1 , monetary reaction function & 0.00000 \\
\hline$R S L 2$ & Coefficient on inflation gap, lead 2 , monetary reaction function & 0.00000 \\
\hline$R S L 3$ & Coefficient on inflation gap, lead 3, monetary reaction function & 0.00000 \\
\hline$R S L 4$ & Coefficient on inflation gap, lead 4 , monetary reaction function & 0.00000 \\
\hline$R S L 5$ & Coefficient on inflation gap, lead 5, monetary reaction function & 0.00000 \\
\hline RSL6 & Coefficient on inflation gap, lead 6 , monetary reaction function & 0.00000 \\
\hline$R S L 7$ & Coefficient on inflation gap, lead 7 , monetary reaction function & 1.57500 \\
\hline$R S L 8$ & Coefficient on inflation gap, lead 8 , monetary reaction function & 1.80000 \\
\hline$R S L 9$ & Coefficient on inflation gap, lead 9 , monetary reaction function & 0.00000 \\
\hline RSL10 & Coefficient on inflation gap, lead 10, monetary reaction function & 0.00000 \\
\hline RSL11 & Coefficient on inflation gap, lead 11 , monetary reaction function & 0.00000 \\
\hline RSL12 & Coefficient on inflation gap, lead 12, monetary reaction function & 0.00000 \\
\hline RSL13 & Coefficient on price level gap, monetary reaction function & 0.00000 \\
\hline SIGMA & Coefficient of intertemporal substitution for forward-looking consumers & 0.66000 \\
\hline$T D O$ & Parameter in the fiscal tax reaction function & 0.40000 \\
\hline$T D 1$ & Parameter in the fiscal tax reaction function & 0.250000 \\
\hline$T D 3$ & Parameter in the fiscal tax reaction function & 0.80000 \\
\hline UB1 & Discount factor in the unemployment model & 0.95000 \\
\hline UD1 & Weight on difference 1 in the $u$ adjustment model & 1.00000 \\
\hline$U D 2$ & Weight on difference 2 in the $u$ adjustment model & 0.50000 \\
\hline UD3 & Weight on difference 3 in the $u$ adjustment model & 0.00000 \\
\hline UD4 & Weight on difference 4 in the $u$ adjustment model & 0.00000 \\
\hline UV1 & Coefficient on the wage gap in the unemployment equation & 0.06700 \\
\hline UV2 & Coefficient on ygap(-2) in the unemployment equation & 0.22500 \\
\hline UV3 & Coefficient on ygap(-3) in the unemployment equation & 0.22500 \\
\hline WB1 & Discount factor in the real wage model & 0.95000 \\
\hline
\end{tabular}


Table 3: Parameters

\begin{tabular}{|c|c|c|}
\hline Mnemonic & Description & Value \\
\hline$\overline{W D 1}$ & Weight on difference 1 in the $w$ adjustment model & 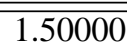 \\
\hline WD2 & Weight on difference 2 in the $w$ adjustment model & 1.00000 \\
\hline WD3 & Weight on difference 3 in the $w$ adjustment model & 0.75000 \\
\hline WD4 & Weight on difference 4 in the $w$ adjustment model & 0.50000 \\
\hline WVI & Coefficient 1 in the VAR in the real wage model & 0.25000 \\
\hline WV2 & Coefficient 2 in the VAR in the real wage model & 1.00000 \\
\hline WV3 & Coefficient 3 in the VAR in the real wage model & 1.00000 \\
\hline$X 2$ & Parameter in equilibrium export equation & 1.00000 \\
\hline$X B 1$ & Discount factor in the export model & 0.65000 \\
\hline$X D 1$ & Weight on difference 1 in the $x$ adjustment model & 5.00000 \\
\hline$X D 2$ & Weight on difference 2 in the $x$ adjustment model & 2.00000 \\
\hline XD3 & Weight on difference 3 in the $x$ adjustment model & 0.00000 \\
\hline XD4 & Weight on difference 4 in the $x$ adjustment model & 0.00000 \\
\hline$X V 1$ & Coefficient 1 in the VAR in the export model & 1.40000 \\
\hline YD1 & Proportion of transfers to forward-looking consumers taxable & 0.50000 \\
\hline YD2 & Proportion of transfers to rule-of-thumb consumers taxable & 0.50000 \\
\hline YGAPO & Coefficient on output gap, lead 0 , monetary reaction function & 0.00000 \\
\hline$Z 1$ & Weight on the lag in exchange rate equation & 0.38000 \\
\hline$Z 2$ & Weight on the uncovered-interest-parity term in exchange rate equation & 0.52000 \\
\hline ZETA & Coefficient on fa.ss gap in c.eq for forward-looking consumers & 0.20000 \\
\hline ZF1 & Weight on the lead in exchange rate expectations & 0.60000 \\
\hline ZL1 & Weight on the lag in exchange rate expectations & 0.40000 \\
\hline
\end{tabular}




\section{References}

Armstrong, John, Richard Black, Douglas Laxton and David Rose. 1995. A Robust Method for Simulating Forward-Looking Models. Part 2 of The Bank of Canada's New Quarterly Projection Model. Technical Report No. 73. Ottawa: Bank of Canada. (A revised version is forthcoming in the Journal of Economic Dynamics and Control.)

Bean, Charles. 1996. "The Convex Phillips Curve and Macroeconomic Policymaking under Uncertainty." London School of Economics and H.M. Treasury, November.

Black, R., D. Laxton, D. Rose and R. Tetlow. 1994. The Steady-State Model: SSQPM. Part 1 of The Bank of Canada's New Quarterly Projection Model. Technical Report No. 72. Ottawa: Bank of Canada.

Black, R., T. Macklem and D. Rose. 1997. “On Policy Rules for Price Stability.” Paper presented at Bank of Canada conference, May 3-4.

Blanchard, O. J. 1985. “Debt, Deficits and Finite Lives.” Journal of Political Economy 93: 223-47.

Buiter, Willem H. and Marcus H. Miller. 1985. "Costs and Benefits of an Anti-Inflationary Policy: Questions and Issues.” In Inflation and Unemployment: Theory, Experience and Policy Making, edited by Victor Argy and John Nevile, 11-38. Boston: Allen and Unwin.

Clark, Peter B. and Douglas Laxton. 1997. "Phillips Curves, Phillips Lines and the Unemployment Costs of Overheating." IMF Working Paper 97/17. Washington: International Monetary Fund, February.

Clark, Peter, Douglas Laxton and David Rose. 1996. "Asymmetry in the U.S. Output-Inflation Nexus." IMF Staff Papers 43 (March): 216-51.

Coletti, Donald, Benjamin Hunt, David Rose and Robert Tetlow. 1996. The Dynamic Model: QPM. Part 3 of The Bank of Canada's New Quarterly Projection Model. Technical Report No. 75. Ottawa: Bank of Canada.

Côté, Agathe and Tiff Macklem. 1996. "The Determination of Interest Rates and the Exchange Rate in the Bank of Canada's Quarterly Projection Model.” In The Determination of Long-Term Interest Rates and Exchange Rates and the Role of Expectations, vol. 2, 252273. Conference Papers. Basle: Bank for International Settlements.

Debelle, Guy, and Douglas Laxton. 1996. "Is the Phillips Curve Really a Curve? Some Evidence for Canada, the United Kingdom, and the United States." IMF Working Paper 96/111. Washington: International Monetary Fund.

Fisher, P. G., L. Mahadeva and J. D. Whitley. 1996. "The Output Gap and Inflation: Experience at the Bank of England.” Paper prepared for the B.I.S. Model-Builders Meeting, Basle, January.

Frenkel, J. A. and A. Razin. 1992. Fiscal Policies and the World Economy. Cambridge: MIT Press. 
Fuhrer, Jeffrey C. and George R. Moore. 1995a. "Inflation Persistence.” The Quarterly Journal of Economics 110 (1) (February): 110-57.

- 1995b. "Monetary Policy Trade-Offs and the Correlation between Nominal Interest Rates and Real Output." American Economic Review 85 (1) (March): 219-39.

Isard, Peter and Douglas Laxton. 1996. "Strategic Choice in Phillips Curve Specification: What if Bob Gordon is Wrong?" Paper presented at European University Institute Conference on "European Unemployment: Macroeconomic Aspects," Florence, Italy.

Laxton, D., G. Meredith and D. Rose. 1995. "Asymmetric Effects of Economic Activity on Inflation: Evidence and Policy Implications." IMF Staff Papers 42 (June): 344-74.

Laxton, D., D. Rose and R. Tetlow. 1993. “Is the Canadian Phillips Curve Non-Linear?” Bank of Canada Working Paper No. 93-7.

Laxton, D., D. Rose and N. Ricketts. 1994. "Uncertainty, Learning and Policy Credibility.” In Economic Behaviour and Policy Choice Under Price Stability, edited by Stephen Poloz, 173-226. Ottawa: Bank of Canada.

Macklem, R. Tiff. 1993. "Terms-of-Trade Shocks, Real Exchange Rate Adjustment, and Sectoral and Aggregate Dynamics." In The Exchange Rate and the Economy: Proceedings of a Conference held at the Bank of Canada 22-23 June 1992, 1-60. Ottawa: Bank of Canada.

Macklem, Tiff, Alain Paquet and Louis Phaneuf. 1996. "Asymmetric Effects of Monetary Policy: Evidence from the Yield Curve." Centre for Research on Economic Fluctuations and Employment, Université de Québec à Montréal. Working Paper No. 42.

Ouliaris, Sam and Dean Corbae. 1985. "The Demand for Money: A Variable Adjustment Model." Economic Letters 18: 197-200.

Pesaran, M. Hashem. 1991. "Costly Adjustment Under Rational Expectations: A Generalization." The Review of Economics and Statistics 73: 353-58.

Poloz, S., D. Rose and R. Tetlow. 1994. “The Bank of Canada's new Quarterly Projection Model (QPM): An introduction.” Bank of Canada Review (Autumn): 23-38.

Rose, D. and J. Selody. 1985. The Structure and Properties of the Small Annual Model (SAM). Technical Report No. 40. Ottawa: Bank of Canada.

Smyth, David. 1984. "Short-run Employment Functions when the Speed of Adjustment Depends on the Unemployment Rate." The Review of Economics and Statistics 66: 138-42.

Taylor, John. 1980. “Aggregate Dynamics and Staggered Contracts.” Journal of Political Economy 88 (February): 1-23.

Tinsley, Peter A. 1993. "Fitting Both Data and Theories: Polynomial Adjustment Costs and ErrorCorrection Decision Rules." Washington: Board of Governors of the Federal Reserve System, Division of Statistics and Research. 
Turner, David. 1995. "Speed Limit and Asymmetric Effects from the Output Gap in the Seven Major Countries.” OECD Economic Studies 24 (1995/I): 57-88.

Weil, Philippe. 1989. “Overlapping Families of Infinitely-Lived Agents.” Journal of Public Economics 38: 183-98. 


\section{Bank of Canada Working Papers}

1997

97-1 Reconsidering Cointegration in International Finance:

Three Case Studies of Size Distortion in Finite Samples

M.-J. Godbout and S. van Norden

97-2 Fads or Bubbles?

H. Schaller and S. van Norden

97-3 La courbe de Phillips au Canada: un examen de quelques hypothèses

J.-F. Fillion and A. Léonard

97-4 The Liquidity Trap: Evidence from Japan

I. Weberpals

97-5 A Comparison of Alternative Methodologies for

Estimating Potential Output and the Output Gap

C. Dupasquier, A. Guay

and P. St-Amant

97-6 Lagging Productivity Growth in the Service Sector:

Mismeasurement, Mismanagement or Misinformation?

D. Maclean

97-7 Monetary Shocks in the G-6 Countries: Is There a Puzzle?

B. S.C. Fung and M. Kasumovich

97-8 Implementation of Monetary Policy in a Regime with Zero Reserve Requirements

K. Clinton

97-9 Mesures du taux d'inflation tendenciel

T. Laflèche

97-10 The Structure of Interest Rates in Canada:

Information Content about Medium-Term Inflation

J. Day and R. Lange

97-11 A Band-Aid Solution to Inflation Targeting R. Amano, R. Black, and M. Kasumovich

97-12 A Micro Approach to the Issue of Hysteresis in Unemployment::

Evidence from the 1988-1990 Labour Market Activity Survey G. Wilkinson

97-13 What Does Downward Nominal-Wage Rigidity Imply for Monetary Policy? S. Hogan

97-14 Menu Costs, Relative Prices, and Inflation: Evidence for Canada $\quad$ R. Amano and R. T. Macklem

97-15 The Effects of Budget Rules on Fiscal Performance and Macroeconomic

Stabilization

J. Millar

97-16 Canadian Policy Analysis Model: CPAM R. Black and D. Rose

Earlier papers not listed here are also available.

Single copies of Bank of Canada papers may be obtained from

Publications Distribution, Bank of Canada, 234 Wellington Street Ottawa, Ontario K1A 0G9

E-mail: publications@bank-banque-canada.ca

WWW: http://www.bank-banque-canada.ca/

FTP: $\quad$ ftp.bank-banque-canada.ca (login: anonymous, to subdirectory

/pub/publications/working.papers/) 